\title{
$\mathrm{C}|\mathrm{E}| \mathrm{D}|\mathrm{L}| \mathrm{A} \mid \mathrm{S}$
}

Centro de Estudios

Distributivos, Laborales y Sociales

Maestría en Economía

Facultad de Ciencias Económicas

Universidad Nacional de la Plata

\section{Recent Trends in Inequality and Poverty in Developing Countries}

Facundo Alvaredo y Leonardo Gasparini

Documento de Trabajo Nro. 151

Noviembre, 2013

ISSN 1853-0168 


\title{
Recent Trends in Inequality and Poverty
}

\section{in Developing Countries *}

\author{
Facundo Alvaredo \\ Leonardo Gasparini*
}

\begin{abstract}
This chapter reviews the empirical evidence on the levels and trends in income/consumption inequality and poverty in developing countries. It includes a discussion of data sources and measurement issues, evidence on the levels of inequality and poverty across countries and regions, an assessment of trends in these variables since the early 1980s, and a general discussion of their determinants. There has been tremendous progress in the measurement of inequality and poverty in the developing world, although serious problems of consistency and comparability still remain. The available evidence suggests that on average the levels of national income inequality in the developing world increased in the 1980s and 1990s, and declined in the 2000s. There was a remarkable fall in income poverty since the early 1980s, driven by the exceptional performance of China over the whole period, and the generalized improvement in living standards in all the regions of the developing world in the 2000s.
\end{abstract}

JEL Codes: D31, 132

\footnotetext{
* This paper corresponds to chapter 10 of the Handbook of Income Distribution, volume 2, edited by A. Atkinson and $F$. Bourguignon.

** Facundo Alvaredo is with CONICET, EMod/OMI-Oxford University and Paris School of Economics; Leonardo Gasparini is with CEDLAS, Facultad de Ciencias Económicas, Universidad Nacional de La Plata and CONICET. This paper was completed while Leonardo Gasparini was visiting professor at the University of British Columbia. We are grateful to participants to the conference "Recent Advances in the Economics of Income Distribution" (Paris), the AAEP Meetings (Rosario), and especially to Francois Bourguignon and Tony Atkinson for valuable comments and suggestions. We are also grateful to David Jaume, Darío Tortarolo, Carolina López, Julian Amendolaggine, Santiago Garganta, Florencia Pinto, Pablo Gluzmann, Leopoldo Tornarolli, Javier Alejo, Juan Zoloa, and Carolina García Domench (all at CEDLAS) for outstanding research assistance. We alone are responsible for any errors. Financial support from the ESRC-DFID joint fund is gratefully acknowledged.
} 


\section{INDEX}

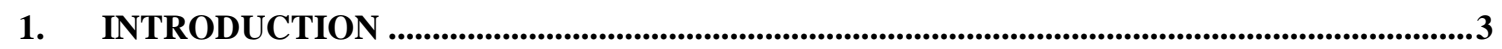

2. THE DEVELOPING WORLD: CHARACTERIZATION AND DATA....................................4

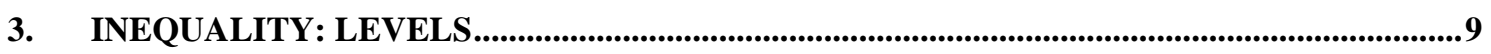

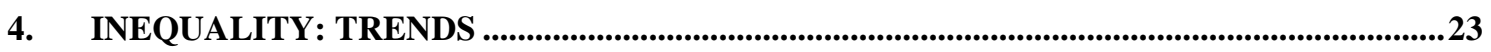

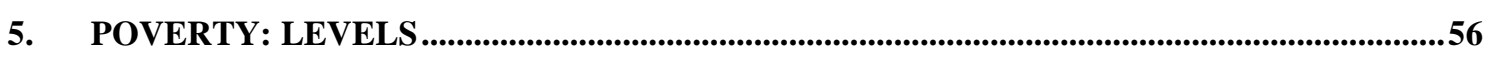

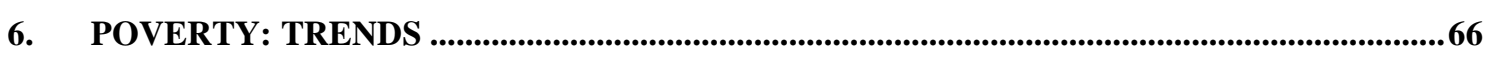

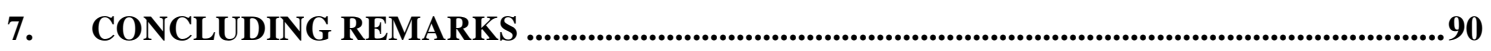




\section{Introduction}

Poverty and inequality are certainly among the main concerns in the developing world. A typical developing country is characterized by high levels of material deprivation, and large dispersion in individual wellbeing, at least when compared to a typical developed economy. Fighting poverty and minimizing the unjust inequalities are top priorities in the developing world. The United Nations, in the famous declaration of the Millennium Development Goals (MDGs), proposed as target number 1 to halve income poverty in the developing world from 1990 to 2015 . The reduction of inequality does not occupy the same privileged position in the agenda, but few would not list it as a central social concern.

While chapter 9 of this Handbook deals with poverty and inequality in the developed world, this chapter documents patterns and changes in the developing countries. There is no need to argue about the relevance of including a separate chapter in the Handbook: the developing world is home of $85 \%$ of total world population, and bears levels of poverty and inequality far higher than in the rich countries. While in a typical developing economy the share of people striving to survive with less than 2 dollars a day is more than $30 \%$, that share is close to zero in the industrialized countries. In fact, on this basis poverty is an issue exclusively of the developing world. The differences in income inequality are presumably also large, although the comparisons are hindered by the fact that national household surveys typically capture income in developed countries and consumption expenditures in developing ones.

High poverty and inequality are pervasive characteristics of the developing world; however, they are not immutable features of these economies. There is convincing evidence pointing to a robust decline in the levels of absolute income poverty in the developing world over the last decades, and substantial progress in the reduction of deprivation in various non-monetary dimensions - education, health, sanitation, access to infrastructure. Changes in income inequality have been much less clear, as relative inequality has risen in some countries and fallen in others. In fact, the evidence suggests that on average the developing countries are today (2013) somewhat more unequal than three decades ago.

This chapter reviews the empirical evidence on the levels and trends in income inequality and poverty in developing countries. We focus the analysis on the income/consumption approximations to welfare; in particular the chapter deals mainly with relative inequality across individuals in household consumption expenditures per capita, and with absolute poverty defined over that welfare variable, and considering alternative international lines defined in US dollars adjusted for purchasing power parity (PPP). This choice is restricted by space limitations and does not imply ignoring that a general assessment of poverty and inequality should also include other nonmonetary dimensions (e.g. health, education) and other monetary variables (e.g. wealth). Other chapters in the Handbook contribute to fill those gaps. 
The analysis in this chapter is mostly focused on inequality and poverty within countries and not within supra-national regions or in the world. ${ }^{1}$ Although issues of global inequality are increasingly relevant, inequality is still primarily a national concern. People are generally worried about inequality mainly in their countries, and public policies are typically aimed at reducing disparities among individuals within national boundaries.

The empirical evidence shown in this chapter is drawn from the academic literature, regional and country papers, and open-access databases, in particular the PovcalNet project developed in the World Bank. Although most of the evidence is based on statistics obtained from national household surveys, we also report results from tax records (the World Top Incomes Database, WTID) and international surveys (the Gallup World Poll) to illustrate some issues. Even though the main purpose of the chapter is presenting basic evidence on levels and trends, we also briefly review the main discussions on determinants of recent changes in inequality and poverty.

The rest of the chapter is organized as follows. In section 2 we briefly characterize the economies in the developing world, and discuss the data sources and some measurement issues. The following two sections are assigned to the main topic in this volume - inequality. In section 3 we document the levels of income inequality in the developing world, while in section 4 we summarize the evidence on trends since the early 1980s. The next two sections repeat the sequence for poverty: section 5 compares levels across countries, and section 6 summarizes trends and discusses the evidence at the regional level. ${ }^{2}$ Section 7 closes with a summary and some final remarks.

\section{The developing world: characterization and data}

In this section we briefly characterize the economies of the developing world, and review the sources of data to measure and analyze income poverty and inequality.

\subsection{Developing countries}

The division between developed and developing countries is a helpful simplification that can be done in different arbitrary ways. In this chapter we follow the World Bank's main criterion based on gross national income (GNI) per capita: developing countries are those with per capita GNI below a certain nominal threshold (US\$12,276 in 2011). These nations are usually classified into six geographical regions: East Asia and Pacific (EAP), Eastern Europe and Central Asia (ECA), Latin America and the Caribbean (LAC), Middle East and North Africa (MENA), South Asia (SA) and Sub-Saharan Africa (SSA).

\footnotetext{
${ }^{1}$ Global inequality is analyzed in chapter 12 of this volume.

2 The separate treatment of inequality and poverty is somewhat artificial, as they are just two characteristics of the same income distribution. However, and despite some possible overlapping and duplications, we prefer to follow most of the literature and discuss both concepts separately.
} 
The Appendix includes a list of all the developing countries in each region with their populations. ${ }^{3}$ The developing countries cover almost $75 \%$ of the total land area in the world and represent $85 \%$ of the total population. Table 2.1 summarizes some basic demographic and economic statistics.

Table 2.1

Population, GNI per capita and Human Development Index, 2010 Developing countries, by region

\begin{tabular}{lccccc}
\hline \hline & & & \multicolumn{2}{c}{ GNI per capita } & \\
& Countries & $\begin{array}{c}\text { Population } \\
\text { (millions) }\end{array}$ & PPP & $\begin{array}{c}\text { Atlas } \\
\text { method }\end{array}$ & HDI \\
\hline Developing countries & $\mathbf{1 5 3}$ & $\mathbf{5 , 8 4 0}$ & $\mathbf{7 , 0 2 3}$ & $\mathbf{4 , 2 9 1}$ & $\mathbf{0 . 6 0 8}$ \\
East Asia and Pacific & 24 & 1,961 & 4,911 & 2,992 & 0.619 \\
Eastern Europe and Central Asia & 30 & 478 & 12,558 & 7,815 & 0.751 \\
Latin America and the Caribbean & 31 & 584 & 9,789 & 6,433 & 0.706 \\
Middle East and North Africa & 13 & 331 & 6,462 & 3,647 & 0.636 \\
South Asia & 8 & 1,633 & 3,429 & 1,704 & 0.535 \\
Sub-Saharan Africa & 47 & 853 & 3,288 & 1,798 & 0.450 \\
Developed countries & $\mathbf{6 2}$ & $\mathbf{1 , 0 5 5}$ & $\mathbf{3 7 , 3 0 3}$ & $\mathbf{3 8 , 8 1 8}$ & $\mathbf{0 . 8 5 7}$ \\
\hline Total & $\mathbf{2 1 6}$ & $\mathbf{6 , 8 9 4}$ & $\mathbf{1 5 , 6 8 2}$ & $\mathbf{1 4 , 1 8 1}$ & $\mathbf{0 . 6 6 3}$ \\
\hline
\end{tabular}

Source: population is taken from the United Nations Demographic Yearbook. Gross National Income (GNI) per capita in international dollars adjusted for purchasing power parity (PPP) and in current US\$ (Atlas method) are taken from World Development Indicators. The Human Development Index (HDI) is from the UNDP Human Development Report. GNI and HDI are unweighted averages across countries.

According to these indicators Eastern Europe and Central Asia is the most developed region in the group: per capita GNI is almost twice the mean for the developing world, and the Human Development Index (HDI) is significantly higher. Latin American and the Caribbean ranks second, and Middle East and North Africa third. Although economic growth in Asia has been remarkable in the last decades, per capita GNI and other development indicators are on average still below the mean of the developing world. South Asia is significantly less developed than East Asia and the Pacific. SubSaharan Africa is the poorest and least developed region of the world. The mean of the national per capita GNIs in that region is less than $50 \%$ of the developing world mean, and less than $10 \%$ of the mean of the industrialized economies.

\subsection{Data sources}

National household surveys are the main source of information for distributive analysis. Since one of the central goals of these surveys is measuring living standards, they typically include questions to construct a monetary proxy for wellbeing: income

\footnotetext{
${ }^{3}$ In this chapter we include emerging economies as part of the developing world, a decision that implies some overlapping with chapter 9 . In the period under analysis some countries graduated from the set of developing countries; to avoid selection bias we do not drop them from the analysis.
} 
and/or expenditures on consumption goods. Although some developing countries started to implement national household surveys after World War II, it is only recently that governments engaged in programs of regularly collecting information through household surveys, often with the help of some international organization. Distributive statistics for the developing world are rare before the 1970s, and reasonably robust only from the 1990s on. There has been a remarkable increase in the availability of national household surveys over the last decades. A chapter like this one, that includes a broad assessment of income inequality and poverty in developing countries, could hardly have been written two decades ago, and is a sign of the huge progress made on data collection. However, as we discuss below, data limitations are still stringent, and allow only a still blurred picture of inequality and poverty.

The databases for international distributive analysis can be classified into two groups: those that produce statistics with microdata from surveys or administrative records, and those that collect, organize and report statistics from other sources. The former group includes the World Bank's PovcalNet, the Luxembourg Income Study, the World Income Distribution database, the World Top Incomes Database and some regional initiatives. The second one includes the seminal work by Deininger and Squire (1996) and its follow-up - the WIDER's World Income Inequality Database, the All the Ginis database, and some other projects.

The main source of information for poverty and inequality analysis at a large international scale in the developing world is the World Bank's PovcalNet, a compilation of distributive data built up from national household surveys, generally fielded by national statistical offices. PovcalNet, used for the World Bank's World Development Indicators, includes statistics constructed mostly from household survey microdata, and in some few countries from grouped tabulations. At the moment of writing this database includes more than 850 surveys from almost 130 countries, representing more than $90 \%$ of the population of the developing world, spanning the period 1979-2011. The website of PovcalNet provides public access to data to generate estimates for selected countries and alternative poverty lines from grouped data. ${ }^{4}$ Martin Ravallion and Shaohua Chen, the developers of PovcalNet, have produced several papers exploiting the dataset (Ravallion and Chen, 1997; Chen and Ravallion, 2001, 2010, 2012). This project has been increasingly influential in shaping the assessment of inequality, and in particular poverty, in the developing world by researchers and policy practitioners. It is, for instance, the source used to monitor the poverty-reduction goal of the MDGs. This chapter draws heavily on statistics computed by the PovcalNet project.

Some regional initiatives aimed at computing social statistics from household survey microdata in a standardized way are useful to study distributive issues in specific

\footnotetext{
${ }^{4}$ Statistics are derived from the estimation of a general quadratic and a beta Lorenz curves from grouped data. Shorrocks and Wan (2008) propose an algorithm that reproduces individual data from grouped statistics with a higher degree of accuracy.
} 
geographic areas, and as sources of information for world databases. For instance, the Socioeconomic Database for Latin America and the Caribbean (SEDLAC), jointly developed by CEDLAS at the Universidad Nacional de La Plata (Argentina) and the World Bank's LAC poverty group (LCSPP), includes distributive and labor statistics for LAC constructed using consistent criteria across countries and years. BADEINSO, developed by the United Nations' ECLAC, is also a large and good-quality database on economic and social variables in LAC. In Eastern and Central Europe the World Bank ECA database includes statistics for 28 countries since 1990 computed from direct access to household surveys. The Household Expenditure and Income Data for Transitional Economies developed by Branko Milanovic in the World Bank is the predecessor of that database. Milanovic has also built the World Income Distribution (WYD) database, which includes data for five benchmark years $(1988,1993,1998,2002$ and 2005) for 146 countries, $75 \%$ obtained from direct access to household surveys. The dataset has been used in several studies to compute global inequality (Milanovic, 2002, 2005, 2012). The Luxembourg Income Study (LIS), described in chapter 9 of this volume, includes distributive information computed from household survey microdata for developed countries. LIS also reports statistics for several transitional economies in Eastern Europe and recently has added some developing countries in Latin America (Brazil, Colombia, Guatemala, Mexico, Peru and Uruguay).

The growth in the availability of distributive statistics stimulated efforts to gather and organize them. Deininger and Squire (1996) put together a large dataset of quintile shares and Gini coefficients for most countries since World War II taken from different studies and national reports. This panel database, which greatly promoted the empirical study of the links between inequality and other economic variables, was updated and extended by the UNU/WIDER-UNDP World Income Inequality Database (WIID) (WIDER, 2008). ${ }^{5}$ The WIID database includes Gini coefficients, quintile and decile shares, and the income shares of the top $5 \%$ and bottom $5 \%$. The information is drawn from very different sources, which raises comparability concerns. ${ }^{6}$ To provide guidance in the use of the database, ratings are given to the observations, based on the survey quality, the coverage, and the quality of the information provided by the original source. The SWIID database is an effort to identify reasonably comparable information in WIID (Solt, 2009). ${ }^{7}$

\footnotetext{
5 WIID was initially compiled over 1997-1999 for the UNU/WIDER-UNDP project "Rising Income Inequality and Poverty Reduction: Are They Compatible?" directed by Giovanni Andrea Cornia. Tabatabai (1996) at International Labour Organization also made an independent effort to put together distributive statistics for many countries in the world.

${ }^{6}$ Analyzing the Deininger and Squire (DS) dataset, Atkinson and Brandolini (2001) conclude that "users could be seriously misled if they simply download the accept series (i.e., the "high quality" subset)". Although WIID implies a significant improvement from the original DS dataset, a similar word of caution applies.

${ }^{7}$ SWIID should also be reviewed critically: in many cases it requires a case-by-case analysis, which is simply a sign that much effort is still needed in putting together comparable statistics. As it is based on secondary datasets, external problems are inadvertently incorporated.
} 
The All the Ginis database, assembled also by Branko Milanovic, is a compilation and adaptation of Gini coefficients retrieved from five datasets: LIS, SEDLAC, WYD, the World Bank ECA database, and WIID. Besides gathering all the information in a single file, the All the Ginis database is useful as it provides information on the welfare concept and recipient unit to which the reported Gini refers, facilitating the comparisons.

The Chartbook of Economic Inequality, assembled by Atkinson and Morelli (2012), presents a summary of evidence about changes in economic inequality (income/consumption, earnings and wealth) in the period from 1911 to 2010 for 25 countries. The information drawn from household surveys for the seven countries in the developing world included in the database (Argentina, Brazil, India, Indonesia, Malaysia, Mauritius and South Africa) starts in the 1950s.

All the datasets mentioned above are based on data from national household surveys. ${ }^{8}$ Even when they are the best available source of information for distributive analysis, household surveys are plagued with problems for international comparative studies, because, among other reasons, the questionnaires and the procedures to compute income/consumption variables differ among countries, and frequently also within a country over time. Some surveys inquire about income and others about consumption, some capture net income and some gross income, in some cases variables are reported on a weekly basis and in others on a monthly basis, items as the imputed rent for owner occupied housing are included in some surveys and ignored in others. ${ }^{9}$ Even in those projects that made explicit efforts to reduce these differences, comparability issues persist, as problems rooted in differences in questionnaires are difficult to be completely overcome. These problems are well recognized in the literature. For instance, Chen and Ravallion (2012) state that “...there are problems that we cannot deal with. For example, it is known that differences in survey methods (such as questionnaire design) can create non-negligible differences in the estimates obtained for consumption or income". In a survey of global income inequality, Anand and Segal (2008) share those concerns.

There are some alternatives to reduce the comparability problems, although they all come at a price. Gallup conducts a survey in nearly all nations in the world with almost exactly the same questionnaire. The Gallup World Poll is particularly rich in selfreported measures of quality of life, opinions, and perceptions, but it also includes basic questions on demographics, education, and employment, and a question on household income. In principle, the Gallup World Poll allows a distributive analysis in nearly all the countries in the world based on the same income question. The downside is that measurement errors may be very large when reported income is

\footnotetext{
${ }^{8}$ The exception is the Chartbook of Economic Inequality, that uses a range of sources.

${ }^{9}$ In addition, the typical problems of under-reporting and selective compliance are negligible in some cases and endemic in others. See Deaton $(2003,2005)$ and Korinek et al. (2006).
} 
based only on one question and with sample sizes of just around 1000 observations per country. ${ }^{10}$

The Estimated Household Income Inequality (EHII) data set produced by the University of Texas Inequality Project (UTIP) is based on UTIP-UNIDO, a global data set that calculates industrial pay-inequality measures for 156 countries from 1963 to 2003, using the between-groups component of a Theil index, measured across industrial categories in the manufacturing sector (Galbraith and Kum, 2005). ${ }^{11}$ Although in principle the use of industrial pay information could lend some homogeneity into the comparisons, the technique employed may not provide an accurate measure of inequality over the whole income distribution.

\section{Inequality: levels}

In this section we present results regarding the level of inequality in the developing countries, deferring to the next section the discussion of the trends. In most of the section we measure inequality computed over the distribution of household consumption per capita, using data from PovcalNet. ${ }^{12}$ Consumption is usually regarded as a better measure of current welfare than income on both theoretical and practical grounds, especially in developing countries (Deaton and Zaidi, 2002). As it is usual in this literature, we frequently refer to income inequality, despite the fact that statistics are constructed over the distribution of consumption expenditures.

As discussed above, this chapter is mainly focused on within-country inequality, so welfare disparities are measured among individuals living within the national boundaries. Although globalization is increasingly raising global inequality concerns, inequality remains mainly a national matter. This view also leads us to mostly document unweighted statistics of inequality measures across countries, a practice that is consistent with the typical cross-country approach in the development literature. Weighting by population would imply an assessment of inequality in a region or in the world strongly affected by some highly-populated countries, such as

\footnotetext{
${ }^{10}$ Gasparini and Gluzmann (2012) compare basic demographic statistics drawn from the Gallup Poll with those computed from the national household surveys of the LAC countries for year 2006, and conclude that in most countries statistics from the Gallup Poll, including income poverty and inequality, are roughly consistent with those from national household surveys.

${ }^{11}$ Specifically, EHII consists on estimates of gross household income inequality, computed from an OLS regression between the Deininger and Squire inequality measures and the UTIP-UNIDO manufacturing pay inequality measures, controlling for the source of information in the inequality data (income/expenditure, gross/net, and household/per capita measures) and for the share of manufacturing employment in total employment.

${ }^{12}$ The drawbacks of computing inequality in the distribution of consumption or income per capita to measure distributive justice have been widely acknowledged. Among other limitations, it is a onedimensional approach, it is focused on results not opportunities, it ignores the value of publicly provided goods such as education and health services, and it adopts a simple adjustment for demographics ignoring intra-household inequality, economies of scale and differences in needs (Ferreira and Ravallion, 2009). However, extending inequality measurement to alleviate these limitations in a way that keeps international comparisons feasible has been proved difficult.
} 
China, India and Indonesia in Asia, or Brazil and Mexico in Latin America, and almost ignoring the situation in other less-populated nations. Having said that, since the decision of taking each political entity as a unit in the analysis is certainly debatable; we show some results using both unweighted and population-weighted statistics. ${ }^{13}$

\subsection{Inequality in the developing countries}

We start by comparing inequality levels across developing countries based on the Gini coefficient for the distribution of household consumption per capita for year 2010, computed in PovcalNet mostly from household survey microdata. Other inequality measures are highly correlated with the Gini coefficient. For instance, in PovcalNet and WIID datasets the Pearson and Spearman correlations of the Gini and several extreme inequality measures (e.g. the 90/10 and 80/20 income-share ratios) exceed 0.9.

PovcalNet includes information for the distribution of per capita consumption expenditures, except in almost all Latin American and a few Caribbean countries, for which income inequality statistics are reported. In the analysis that follows we adjust the income Gini coefficients in that region to reflect the gap between income and consumption inequality estimates. Specifically, we selected seven Latin American countries with household surveys that include reasonably good consumption and income data in several years: ${ }^{14}$ on average the ratio of the consumption/income Ginis is 0.861 (standard deviation of 0.046). We apply that coefficient to the 22 Latin American and Caribbean countries with income data to approximate their consumption Ginis. ${ }^{15}$

In most cases the observations correspond to year 2010, or adjacent years. However, some countries are lacking a recent household survey (or it was dropped due to quality concerns). In fact, in 24 countries the survey used to estimate inequality in 2010 was carried out between 2000 and 2005, while in 6 cases ( 5 of them in the Caribbean) the observation corresponds to the 1990s. With that caveat in mind, the PovcalNet dataset has relatively recent distributive information for $82 \%$ of the countries in the developing world, representing $97 \%$ of its total population (see Table A.1 in the Appendix). The country coverage across regions is heterogeneous. In East Asia and Pacific PovcalNet includes 12 out of the 24 developing countries, which nonetheless represent $96 \%$ of the total population of the area. The coverage in Eastern Europe and Central Asia is almost complete, lacking information only for the small Kosovo. In LAC the coverage is complete in continental Latin America, but weak in the Caribbean. Anyway, countries with information represent $98 \%$ of the total population in LAC (the

\footnotetext{
${ }^{13}$ See some arguments on this debate in Bourguignon et al. (2004).

${ }^{14}$ The countries are Argentina, Costa Rica, Ecuador, Mexico, Nicaragua, Panama and Peru.

${ }^{15}$ We decided to apply the same coefficient to all LAC countries after failing to find significant regularities between the ratio consumption/income Ginis and other observable variables for the seven countries in the sample. WDR (2006) reports consumption and income Ginis in four Latin American countries; the mean ratio of the Ginis is 0.81 . The value is somewhat lower $(0.77)$ for the eight non-LA countries in the sample.
} 
main missing country in terms of population is Cuba). The dataset in Middle East and North Africa does not contain information only for Lebanon and Libya, which represent $3 \%$ of the MENA population. In South Asia the only country missing is Afghanistan, while in Sub-Saharan Africa there is information for 42 out of the 47 countries, representing $95 \%$ of the population.

Figure 3.1 displays the range of Gini coefficients for 122 countries around year 2010, ranking from the least unequal (Ukraine, 25.6) to the most unequal economy (South Africa, 63.1). ${ }^{16}$ The mean value is 39.8 , while the median is 39.2. More than half of the observations are in the range $[35,45]$. Only seven Eastern Europe countries have Ginis below 30, and five Sub-Saharan African countries have Ginis higher than 55 . The population-weighted mean is less than one point lower than the simple mean (39.1), a result affected by the relatively low level of inequality in populous India and Indonesia (China has a Gini somewhat higher than the world mean). Figure 3.1 shows the position of some of the most populated countries: Brazil has high inequality levels, China and Russia intermediate values, and India and Indonesia relatively low levels in the context of the developing world.

\section{Figure 3.1}

\section{Gini coefficients for the distribution of household consumption per capita Developing countries, 2010}

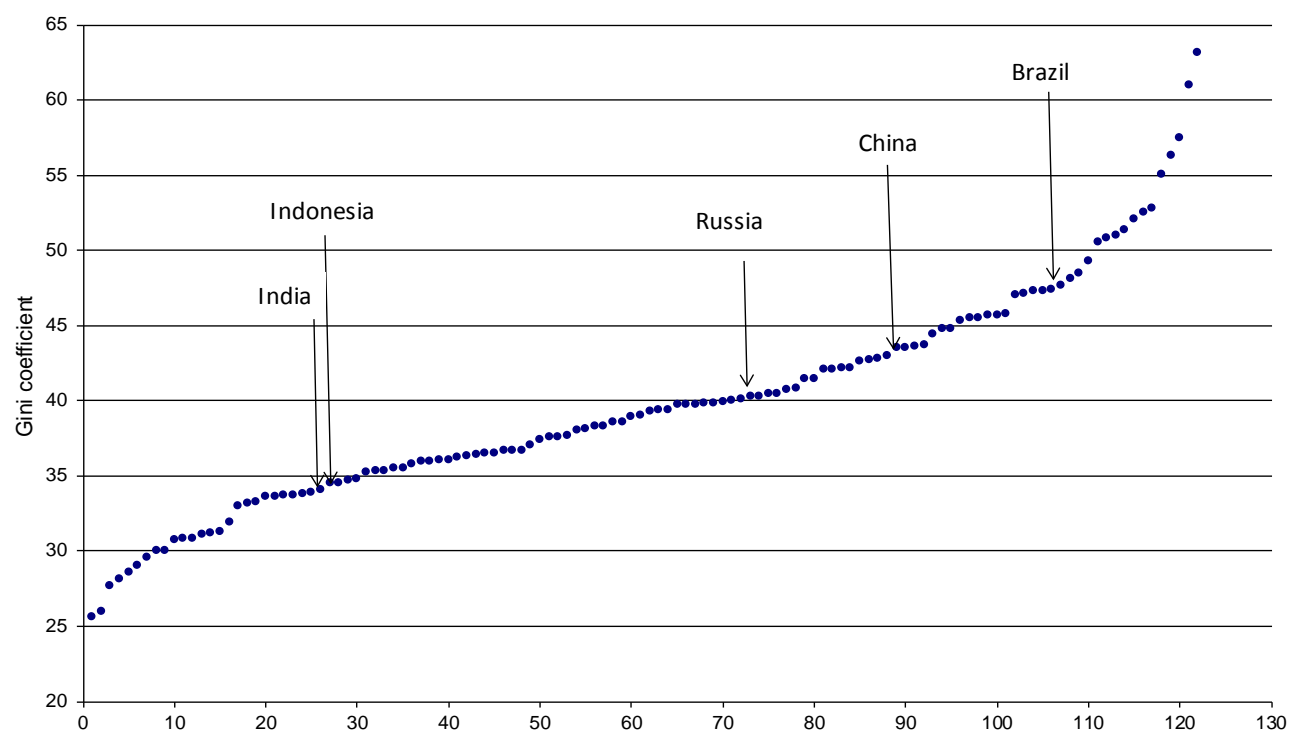

Source: own calculations based on PovcalNet (2013).

Note: countries sorted by their Gini coefficients.

The variability of Gini coefficients across countries is large compared to the changes within countries over time, at least for the period for which we have more robust information (since the early 1980s). Li, Squire and Zou (1998) find in the Deininger and

\footnotetext{
${ }^{16}$ PovcalNet reports Ginis above 63.1 for Comoros and Seychelles, two small island countries in the Indian Ocean. However, the results are not well established. For instance, the reported Gini in Seychelles is 42.7 in 2000 and 65.8 in 2007, a highly implausible change in just seven years.
} 
Squire dataset that $90 \%$ of the total variance in the Gini coefficient is explained by variation across countries, while only a small percentage is accounted by variation over time. From this observation Li et al. (1998) conclude that inequality should be mainly determined by factors which differ substantially across countries, but tend to be relatively stable within countries over time. We find a similar result in a panel of developing countries from 1981 to 2010 (PovcalNet data): 88.5\% of the variance in that panel is accounted by variation across countries.

The inequality rankings are relatively stable over time. The Spearman-rank correlation coefficient for the Ginis in 1981 and 2010 is 0.68 , while it rises to 0.74 for 1990 and 2010 , both significant at $1 \%$. The last decades witnessed enormous economic, social and political changes in the developing world, but, although the income distributions have been affected with various intensities, the world inequality ranking has not changed much, a fact that suggests the existence of some underlying factors that are stronger determinants of the level of inequality.

In Figure 3.2 developing countries are grouped in regions. Sub-Saharan Africa is the geographic area that includes countries with the highest inequality levels, but it is also the region with the highest dispersion, possibly in part due to measurement errors (Table 3.1). Although eight out of the ten highest Gini coefficients belong to SubSaharan African countries, and the arithmetic mean of the Gini coefficient is the highest in the world, the median is lower than in Latin America. ${ }^{17}$

\section{Figure 3.2}

Gini coefficients for the distribution of household consumption per capita Developing countries, 2010

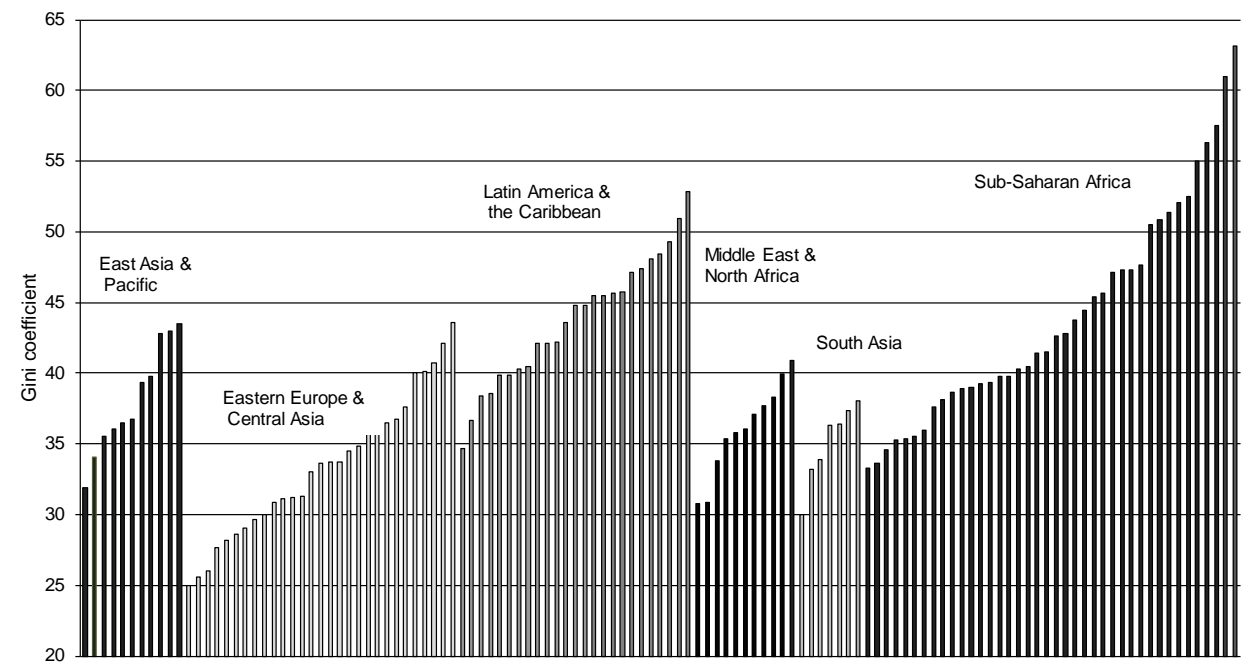

Source: own calculations based on PovcalNet (2013).

Note: each bar represents a country in a given geographic region of the developing world.

\footnotetext{
${ }^{17}$ The harmonic mean is similar in SSA than in LAC.
} 
Table 3.1

Gini coefficients for the distribution of household consumption per capita Developing countries, 2010

\begin{tabular}{lccccc}
\hline \hline & Mean & Median & Coef. Var. & Min. & Max. \\
\hline East Asia and Pacific & 38.1 & 36.7 & 0.101 & 31.9 & 43.5 \\
Eastern Europe and Central Asia & 33.6 & 33.7 & 0.144 & 25.6 & 43.6 \\
Latin America and the Caribbean & 43.8 & 44.8 & 0.104 & 34.7 & 52.8 \\
Middle East and North Africa & 36.0 & 36.1 & 0.091 & 30.8 & 40.9 \\
South Asia & 35.0 & 36.3 & 0.081 & 30.0 & 38.1 \\
Sub-Saharan Africa & 44.4 & 42.1 & 0.175 & 33.3 & 63.1 \\
\hline Developing countries & 39.8 & 39.2 & 0.181 & 25.6 & 63.1 \\
\hline
\end{tabular}

Source: own calculations based on PovcalNet (2013).

Note: unweighted statistics.

Latin America and the Caribbean has been typically pointed out as the most unequal region in the world. Deininger and Squire (1996), for instance, state that their dataset confirm the "familiar fact that inequality in Latin America is considerably higher than in the rest of the world". ${ }^{18}$ This type of assessment however is usually made combining income Ginis for LAC with consumption Ginis for other regions, and/or ignoring SubSaharan Africa. With the adjustment mentioned above to take the consumption/income gap into consideration (factor 0.861), we find that the mean Gini for LAC is 43.8, slightly lower than in SSA (44.4), but the median is higher (44.8 in LAC and 42.1 in SSA). To reach the result of a higher mean Gini in LAC than in SSA we would need an adjustment parameter higher than 0.92; such value is larger than what we estimated in all LA countries in the sample, except Mexico.

The rest of the regions in the developing world have Ginis mostly below 40. The arithmetic mean is 38.1 in East Asia and Pacific, 36.0 in Middle East and North Africa, and 35.0 in South Asia. Inequality is likely to be higher in MENA, since several oilproducing countries are excluded for being high-income economies (and also for lack of information). ${ }^{19}$ Eastern Europe and Central Asia is the region with the lowest inequality levels, with a mean Gini coefficient of 33.6. Interestingly, the dispersion measured by the coefficient of variation is higher than in the rest of the regions, except SSA.

Almost all very highly unequal countries (Gini coefficients above 50) are in Sub-Saharan Africa (Table 3.2). This region, however, has a similar share of countries in the high and middle categories. In contrast, in LAC most countries have high levels of inequality, while in EAP, MENA and SA most countries are in the middle-inequality group. Only ECA has economies with low inequality (Gini coefficients below 30 ).

\footnotetext{
${ }^{18}$ See also Lopez Calva and Lustig (2010) and Chen and Ravallion (2012).

${ }^{19}$ Bahrain, Kuwait, Oman, Qatar, Saudi Arabia, United Arab Emirates are in that group. Malta and Israel are also ignored for being developed and Lebanon and Libya are excluded for lack of information.
} 
Table 3.2

Classification of countries by level of inequality and by region

Developing countries, 2010

\begin{tabular}{lccccc}
\hline \hline & \multicolumn{5}{c}{ Inequality } \\
\cline { 2 - 5 } & $\begin{array}{l}\text { Very high } \\
{[50-70]}\end{array}$ & $\begin{array}{c}\text { High } \\
{[40-50)}\end{array}$ & $\begin{array}{c}\text { Middle } \\
{[30-40)}\end{array}$ & $\begin{array}{c}\text { Low } \\
{[20-30)}\end{array}$ & Total \\
\hline East Asia and Pacific & 0 & 3 & 8 & 0 & 11 \\
Eastern Europe and Central Asia & 0 & 5 & 16 & 7 & 28 \\
Latin America and the Caribbean & 2 & 17 & 6 & 0 & 25 \\
Middle East and North Africa & 0 & 1 & 10 & 0 & 11 \\
South Asia & 0 & 0 & 7 & 0 & 7 \\
Sub-Saharan Africa & 10 & 14 & 16 & 0 & 40 \\
\hline Total & 12 & 40 & 63 & 7 & 122 \\
\hline
\end{tabular}

Source: own calculations based on PovcalNet (2013).

Note: countries are classified according to the value of the Gini coefficient

for the distribution of household consumption per capita.

The All the Ginis dataset (ATG) includes Gini coefficients from LIS, SEDLAC, WYD, the World Bank ECA database and WIID. We selected consumption Ginis from ATG for year 2005 or close, and applied a similar adjustment as described above for those countries in LAC with only income Ginis. The basic results are similar to the ones obtained with PovcalNet data. The linear correlation coefficient for the Gini between both data sources is 0.763 , while the Spearman rank correlation is 0.771 , both significant at $1 \%$. The Gini coefficients in ATG go from 23.1 (Czech Republic) to 62.9 (Comoros). The mean and median coincide in 40.1. Again, more than half of the observations are in the range $[35,45]$. Only several Eastern European countries have Ginis below 30, while only four Sub-Saharan African countries have Ginis higher than 55.

The evidence on inequality levels in the developing world drawn from WIID is similar. For instance, based on a sample of income Ginis for around 2005, Gasparini et al. (2013) find that the mean Gini for the six Sub-Saharan African countries in the dataset is 56.5, followed by Latin America (52.9), Asia (44.7) and Eastern Europe and Central Asia (34.7). ${ }^{20}$ We find that the linear correlation coefficient for year 2005 for the Gini coefficient in PovcalNet and WIID is 0.871, and the Spearman coefficient is 0.820 .

The Luxembourg Income Study database (see chapter 9 of this volume) covers 36 countries, including 6 in Latin America, which occupy the top places in all the income inequality rankings. The LA Ginis go from 50.6 in Colombia to 43.9 in Uruguay; the most unequal non-LA country is Russia with a value of 40.8 , while the rest of the countries in LIS go from 37 (USA) to 22.8 (Denmark). The mean Gini for the Eastern European countries in LIS is slightly higher than the mean for the high-income economies. Data from the World Development Indicators also suggest that inequality in the developing world is significantly higher than in the OECD high-income countries. The mean income Gini for the latter group is 32.2 , which is lower than in any other region in the world.

\footnotetext{
${ }^{20}$ The OECD high-income countries rank as the least unequal in the world with a mean income Gini of 32.8 .
} 
The EHII database confirms the high inequality levels of Sub-Saharan Africa and Latin America, but perhaps surprisingly, it records similar levels in South Asia and Middle East and North Africa. ${ }^{21}$ The mean Gini for the period 1998-2002 is 47.3 in SSA, 46.4 in LAC, 46.4 in MENA and 47.2 in SA. According to this dataset inequality is relatively lower in East Asia and Pacific (44.9) and Eastern Europe and Central Asia (44.0). The estimated level of the Gini coefficient is substantially lower in the developed economies; the mean is equal to $36.5 .^{22}$ The Pearson (Spearman) correlation coefficient between EHII and PovcalNet Ginis is 0.642 (0.603), lower than the resulting value when comparing PovcalNet with WIID or ATG, but still significant at $1 \%$.

Most international databases do not provide confidence intervals for the point estimates of the distributive measures, making impossible the assessment of the statistical significance of the differences among countries. However, given that the indicators are calculated from large national household surveys, the confidence intervals are typically relatively narrow. SEDLAC provides the confidence intervals for all the Gini coefficients in Latin America: for instance, the $95 \%$ confidence interval for the income Gini was [43.9, 44.7] in Argentina 2010, [53.5, 54.0] in Brazil 2009; and [47.0, 47.9] in Mexico 2010. Differences in the point estimates of more than 1 Gini point are always statistically significant (Figure 3.3).

\section{Figure 3.3}

\section{Gini coefficient and confidence intervals (95\%) \\ Distribution of household income per capita \\ Latin American countries, 2010}

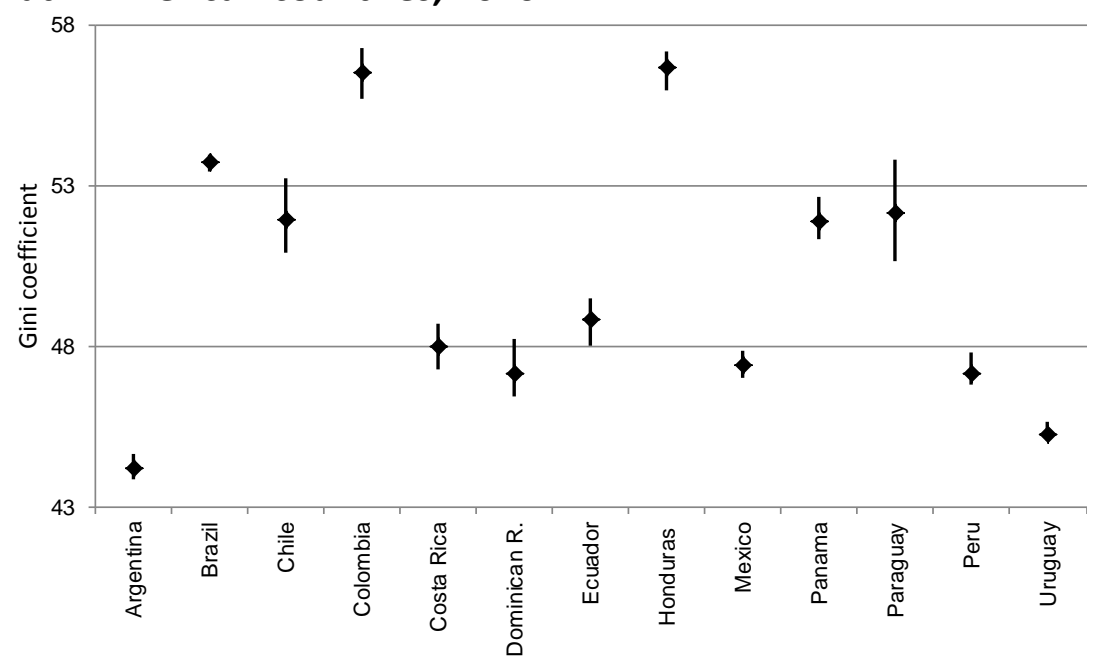

Source: own calculations based on SEDLAC (CEDLAS and the World Bank).

\footnotetext{
${ }^{21}$ See also Galbraith and Kum (2005).

${ }^{22}$ This mean excludes the oil-rich Arab countries. When including these countries in the sample the mean Gini jumps to 39.
} 


\subsection{Inequality beyond the Gini coefficient}

The international databases usually allow a closer look at the distributions in the world beyond a single parameter, such as the Gini coefficient. Table 3.3 reports some basic statistics of the decile shares in 120 countries around $2010 .{ }^{23}$ On average (unweighted) the poorest $10 \%$ of the population in a country accrues $2.6 \%$ of total consumption reported in the survey: that share climbs to $31.5 \%$ for the top $10 \%$. In a typical developing country the aggregate consumption of the poorest $60 \%$ of the population is similar than the consumption of the top $10 \%$.

It is interesting to notice that the coefficient of variation of the decile consumption shares across countries is decreasing up to the top decile, when it strongly rises: countries in the world seem substantially different in the consumption share of the poor and the rich, but not in the share of the middle strata, in particular the uppermiddle strata. This fact is naturally related to the typical shape of the real-world income distributions. For instance, under log-normality, the derivative of the decile shares with respect to the standard deviation of log incomes is U-shaped.

Table 3.3

Deciles shares, distribution of household consumption per capita Developing countries, 2010

\begin{tabular}{cccccc}
\hline \hline Deciles & Mean & Std. Dev. & Coef.Var. & Min. & Max. \\
\hline 1 & 2.6 & 0.81 & 0.31 & 1.0 & 4.4 \\
2 & 3.8 & 0.86 & 0.23 & 1.5 & 5.8 \\
3 & 4.8 & 0.90 & 0.19 & 2.0 & 6.8 \\
4 & 5.8 & 0.92 & 0.16 & 2.6 & 7.8 \\
5 & 6.8 & 0.92 & 0.13 & 3.5 & 8.8 \\
6 & 8.1 & 0.87 & 0.11 & 4.7 & 9.9 \\
7 & 9.6 & 0.80 & 0.08 & 6.6 & 11.0 \\
8 & 11.7 & 0.65 & 0.06 & 9.0 & 12.7 \\
9 & 15.3 & 0.84 & 0.05 & 12.7 & 17.6 \\
10 & 31.5 & 6.12 & 0.19 & 19.5 & 51.7 \\
\hline
\end{tabular}

Source: own calculations based on PovcalNet (2013).

Note: unweighted statistics.

The aggregate consumption share of deciles 5 to 9 is on average around $50 \%$, and it is very stable across countries. Palma (2011) has labeled this phenomenon the homogeneous middle. Variability across countries is actually smaller in the uppermiddle deciles (deciles 7 to 9). ${ }^{24}$ The proportion of total consumption accruing to that group is quite similar in all geographic regions of the world: it ranges from $35.9 \%$ in SSA to $37.3 \%$ in ECA. The main difference across regions lies in the share of the bottom

\footnotetext{
${ }^{23}$ Again, figures for Latin American (and a few Caribbean) countries are estimated based on the comparison of income and consumption microdata of seven countries in that region.

${ }^{24}$ Take the distribution of the shares of deciles 7 to 9 in total consumption across countries. While the percentile 10 of that distribution is 34.7 , the percentile 90 is just 38.3. The corresponding intervals for the distribution of the share accruing to the poorest $60 \%[25.4,38.2]$ and the richest $10 \%[24.3,39.3]$ are much wider.
} 
$60 \%$ compared to those in the upper $10 \%$. For example, while the share of deciles 7 to 9 in total consumption is almost the same in ECA (37.3\%) and LAC (37.1\%), the share of the bottom $60 \%$ is more than 7 points higher in the former ( $36.4 \%$ and $29.1 \%$ ).

The correlation coefficients for the decile shares in total consumption provide information about the structure of the distributions across countries (Table 3.4). In a cross-country perspective, gains are highly positively correlated in the first 8 deciles; on the other hand, for decile 10 correlations are all negative and large, except with decile 9, for which the correlation is non-significant. Gains in the participation of the richest $10 \%$ are tightly linked to losses in the share of the poorest $80 \%$ of the population. The table suggests that when we move up in the ladder of countries according to the share of the bottom deciles, we expect to see gains in the lowest strata obtained mostly against the share of the upper $10 \%$ of the population (and not for instance against the middle strata, and in alliance with the rich).

Table 3.4

Correlation coefficients across countries of decile consumption shares Developing countries, 2010

\begin{tabular}{|c|c|c|c|c|c|c|c|c|c|c|}
\hline & $\mathrm{d} 1$ & $\mathrm{~d} 2$ & d3 & $\mathrm{d} 4$ & d5 & d6 & $\mathrm{d} 7$ & d8 & d9 & $\mathrm{d} 10$ \\
\hline $\mathrm{d} 1$ & 1 & & & & & & & & & \\
\hline $\mathrm{d} 2$ & $0.9355^{\star}$ & 1 & & & & & & & & \\
\hline d3 & $0.8930 *$ & $0.9883^{\star}$ & 1 & & & & & & & \\
\hline $\mathrm{d} 4$ & $0.8421^{*}$ & $0.9624^{\star}$ & $0.9910^{*}$ & 1 & & & & & & \\
\hline d5 & $0.8042^{*}$ & $0.9273^{\star}$ & $0.9647^{*}$ & $0.9787^{*}$ & 1 & & & & & \\
\hline d6 & $0.7336^{*}$ & $0.8739 *$ & $0.9291^{*}$ & $0.9623^{*}$ & $0.9847^{*}$ & 1 & & & & \\
\hline $\mathrm{d} 7$ & $0.6310^{*}$ & $0.7734^{\star}$ & $0.8436^{\star}$ & $0.8950^{\star}$ & $0.9378^{*}$ & $0.9736^{\star}$ & 1 & & & \\
\hline d8 & $0.3127^{\star}$ & $0.4711^{*}$ & $0.5624^{\star}$ & $0.6446^{\star}$ & $0.7253^{\star}$ & $0.8085^{\star}$ & $0.8982^{*}$ & 1 & & \\
\hline d9 & $-0.5793^{\star}$ & $-0.4905^{\star}$ & $-0.4112^{*}$ & $-0.3258^{*}$ & $-0.2389 *$ & -0.1232 & 0.0527 & $0.4390^{*}$ & 1 & \\
\hline $\mathrm{d} 10$ & $-0.7844^{\star}$ & $-0.9032^{*}$ & $-0.9452^{\star}$ & $-0.9689 *$ & $-0.9844^{*}$ & $-0.9891^{*}$ & -0.9650 * & $-0.7962^{*}$ & 0.118 & 1 \\
\hline
\end{tabular}

Source: own calculations based on PovcalNet (2013).

$*=$ significant at $1 \%$.

\subsection{Inequality in the Gallup World Poll}

The Gallup World Poll provides new evidence on the international comparisons of income inequality, as it includes identical income and household structure questions applied to national samples in 132 countries. Of course, the reliability of the national inequality estimates in Gallup is lower than those obtained with household surveys, since only one income question is used to approximate well-being, and the sample sizes are considerably smaller. However, Gluzmann (2012) finds that the correlation coefficient between the Gini coefficients computed with Gallup microdata and those reported in the World Development Indicators (WDI) that are based on per capita income is high (0.85). Interestingly, the relationship with the consumption Ginis in WDI is much weaker; the linear correlation coefficient is 0.21 , non-significant at $10 \%$. International surveys with similar questionnaires across countries, such as the Gallup World Poll, could hardly be a substitute for household surveys as the main source for distributive analysis at the country level, but they may have a great potential for 
international comparisons of social variables. Future improvements in the quality of these surveys could turn them into a very valuable source for comparative international research.

Gasparini and Gluzmann (2012) use microdata from the Gallup World Poll 2006 to compute inequality in each region of the world. According to the unweighted mean of the national income Gini coefficients, Latin America is the most unequal region in the world (excluding Africa, which is not in the sample). The cross-country Gini in Latin America is 49.9, slightly larger than in South Asia (48.9), and Eastern Asia and Pacific (47.1). Countries in Eastern Europe and Central Asia (41.8), North America (39.2) and especially Western Europe (34.0) are the least unequal. Alternatively, regional inequality can be measured by considering each region as a single unit, and computing inequality among all individuals in that unit, after translating their incomes to a common currency - a concept usually labeled global inequality (see chapter 12 of this Handbook). The global Gini in Latin America is 52.5, a value higher than in Western Europe (40.2), North America (43.8) and Eastern Europe and Central Asia (49.8), but lower than in South Asia (53.2) and Eastern Asia and Pacific (59.4). The change in the rankings between the two concepts of inequality is driven by the differences across regions in the heterogeneity among countries in terms of mean income. Gasparini and Gluzmann (2012) report that the between component in a Theil decomposition accounts for $8 \%$ of total regional inequality in Latin America and $32.4 \%$ in East Asia and Pacific.

\subsection{Top incomes}

Until the recent developments in the literature of top incomes from tax records (Atkinson and Piketty, 2007, 2010; see also chapter 16 in this volume), inequality research has been mostly based on household surveys, which suffer from several limitations when focusing on the upper end of the distribution. Household surveys are all but ideal for studying top shares: the rich are usually missing from surveys, either for sampling reasons or because they refuse to cooperate with the time-consuming task of completing or answering to a long form. Because extreme observations are sometimes regarded as data "contamination", the rich may be intentionally excluded or top coded so as to minimize bias problems generated by presumably less-reliable outliers, or to preserve anonymity. Additionally, survey data present severe underreporting at the top: the richest individuals are more reluctant to disclose their incomes, or have diversified portfolios with income flows that are difficult to value.

Székely and Hilgert (1999) look at surveys from eighteen Latin American household surveys and confirm that the ten highest incomes reported are often not much larger than the salary of an average manager in the given country at the time of the survey. In general, the profile of the average individual in the top $10 \%$ of the distribution is closer to the prototype of highly educated professionals earning labor incomes, rather than capital owners. Consequently, the inequality that we are able to measure with 
household surveys can be severely affected, regarding both levels and dynamics, in those cases or periods in which an important part of the story takes place at the top.

Tax and register data are being increasingly preferred over surveys in studying distributive issues at the top. In fact, under certain conditions registry data can provide valuable information to improve survey-based estimates. Typically, incomes reported to the surveys are checked against the registers, or incomes are directly taken from administrative sources for the individuals in the sample. Even if the combination of survey and administrative data can be seen as an improvement, there remains the issue of the sampling framework for the top of the distribution. ${ }^{25}$ In any case, statistics offices in the developing world are not exploiting register data to complement surveys yet.

The use of tax statistics is not without drawbacks. First, since only a fraction of the population files a tax return, studies using tax data are restricted to measuring top shares, which are silent about changes in the lower and middle part of the distribution. Second, tax data are collected as part of an administrative process and do not seek to address research needs; both income and tax units are defined by the tax laws and vary considerably across time and countries. Third and most important, estimates are affected by tax avoidance and tax evasion; the rich, in particular, have a strong incentive to understate their taxable incomes. These elements, which are common to all countries, become critical in the developing world, characterized by tax systems with low enforcement and multiple legal ways to avoid the tax. ${ }^{26}$

A number of researchers have addressed the differences in the ability of tax and survey data to represent income inequality, trying to reconcile the evidence using the two sources (see Alvaredo, 2011; Burkhauser et al., 2012 for the US). Unfortunately, and despite multiple requests, at the moment of writing only a few developing countries have made available microdata from the income tax (namely Colombia, Ecuador and Uruguay). Alvaredo and Londoño (2013), and Alvaredo and Cano (forthcoming) show that, in contrast to survey-based results, high-income individuals are, in essence, rentiers and capital owners. This feature differs from the pattern found in several developed countries in recent decades, where it has been shown that the large increase in the share of income going to the top groups has been mainly due to spectacular increases in executive compensation and high salaries, and to a lesser

\footnotetext{
${ }^{25}$ If high-income individuals are not properly identified in the sample framework, comparing the incomes reported to the surveys against those in the registers one by one is only a partial improvement. In the UK, for example, the ONS scales up the surveys' incomes so that the surveys' averages match the average income in tax data.

${ }^{26}$ The reasons for which the rich and wealthy may be particularly dissuaded from disclosing their fortunes and incomes to authorities in the developing world may go beyond tax concerns, lest the information revealed fall into the wrong hands. Alvaredo and Londoño (2013) report that in Colombia, until recently plagued by high insecurity, anecdotal evidence suggests that during the intense political violence of the 1990s leaked personal tax returns were used by criminal groups to target victims and kidnap for ransom.
} 
extent to a partial restoration of capital incomes. While the working rich have joined capital owners at the top of the income hierarchy in the United States and other English-speaking countries, Colombia and Ecuador remain more traditional societies where the top income recipients are still the owners of the capital stock.

Results confirm that incomes reported to the tax authorities are considerably higher than those recorded in the surveys at the top. A natural question, which has received much attention lately, is the extent to which tax data can complement household surveys in examining the level of inequality in developing countries. Alvaredo and Londoño (2013) compare the Colombian household survey with the tax micro-data over the years 2007-2010. The total household income from the survey is $60-65 \%$ of the NAS measure of disposable income. ${ }^{27}$ Such gap cannot be seen as an accurate measure of missing income in household surveys, because both sources are different, but a partial explanation may well be at the top of the distribution. As a simple exercise, these authors replace all the incomes above the percentile 99 in the survey with those from tax data (net of taxes and social security contributions to render both sources comparable), under the assumption that the top $1 \%$ is poorly captured in the survey. Two elements are worth mentioning. First, the difference between the adjusted survey's total income (that is, the survey's incomes of the bottom $99 \%$ plus the net-of-tax incomes from the tax data above the percentile 99) and the NAS figure goes down to $75-80 \%$. Second, the Gini coefficient of individual incomes goes up from 55 to 61 in $2010 .^{28}$

These findings challenge the general skepticism regarding the use of tax data from developing countries to study inequality. Such estimates should be regarded as a lower bound, to take into account the effects of evasion and under reporting. Nevertheless, they show that incomes reported to tax authorities can be a valuable source of information, under certain conditions that require a case-by-case analysis.

\subsection{Inequality and development}

Is the level of inequality in a country associated to its development stage? In this section we take advantage of a cross-section of national Gini coefficients for year 2010 to take a look at this issue. Of course, this topic is related to the long-lasting debate initiated with the seminal contributions by Lewis (1954) and Kuznets (1955), who argued that the process of industrialization would imply an inverse $U$ pattern for inequality. However, the empirical test for the Kuznets curve requires time-series or

\footnotetext{
${ }^{27}$ The National Accounts-based measure of household disposable income has been defined as: balance of households' primary incomes + social benefits other than social transfers in kind - employers' actual social contributions - imputed social contributions - attributed property income of insurance policyholders - imputed rentals for owner occupied housing - fixed capital consumption - employees' social security contributions - taxes on income and wealth paid by households.

${ }^{28}$ These results are still approximations, as defining individual actual incomes from the Colombian tax records is not always straightforward.
} 
panel data, and not just a cross-section, since it is a hypothesis about the dynamics of an economy over its development process. The causal relationship between development and inequality is the subject of a large literature that has to face numerous empirical challenges, and hence it is far from settled (see Anand and Kanbur, 1993; Fields, 2002; Banerjee and Duflo, 2003; Dominics et al., 2008; and Voitchovsky, 2009 for assessments). In this section we simply document the empirical relationship between these two variables across countries in a recent point in time without exploring the difficult issue of causality.

The first panel in Figure 3.4 plots the Gini coefficient for the distribution of consumption per capita against per capita gross national income (GNI). ${ }^{29}$ The figure seems to reveal a decreasing relationship between inequality and development. The linear correlation coefficient between the Gini coefficient and per capita GNI is -0.56 (statistically significant at the $1 \%$ level). An inverse-U shape shows up in the second panel of Figure 3.4, when per capita GNI is presented in logs. However, the increasing segment of the curve covers only very poor Sub-Saharan African countries. The relationship Gini-GNI is decreasing in the range of GNI of most countries in the world.

\footnotetext{
${ }^{29}$ The Gini for the developed countries is computed over the distribution of income per capita, and not consumption per capita, a fact that probably underestimates the slope of the curve.
} 


\section{Figure 3.4}

Inequality and development

Per capita gross national income (GNI) and Gini coefficient, 2010
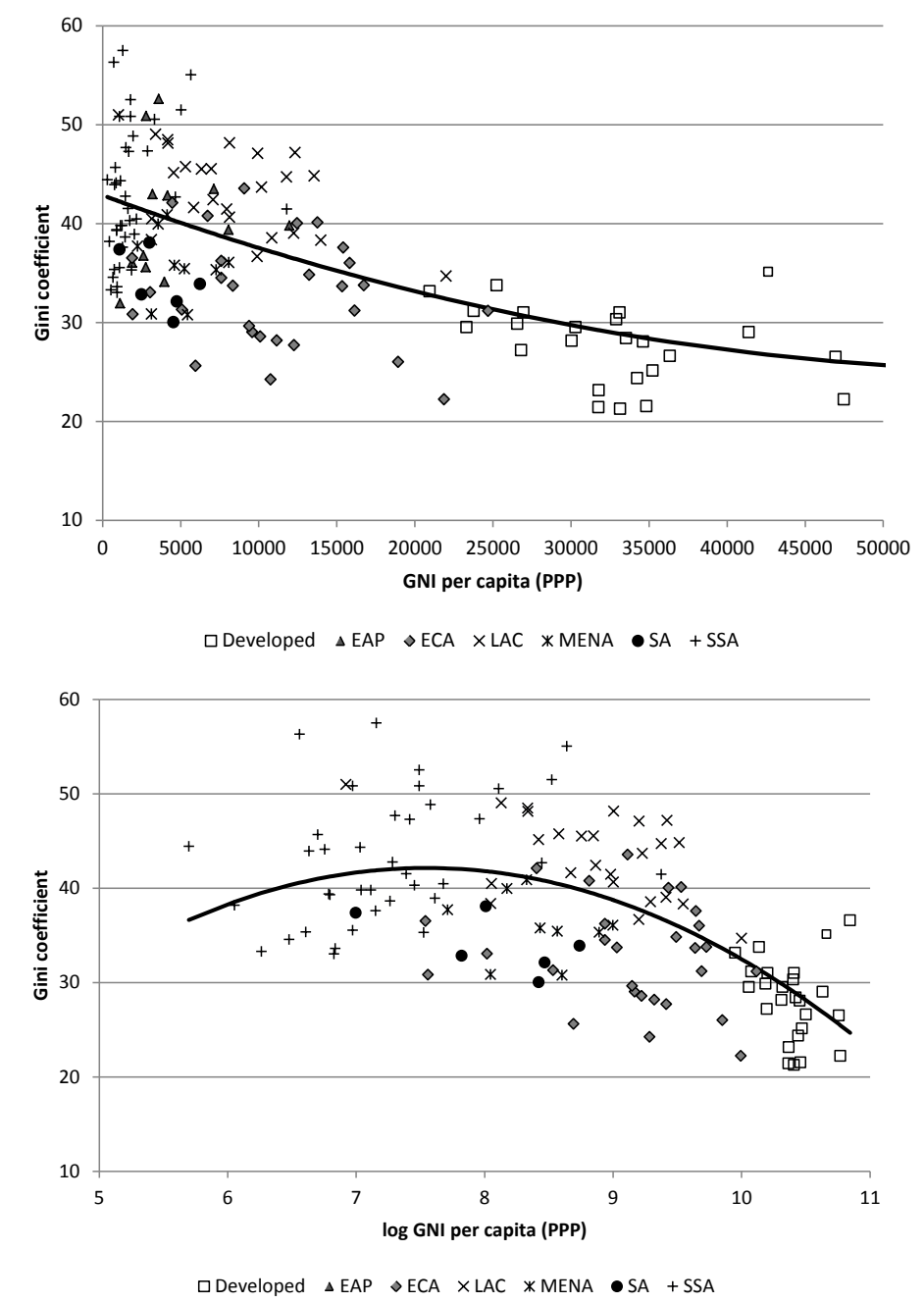

Source: own calculations based on WDI and PovcalNet (2013).

The results of the regressions in Table 3.5 and the Lind and Mehlum (2010) test confirm an inverse $U$ shape for the relationship between the Gini coefficient and log GNI per capita in a cross-section of countries. ${ }^{30}$ The result seems also valid, although becomes considerable weaker, when restricting the sample to developing economies. The turning points implicit in the regressions correspond to around US\$1800, a value that is lower than the per capita GNI of most developing countries, except for some economies in Sub-Saharan Africa. The inclusion of regional dummies reveals that East Asian, and especially Latin American and Sub-Saharan African countries are particularly unequal, even when controlling for their levels of economic development. ${ }^{31}$

\footnotetext{
${ }^{30}$ It is also confirmed estimating GDP with the Atlas method, and using the All the Ginis database.

${ }^{31}$ The Latin American "excess inequality" is documented in Londoño and Székely (2000); Gasparini, Cruces and Tornarolli (2011), and others.
} 
Table 3.5

Relationship between Gini coefficient and GNI per capita

\begin{tabular}{|c|c|c|c|c|}
\hline & \multicolumn{2}{|c|}{ All countries } & \multicolumn{2}{|c|}{ Only developing countries } \\
\hline & (i) & (ii) & (iii) & (iv) \\
\hline \multirow[t]{2}{*}{$\log$ GNIpc } & 24.24 & 24.44 & 18.01 & 26.54 \\
\hline & $(9.52)^{\star *}$ & $(4.48)^{\star \star \star}$ & $(8.23)^{\star}$ & $(6.58)^{\star \star}$ \\
\hline \multirow[t]{2}{*}{ log GNIpc squared } & -1.606 & -1.409 & -1.202 & -1.541 \\
\hline & $(0.552)^{\star \star}$ & $(0.34)^{\star \star \star}$ & $(0.53)^{\star}$ & $(0.48)^{\star \star}$ \\
\hline \multirow[t]{2}{*}{ Developed countries } & & -1.416 & & \\
\hline & & $(2.76)$ & & \\
\hline \multirow[t]{2}{*}{ East Asia \& Pacific } & & 7.352 & & 7.170 \\
\hline & & $(1.43)^{\star \star \star}$ & & $(1.62)^{\star \star \star}$ \\
\hline \multirow{2}{*}{\multicolumn{2}{|c|}{ Latin America \& Caribbean }} & 10.238 & & 10.157 \\
\hline & & $(0.53)^{\star \star \star}$ & & $(0.62)^{\star \star \star}$ \\
\hline \multirow{2}{*}{\multicolumn{2}{|c|}{ Middle East \& North Africa }} & 2.334 & & 2.144 \\
\hline & & $(1.28)$ & & $(1.48)$ \\
\hline \multirow[t]{2}{*}{ South Asia } & & 1.705 & & 1.515 \\
\hline & & $(1.79)$ & & $(1.97)$ \\
\hline \multirow[t]{2}{*}{ Sub-Saharan Africa } & & 13.749 & & 13.660 \\
\hline & & $(2.33)^{\star \star \star}$ & & $(2.34)^{\star \star \star}$ \\
\hline \multirow[t]{2}{*}{ Constant } & -49.34 & -72.10 & -61.67 & -80.27 \\
\hline & $(38.69)$ & $(13.17)^{\star \star \star}$ & $(28.64)^{\star \star}$ & $(20.06)^{\star *}$ \\
\hline Observations & 146 & 146 & 121 & 121 \\
\hline R-squared & 0.31 & 0.58 & 0.07 & 0.45 \\
\hline \multicolumn{5}{|c|}{ Lind and Mehlum test for inverse U shape } \\
\hline$|t|$ & 2.72 & 2.31 & 1.35 & 2.0 \\
\hline$p$-value & 0.004 & 0.011 & 0.089 & 0.024 \\
\hline
\end{tabular}

Note: robust cluster standard errors in brackets.

* significant at $10 \%$; $* *$ significant at $5 \%$; ** significant at $1 \%$.

Omitted category: Eastern Europe and Central Asia.

Lind and Mehlum test: $\mathrm{H}_{0}$ : monotone or $\mathrm{U}$ shape; $\mathrm{H}_{1}$ : inverse $\mathrm{U}$ shape.

\section{Inequality: trends}

In this section we report the recent trends in income inequality in the developing countries. We start laying out the general patterns, and then deep into the evidence for each region. Although most of the section deals with relative inequality, we devote a section to explore patterns for absolute inequality, and a section to document aggregate welfare changes. We end with a brief summary of the methodologies and main issues in the debate on inequality determinants in the developing world.

\subsection{General changes}

The available evidence suggests that on average the levels of national income inequality in the developing world increased in the 1980s and 1990s, and declined in the 2000s. Using data from PovcalNet, the mean Gini for the distribution of per capita consumption expenditures increased from 37.2 in 1981 to 39.4 in 2010 (Figure 4.1). ${ }^{32}$

\footnotetext{
32 In order to compute changes we discard countries in PovcalNet with less than four observations over the period 1981-2010, or with observations concentrated in a narrow time-period. The sample we use for the calculations on trends include 76 countries that represent $88 \%$ of the developing world
} 
The mean was basically unchanged between 1981 and 1987, ${ }^{33}$ then increased more than three points to reach a value of 40.5 in 1999, and from 2002 it started to fall, although slowly (from 40.6 in 2002 to 39.4 in 2010).

Figure 4.1

Gini coefficient

\section{Unweighted mean for developing countries, 1981-2010}

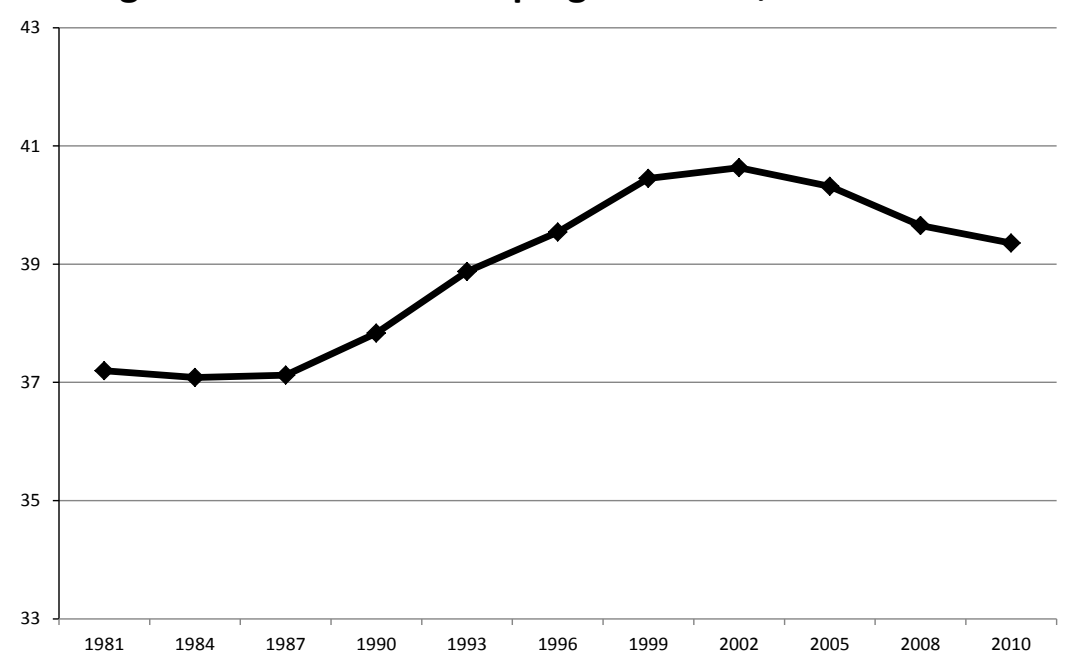

Source: own calculations based on PovcalNet (2013).

Note: the national Gini coefficients are computed over the distribution of household consumption per capita.

Figure 4.2 adds to the picture the changes at different percentiles of the distribution of national Ginis. The figure makes clear that on average the changes in the last decades have not been large, compared to the range over which the Gini varies across countries. The picture also reveals that the growth in the mean Gini in the late 1980s and 1990s was mainly due to the substantial increase in the low-inequality countries, in particular Eastern Europe and Central Asia economies after the fall of communism, and also some Asian economies in the early stage of economic take-off. Instead, the fall in the 2000s was widespread, although more intense in those countries above the median, such as those in Latin America. This observation suggests convergence in the levels of inequality in the developing economies. In fact, the standard deviation for the distribution of Gini coefficients substantially fell over time: 11.2 in 1981, 10.1 in 1990, 7.4 in 1999 and 7.2 in 2010. Countries in the developing world are still very different in terms of income inequality but differences have become considerably smaller over the last three decades.

population. In order to build a constant sample in a few cases Gini coefficients are imputed assuming constant inequality. Income Ginis in LAC are adjusted as explained in the previous section.

${ }^{33}$ This result is in part driven by the lack of information on changes in inequality over this period for several countries in the developing world. See below. 


\section{Figure 4.2}

\section{Gini coefficient \\ Unweighted statistics for developing countries, 1981-2010}

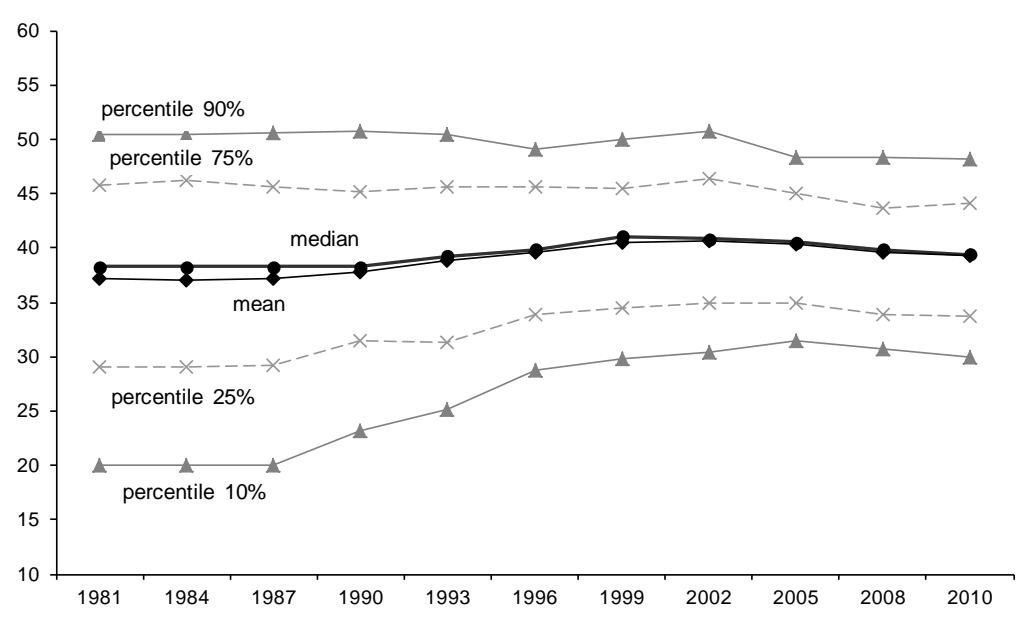

Source: own calculations based on PovcalNet (2013).

Note: the national Gini coefficients are computed over the distribution of household consumption per capita.

A closer inspection of the data reveals that the result of a stable mean Gini in most of the 1980s is driven by the lack of information for several countries, and by a substantial heterogeneity in the changes of those with information (Table 4.1). ${ }^{34}$ The strong rise in the mean Gini in the 1990s is associated to a large proportion of countries with growing inequality in a framework of much improved information. The tide seems to have turned in the 2000s, when most of the countries in the sample experienced a fall in inequality. But even in this decade of widespread social improvement, the country performances in terms of inequality reduction were quite heterogeneous. In fact, in $20 \%$ of the economies of the developing world the Gini coefficient increased between 2002 and 2010, while in 15\% of the countries the changes were smaller than $2.5 \%$.

\footnotetext{
${ }^{34}$ We classify countries in groups according to whether the Gini went up or down by more or less than $2.5 \%$ in a period. That threshold is certainly arbitrary. A change of $2.5 \%$ applied to the mean Gini in the developing world - which is around 40- represents 1 Gini point. A change of 1 point in the Gini coefficient is typically statistically significant, given the sample sizes of the national household surveys.
} 
Table 4.1

Proportion of countries classified in groups according to the change in the Gini coefficient

\begin{tabular}{lccc}
\hline \hline & $1981-1990$ & $1990-2002$ & $2002-2010$ \\
\hline Fall & 14.7 & 22.7 & 65.3 \\
No change & 21.3 & 16.0 & 14.7 \\
Increase & 34.7 & 60.0 & 20.0 \\
No information & 29.3 & 1.3 & 0.0 \\
\hline Total & 100.0 & 100.0 & 100.0 \\
\hline
\end{tabular}

Source: own calculations based on PovcalNet (2013).

Note: "Fall" includes countries where the Gini fell more than $2.5 \%$ in the period, "Increase" include countries where the Gini rose more than $2.5 \%$, "No change" includes countries where the Gini changed less than 2.5\%, "No information" includes countries without two independent observations in each period.

The bulk of the countries in the sample (64\%) experienced a change in the pattern of inequality around the turn of the century, from non-falling to decreasing inequality, while only a few experienced a pattern of continuous increasing (12\%) or decreasing (15\%) disparities over the two decades. The inverse- $U$ shape for the inequality pattern observed for many economies in the developing world could be consistent with the Kuznets story of economic growth for countries located close to the curve turning point. However, we fail to find any significant correlation between the type of the inequality pattern and different measures of development and growth. The inverse- $U$ pattern in the period 1981-2010 appears to have been common to a wide range of economies (more on this below).

The growth in the population-weighted mean of the Gini coefficient across developing countries was stronger than the increase in the unweighted mean (Figure 4.3). While the latter increased 2.2 points in the period 1981-2010, the former jumped 7.5 points. The gap between the two means shrunk from 5.4 points in the early 1980s to almost zero in the late 2000s. This pattern is mainly accounted by the dramatic surge in income inequality in China over the period. Interestingly, the fall in the unweighted mean Gini in the 2000s does not show up in the weighted mean, mainly because of the increase in inequality in China (also in India and Indonesia, but to a lesser extent). Although the Gini coefficient for a typical developing country significantly decreased in the 2000s, the national Gini for a typical person in the developing world did not fall. 


\section{Figure 4.3}

\section{Gini coefficient \\ Weighted and unweighted means \\ Developing countries, 1981-2010}

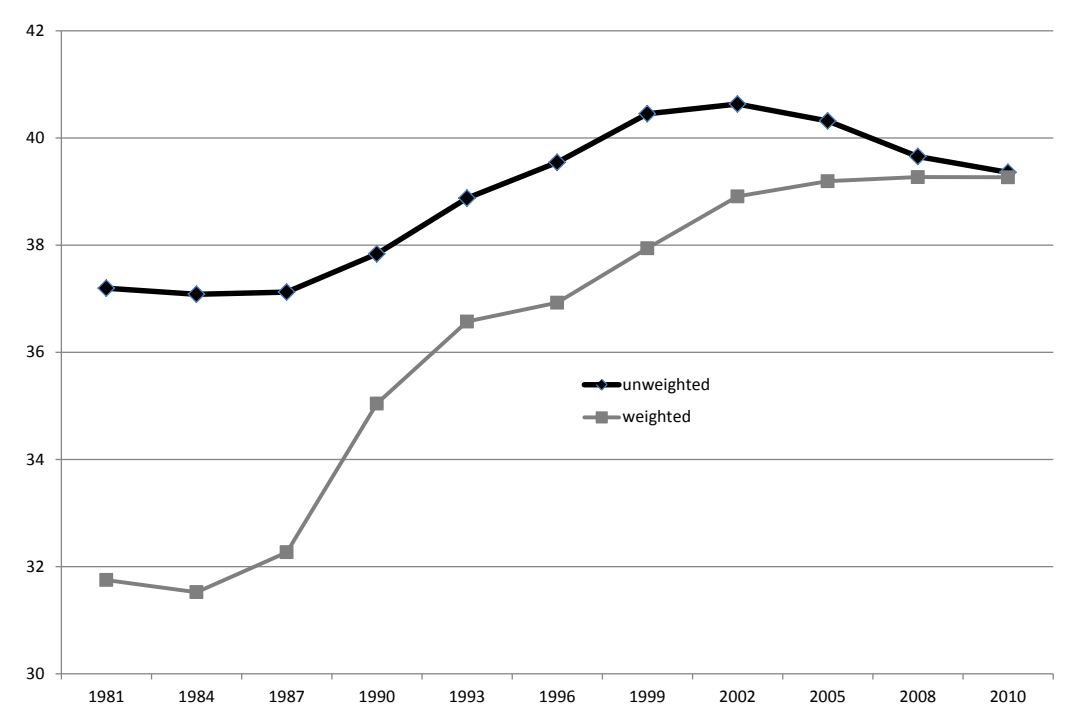

Source: own calculations based on PovcalNet (2013).

Note: the Gini coefficients are computed over the distribution of household consumption per capita.

In the rest of this section we go beyond the Gini coefficient and track changes along the distribution. In Figure 4.4 each point in a growth-incidence curve (GIC) indicates the unweighted mean across countries in the annual rate of growth of real consumption per capita (in PPP US\$) for a given decile of the national distributions. ${ }^{35}$ There is a stark contrast in the GIC corresponding to the 1990s and the 2000s. The first one is clearly increasing, suggesting growing inequalities, while the second is decreasing (and flatter), indicating a fall in well-being disparities in the 2000s. On average, in that decade consumption per capita grew by more than annual $4 \%$ in the three bottom deciles of the national distributions and by $3 \%$ in the top decile.

\footnotetext{
${ }^{35}$ The GIC depicted in Figure 4.4 is not the world growth-incidence curve, where for instance decile 1 would include the poorest $10 \%$ of the world population.
} 


\section{Figure 4.4}

\section{Growth-incidence curves}

Annualized growth rate in consumption per capita by decile

\section{Unweighted mean for developing countries}

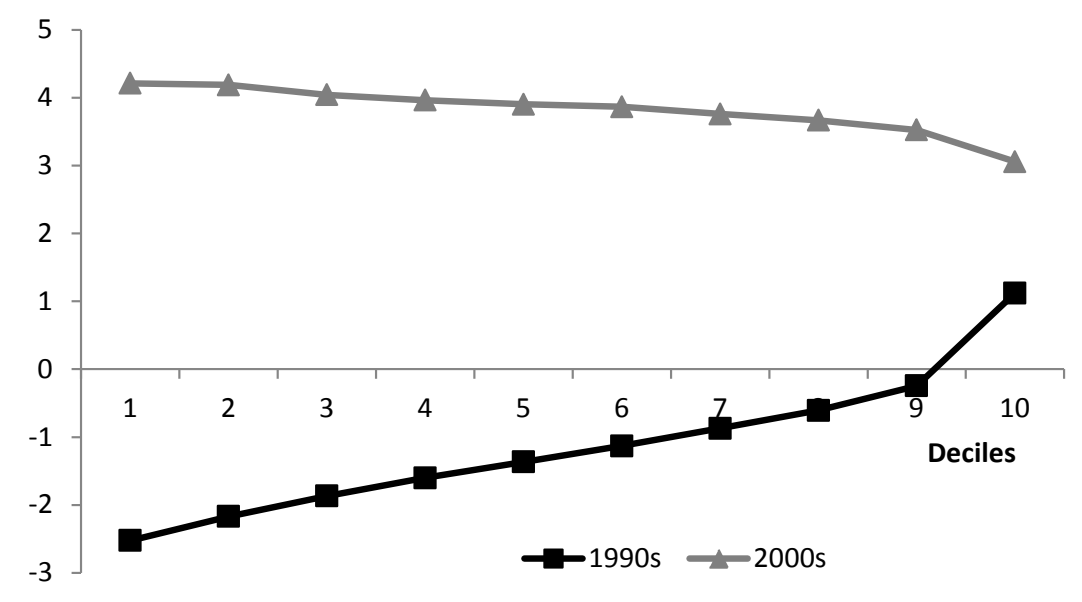

Source: own estimates based on PovcalNet (2013).

Note: annual change in consumption per capita (PPP US\$). 1990s=1990-2002, 2000s=2002-2010.

Naturally, the contrast between decades is also evident when looking at income shares. The results are summarized in Figure 4.5: while the share of the bottom $60 \%$ fell 2 points in the 1990s and increased 0.9 points in the 2000s, the performance of the top $10 \%$ was almost the exact mirror: increased 2.4 points in the 1990s and fell 1 point in the following decade. The share of the "middle" (deciles 7 to 9 ) has remained quite stable over the two last decades (36.9 in 1990, 36.5 in 1999 and 36.6 in 2010). This stratum seems not only quite homogeneous across countries but also over time (Palma, 2011).

\section{Figure 4.5}

Decile shares

Unweighted mean for developing countries, 1990-2010

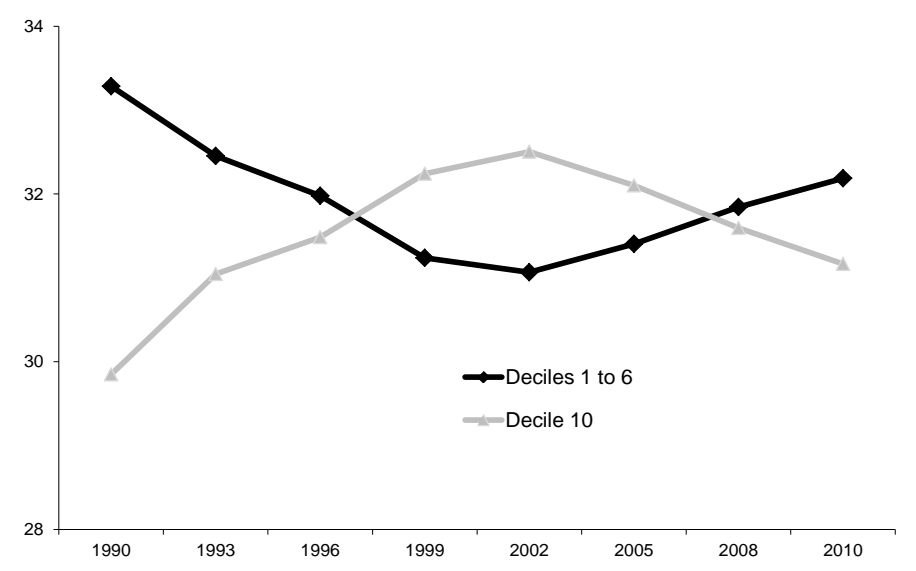

Source: own estimates based on PovcalNet (2013).

Note: the decile shares are computed over the distribution of household consumption per capita. 


\subsection{Changes by region}

Changes in inequality have been heterogeneous across the six geographical regions of the developing world (Figure 4.6). ${ }^{36}$ The mean Gini coefficient in Latin America increased more than two points in the 1990s, and then dropped in the 2000s by a larger amount. The data reveals almost no change in inequality in Sub-Saharan Africa over the two last decades and some decline in the five MENA countries included in the sample. Instead, the Gini coefficient increased more than two points in Asia, and more than six points in Eastern Europe and Central Asia. Figure 4.6 suggests again some pattern toward convergence: the gaps in inequality among regions in the developing world are smaller now than two decades ago. For instance, while the gap in the Gini coefficient between Latin America and ECA was 18 points in the early 1990s, it shrank to 11 points in the late 2000s.

\section{Figure 4.6}

\section{Gini coefficients}

\section{Unweighted means by region, 1990-2010}

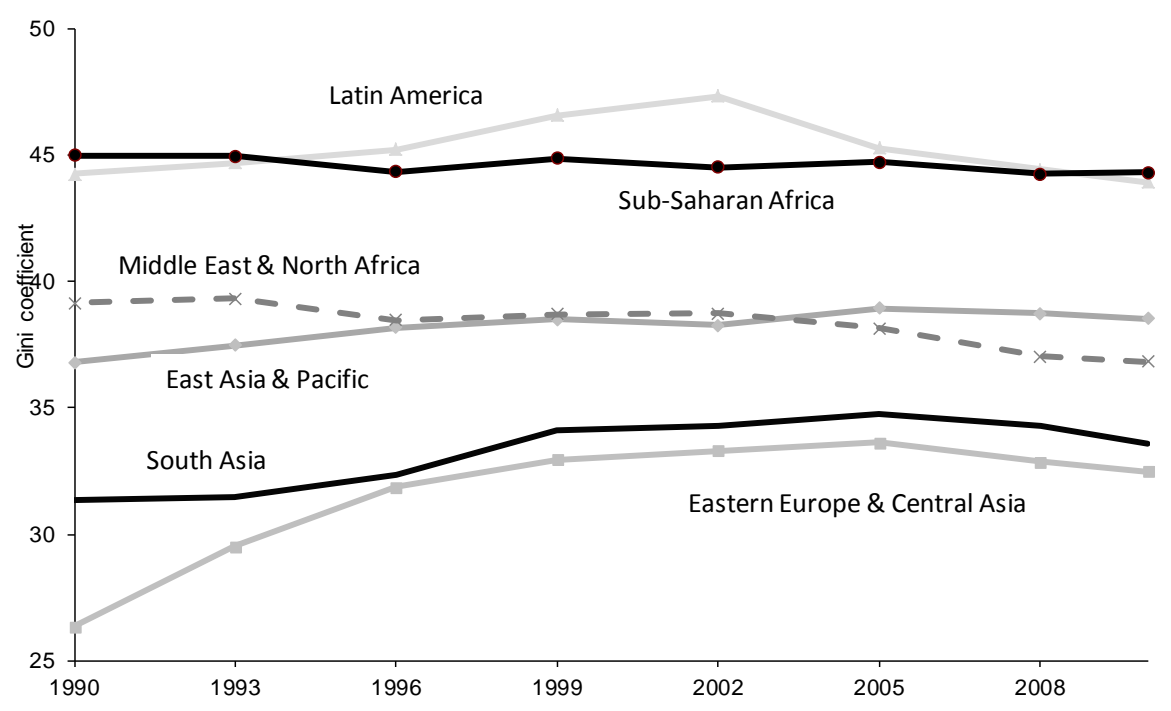

Source: own estimates based on PovcalNet (2013).

Note: the Gini coefficients are computed over the distribution of household consumption per capita.

In all regions the share of countries with falling inequality rose in the 2000s, as compared to the 1990s. The two most remarkable changes in the pattern occurred in Latin America, and in Eastern Europe and Central Asia. While the Gini went down in $26 \%$ of the LA economies in the 1990s, that share increased to $95 \%$ in the $2000 \mathrm{~s}$. In ECA while the growth in inequality was generalized in the 1990s, more than half of the countries experienced reductions in the 2000 s.

\footnotetext{
${ }^{36}$ We prefer not to report the regional patterns before 1990 since the number of observations is small in several regions. The numbers of countries by region in the sample we use to assess inequality trends are: 8 in EAP, 20 in ECA, 19 in LAC (all in Latin America, none from the Caribbean), 5 in MENA, 4 in SA and 20 in SSA.
} 
Using data from PovcalNet, Chen and Ravallion (2012) report changes in the within component of the global mean-log deviation between 1981 and 2008. This within component is a population-weighted measure of the national inequalities. They find substantial increases in East Asia and Pacific (from 0.125 to 0.256) and Eastern Europe and Central Asia (from 0.128 to 0.225), smaller increases in South Asia (from 0.156 to 0.181 ), Latin America and the Caribbean (from 0.541 to 0.561) and sub-Saharan Africa (from 0.338 to 0.347 ) and a fall in MENA (from 0.256 to 0.215). Bastagli et al. (2012) report similar patterns using data from PovcalNet, SEDLAC and LIS.

The picture of national inequalities in the developing world is similar when using other databases. For instance, the unweighted mean Gini in the All the Ginis database assembled by Milanovic grew from 36.2 in 1990 to 40.7 in 1999 and then dropped to 39.7 by 2005 . While in the 1990 s inequality rose in $63 \%$ of the economies in the ATG database, that share dropped to $35 \%$ in the 2000s. The recorded increase in the $1990 \mathrm{~s}$ was generalized across regions, but especially intense in Eastern Europe and Central Asia (9 Gini points), while the fall in the 2000s was larger in MENA and Latin America. Cornia and Kiiski (2001), Cornia (2011) and Dhongde and Miao (2013) document similar results using WIID data. We find that the linear (rank) correlation coefficient for the change in the Gini coefficient between 1990 and 2005 recorded in PovcalNet and WIID is $0.776(0.868)$, significant at $1 \%$. The corresponding values for the comparison between PovcalNet and ATG are 0.721 and 0.765 .

The evidence drawn from the EHII database is also roughly consistent with the patterns discussed above. The mean Gini for the developing world remained almost unchanged in the 1980s, increased in the 1990s from 42.5 in 1990 to 47.0 in 1999, and dropped to 46.5 in 2002 (the latest available date). ${ }^{37}$ While in $62 \%$ of the countries inequality increased in the early 1990s, that share dropped to 55\% between 1993 and 1999, and to 49\% between 1999 and 2002. The regional patterns are roughly consistent with those described above. The main difference is that EHII reveals a dramatic increase in inequality in the Middle East and North Africa (7 Gini points) that is not present in the evidence drawn from household surveys.

In the rest of this section we briefly review the literature on inequality changes in each geographic region of the developing world, while we take a closer look to the story of some particular cases: Brazil, China, India, Indonesia and South Africa.

\section{East Asia and Pacific}

The inequality patterns in East Asia and Pacific can be traced based on information from only 8 out of the 24 countries in the region, which nonetheless represent $96 \%$ of its total population. This set includes Cambodia, China, Indonesia, Lao PDR, Malaysia, Philippines, Thailand and Vietnam. There is scattered evidence for Fiji, Micronesia, Mongolia and Timor-Leste, while information is either lacking or too scarce for

\footnotetext{
${ }^{37}$ These estimates are computed dropping countries with few observations in the period.
} 
American Samoa, Kiribati, Korea, Dem. Rep., Marshall Islands, Myanmar, Palau, Papua New Guinea, Samoa, Solomon Islands, Tonga, Tuvalu and Vanuatu.

The slightly increasing pattern showed in Figure 4.6 for the unweighted mean of the consumption Gini in EAP hides important differences across countries (ADB, 2012; Chusseau and Hellier, 2012; Ravallion and Chen, 2007; Sharma et al., 2011; Solt, 2009; Zin, 2005). Consumption inequality increased in most economies in the region during the 1990s, with the exception of Thailand and Malaysia. The increase was particularly strong in China, where the consumption Gini climbed around 7 points in that decade. The performance in the 2000s was more heterogeneous: inequality continued increasing in China, Lao PDR and Indonesia, and also went up in Malaysia, while there is evidence pointing to a fall in consumption inequality in Cambodia, Philippines, Thailand and Vietnam.

Overall, considering the two decades, EAP combines countries with systematic increases in inequality (China, Indonesia, Lao PDR), several cases in which inequality had a cyclical pattern, ending in 2010 at similar levels than in 1990 (Cambodia, Malaysia, Philippines and Vietnam), and only one successful story of consistent reduction in consumption inequality: Thailand, for which the estimated reduction in the Gini coefficient exceeded five points; from 45.3 to 39.4 over the last two decades. Universal social policies, including basic education and health, have been stressed by many authors as significant drivers of that fall (Jomo and Baudot 2007).

Probably the most striking phenomenon regarding inequality in EAP was the strong rise that took place in the two most populous countries of the region, China and Indonesia: the Gini coefficient went up around five points in Indonesia and more than ten points in China over the last two decades. Such dynamics happened in a context of high growth and falling poverty, most notably in China. Sharma et al. (2011) summarize the main factors behind these changes: (i) the realignment of activity away from agriculture and towards industry and services; (ii) the skill premium rose due to the unmatched growing demand for skills, and even the emigration of skilled workers; (iii) inequalities in educational attainment in secondary and tertiary schooling have become an increasingly important source of unequal incomes; (iv) a lack of infrastructure linking urban areas with rural areas and other barriers to labor mobility have further accentuated inequality; (v) in China most of income inequality (40 per cent) is now accounted for by rural-urban differences in income levels, and the concentration of growth in urban areas is creating a rural-urban divide in employment and earning possibilities, exacerbated by the much more rapid development that occurred in coastal areas. The interested reader is referred to the boxes on China and Indonesia.

\section{China}

Since 1978, when China started the pro-market reforms, GDP has increased at an average rate close to 10 per cent, and household per capita income has grown more 
than 7 per cent per year. Such remarkable economic transformation has been accompanied by important changes in inequality and poverty. China is a successful story of reduction in absolute poverty (World Bank, 2009; Ravallion and Chen, 2007, 2008; Minoiu and Reddy, 2008). Chen and Ravallion (2008) find that between 1981 and 2005 the number of poor people (with a poverty line of \$1.25) went down from 839 to 204 million in terms of consumption, and from 816 to 135 million in terms of income. However, it is argued that it will be harder for China to maintain its past rate of progress against absolute poverty without addressing the problem of rising inequality.

The increase in income inequality in China over the last three decades has been widely documented. Ravallion and Chen (2007) and World Bank (2009) show that income inequality rose from the mid-1980s through 1994, dipping a bit in the late 1990s, and then edging upward thereafter. The Gini coefficient rose from 25 in 1981 to 39 in 1999. Li et al. (2013), among others, document an additional increase in the 2000s, a pattern explained by the widening of the rural-urban income gap, and the increase in income from property and assets, driven by the development of urban residential real-estate markets, the expansion of stock and capital markets, the growth of private enterprises, and other property rights.

In marked contrast to most developing countries, relative inequality is higher in China's rural areas than in urban areas. However, there has been convergence over time with a steeper increase in inequality in urban areas Absolute inequality has increased appreciably, both between and within both urban and rural areas.

\section{Indonesia}

During the thirty years before the Asian crisis of 1997-1998, which coincided with the New Order under Suharto's dictatorship, Indonesia GDP grew at an average rate of $7 \%$ per year, while per capita GDP increased by 3.5 times. The process was not smooth and went through different phases that implied immense structural change. Agriculture was the main economic sector in the 1970s and benefited from the introduction of high yielding variety seeds and other technical progress; the oil commodity boom (1974-1981) generated a windfall income that allowed for the subsidization of rice production and the improvement of the country's infrastructure, with positive effects on life expectancy at birth and school enrollment rates. The period of deregulation and external oriented policies after 1985 set the basis for the development of the manufacturing sector.

Despite problems with the data, scholars agree in that there was a systematic drop in poverty rates between 1976 and 1997. At the same time, overall consumption inequality in Indonesia did not change markedly with development until the late 1980s. On the contrary, the household per capita consumption Gini displayed a falling trend between 1964 and 1987 (from 35 to 32). Subsequently, although urban inequality increased, this was partly offset by declines in rural inequality. Cameron (2002) argues that Indonesia can be considered to be 'lucky' in the sense that its 
industrial center happens to be close to rural Java where many of the country's poorest families make their home. These households benefited from the off-farm employment opportunities that industrialization offered. Alatas and Bourguignon (2000) found that the returns to land size decreased between 1980 and 1996; opportunities for off-farm earnings for rural households also contributed to falling rural inequality.

Inequality (but not poverty) started to rise seven years before the crisis. Alatas and Bourguignon (2000) decompose such increase between components associated with changes in the structure of earnings, changes in occupational choice and changes in the socio-demographic structure of the population. They find as main explanations the migration from rural to urban areas and the increase in non-farm self-employed work.

Indonesia was severely hit by a financial crisis: in 1997-1998 GDP dropped by $15 \%$. This turned into a sharp decrease in inequality and an increase in poverty. Skoufias and Suryahadi (2000) find that this pattern seems to have arisen from a decrease in regional inequality. Urban areas (which tend to be wealthier than neighboring rural areas) were hit harder, and the urban middle class, who lost their formal sector jobs, was harshly affected. As the crisis reduced the per capita expenditure of households, the percentage reduction was probably less among the poorer population than among the less poor population. Since 2001, and along with the process of decentralization of powers to local authorities, a general pattern of rising consumption inequality has been observed: the Gini increased by 5 points from 33 in 2002 to 38 in 2010. Miranti et al. (2013) suggest that the recent increases in inequality may be linked to the higher share of workers employed in the informal sector (70 per cent), hence not covered by minimum wage legislation or employment protections.

\section{Eastern Europe and Central Asia}

The transition from central planning to market system in the countries of Eastern Europe (EE) and those belonging to the former Soviet Union (FSU) had profound socioeconomic impacts, which could be better documented (compared to the situation in previous decades) due to the improvements in the production and release of information by the new administrations (Milanovic, 1998). ${ }^{38}$ The fall of the communist regimes was followed by a substantial increase in inequality in almost all countries. ${ }^{39}$ According to PovcalNet data the mean Gini for the distribution of per capita consumption expenditures grew from 26.4 in 1990 to 31.9 in 1996. The increase in the first half of the 1990s was particularly strong in those countries belonging to the FSU and in Southeast Europe, and somewhat milder in those economies that joined the European Union. Such developments have been linked to the process of privatization,

\footnotetext{
38 Much information also existed about pre-1990 earnings and household incomes in (former) Czechoslovakia, Hungary and Poland (Atkinson and Micklewright, 1992)

39 Milanovic and Ersado (2010); Ivaschenko (2002); Ferreira (1999); Milanovic (1998); Cornia (1996); Cornia and Reddy (2001); Mitra and Yemtsov (2006).
} 
which implied an increase in earnings dispersion in comparison to the more compressed wage structure of the state-owned firms. One key characteristic of the planned economies was the imposition of wage "grids" that forced a wage compression; the fast transition from wage setting under the wage grids toward a less regulated labor market provoked a rise in the returns to education, and hence a surge in inequality. ${ }^{4041}$ The economic liberalization also triggered changes in the sectorial structure of the economy; in particular the ensuing de-industrialization during the transition is linked to an increase in inequality (Ferreira, 1999, Milanovic, 1999, Ivaschenko, 2002; Birdsall and Nellis 2003). Milanovic and Ersado (2010) highlight the role played by the inception or increase of tariffs for utilities, while Standing and Vaughan-Whitehead (1995) point to the weakening of the minimum wage as key factors behind the increase in inequality.

After the initial surge in the early 1990s, inequality continued growing in the region in the second half of the 1990s although at slower rates. The patterns were more heterogeneous in the 2000s; inequality increased in some economies, but went down in most countries, especially those in the FSU (World Bank, 2005). The mean Gini for Eastern Europe and Central Asia in the late 2000s was lower than in the late 1990s but still significantly higher (around 7 Gini points) than before the transition. ${ }^{42}$

\section{Latin America and the Caribbean}

All Latin American countries carry out household surveys that provide information to obtain estimates of poverty and inequality. All regular surveys in the region include income questions; still in a few of them consumption expenditures are reported, as well. The increasing availability of surveys in Latin America allowed the creation of databases that make efforts to standardize the generation of poverty and inequality statistics, favoring a close monitoring of the social and labor situation in the region (SEDLAC by CEDLAS and the World Bank, and BADEINSO by UN's ECLAC). In contrast, the situation in the Caribbean is much less favorable, as surveys are isolated and information is not easy to access. In fact, trends shown in the literature and in this section are restricted to Latin America, which represents $94 \%$ of total LAC population.

Latin America experienced two distinct distributive patterns in the last three decades (IDB, 1999; de Ferranti et al., 2004; Lopez Calva and Lustig, 2010; Gasparini et al., 2011). During the 1980s, 1990s, and the crises at the turn of the century, income inequality soared in most countries for which comparable data are available. The mean Gini for the distribution of household per capita income crawled from 50.1 in 1980 to

\footnotetext{
${ }^{40}$ See Fleisher, Sabirianova and Wang (2005) for a study of 10 transition economies and Gorodnichenko and Sabirianova (2005) for the cases of Russia and Ukraine.

${ }^{41}$ In Hungary, for instance, the income share accrued by the top 1\% almost doubled between 1992 and 2009 , from $6-7 \%$ to $12 \%$. Half of the increase was due to capital income, while the other half to increased earnings (Mavridis and Mosberger, forthcoming).

42 The reader is referred to chapter 20 for a survey of cross-country studies on the multiple causes of inequality in $\mathrm{OECD}$, including many countries in Eastern Europe.
} 
51.5 in 1986, 51.9 in 1992, 53.0 in 1998 and 53.4 in 2002 (Gasparini et al., 2013). The frequent macroeconomic crises that hit the region in that period were unequalizing because the poor were less able to protect themselves from high and runaway inflation, and adjustments programs frequently hurt the poor and the middle-ranges disproportionately (Lustig, 1995). The market-oriented reforms that started in Chile in the 1970s and became widespread in the region in the 1990s were associated with rising inequality, although this pattern had a notable exception in the case of Brazil (López Calva and Lustig, 2010). In most countries employment reallocations brought about by trade liberalization and the skilled-biased technical change associated to the modernization of the economy implied a sizeable reduction in the demand for unskilled labor, which led to higher inequality. In some countries adjustments that led to a contraction in the demand for labor affected unskilled workers disproportionately. All these changes took place in a framework of weak labor institutions and safety nets, and hence their consequences made a full impact on the social situation (Gasparini and Lustig, 2011).

Starting in the late 1990s in a few countries and in the early 2000s for the rest, inequality began to decline. The mean Gini for the distribution of household per capita income dropped from 53.4 in 2002 to 50.9 in 2008 (Gasparini et al., 2013). Updated SEDLAC and BADEINSO statistics suggest that the downward trend continued, and that at the time of writing (2013) the mean income Gini in the region would be again at around the value of the early 1980s. The evidence, in fact, indicates that between 2002 and 2012, income inequality went down in all Latin American economies. This remarkable decline appears to be driven by a large set of factors, including the improved macroeconomic conditions that fostered employment, the petering out of the unequalizing effects of the reforms in the 1990s, the expansion of coverage in basic education, stronger labor institutions, the recovery of some countries from severe unequalizing crises and a more progressive allocation of government spending, in particular monetary transfers. The empirical evidence on the driving factors of the recent fall in inequality is, however, still scarce and fragmentary (López Calva and Lustig, 2010; Gasparini and Lustig, 2011; Cornia, 2011).

\section{Brazil}

For decades Brazil was singled out as the most unequal economy in Latin America, and in some rankings even the most unequal in the world. In the late 1980s the Gini coefficient for the distribution of household per capita income reached values higher than 60. But from that point on inequality started to decrease, first slowly in the 1990s, and then more dramatically in the 2000s. ${ }^{43}$ By 2011 the Gini reached an unprecedented low value of 52.7, several points below the level of some other Latin

\footnotetext{
43 See Barros et al. (2010), Ferreira et al. (2007), Foguel and Azevedo (2007), Hoffmann (2006) and Langoni (2005).
} 
American economies (e.g. Honduras, Colombia, Bolivia). ${ }^{44}$ Brazil - the fifth most populous nation in the world - is still a high-inequality country, but it stands out as a successful case of consistent reduction of income disparities.

Data from the Brazil's national household survey (PNAD) reveals a drop in the Gini of 2 percentage points in the late 1970s, and no systematic changes for most of the 1980s, until a deep macroeconomic crisis hit the country, pulling inequality to unprecedented levels. The Gini went up from 59.2 in 1986 to 62.8 in 1989 and returned to 59.9 in 1993. During the 1990s the Gini moved down very slowly, decreasing by just 1 percentage point between 1993 and 2001. That pace drastically increased in the 2000s: the Gini went down from 58.8 in 2001 to 52.7 in 2011, averaging a fall of 0.6 percentage points a year. During ten years per capita income of the poorest $10 \%$ of the Brazilian population grew at an average annual rate of $7 \%$, almost three times the national average.

In an in-depth study of the determinants of inequality changes in Brazil, Barros et al. (2010) highlight the role played by the sharp fall in earnings inequality and the substantial increase in public transfers as the two main direct determinants of the decline in income disparities since the early 2000s. ${ }^{45}$ They find that half of the reduction of inequality in labor incomes was associated to the educational progress that took place over the previous decade, that significantly increased the ratio between skilled and unskilled workers. The average years of education for the adult population grew $22 \%$ in the 2000 s and the Gini coefficient computed over the distribution of that variable fell $23 \%$, values well above the mean for Latin America (Cruces et al., 2013). Using different decomposition techniques, Barros et al. (2010) and Azevedo et al. (2011) find a sizeable impact of the fall in the returns to education on earnings inequality. Several authors have also found a reduction in spatial and sectorial labor market segmentation. Although it is not yet clear which factors are behind these trends, the evidence seem to point to a relatively faster expansion of some productive sectors in the Brazilian agricultural 'hinterland' as opposed to the metropolitan/industrial areas (Lustig et al., 2012). The substantial increase in the minimum wage $-68 \%$ in real terms between 2002 and 2010 (CEPAL, 2011)- is also underlined as one important force behind the fall in household income inequality, given that the minimum wage sets the floor for both unskilled workers earnings and for social security benefits.

The strong expansion of public transfers accounts to a large share of the fall in income inequality in Brazil (Azevedo et al., 2011; Barros et al., 2010; Bérgolo et al., 2011; Lustig et al., 2012). The main force was the rapid expansion in the coverage of government cash transfers targeted to the poor, mainly a transfer to the elderly and disabled

\footnotetext{
${ }^{44}$ These values are taken from SEDLAC (2013). All sources confirm the strong decreasing pattern in inequality in Brazil.

${ }^{45}$ For evidence and discussion on inequality in the 1990s see Ferreira and Paes de Barros (1999), and Ferreira et al. (2006).
} 
(Benefício de Prestação Continuada) and Brazil's signature conditional cash transfer program Bolsa Família. ${ }^{46}$

\section{Middle East and North Africa}

Data constraints are particularly limiting when analyzing distributive issues in Middle East and North Africa. The lack of accessible and comparable household surveys makes it difficult even to identify the extent of poverty and inequality in most MENA countries. The oil-rich economies (Bahrain, Kuwait, Oman, Qatar, United Arab Emirates, and Saudi Arabia) enjoy high levels of per capita income, and are usually not included into the analysis of the developing world. In any case, distributive data is rarely available for these economies. A second group, by far the largest in terms of population, consists of middle income countries. Within this group there are no public accessible information for Lebanon and Libya, just one data point for Djibouti, Iraq, Syrian Arab Republic, West Bank and Gaza, and only a few for Algeria and Yemen. In sum, the only MENA countries for which it is possible to track changes in poverty and inequality over time are Egypt, Iran, Jordan, Morocco and Tunisia, but even in these cases data is scattered and often of low-quality. MENA has a long way to go to build a reliable, comparable and sustainable system of household surveys and distributive statistics.

Despite this constraint, several studies shed some light about the trends in inequality in this region. ${ }^{47}$ Authors coincide in dividing the last four decades into three periods. The first one, spanning until 1985, was characterized by rapid economic growth. Page (2007) reports a substantial reduction in income inequality between the mid-1970s and the early 1990s. ${ }^{48}$ Data from PovcalNet confirms that fall, although the magnitude is more modest. "Middle Eastern economies entered their rapid growth period with income distributions that were becoming more egalitarian, reflecting the political ideology and policies of post-colonial governments" (Page, 2007). The second period covers the late 1980 s and most of the 1990s, and is characterized by low economic growth, and meager or no social gains: real per capita incomes increased by less than $1.5 \%$ per year, while income distributions were rather stable. The downward pattern in inequality appeared to have resumed in the 2000s, although at a slow pace. According to our estimates based on PovcalNet the mean Gini fell from 38.7 in 2002 to 36.8 in 2010. These values place MENA as a region of moderate inequality within the developing world, a fact that have puzzled some authors, that would predict higher

\footnotetext{
${ }^{46}$ See Fiszbein and Schady (2009) and Veras Soares (2007).

47 See Acar and Dogruel (2012), Adams and Page (2003), Bibi and Nabli (2010), lqbal (2006), Page (2007), and Salehi-Isfahani (2010).

${ }^{48}$ According to Iqbal (2006) reliable pre-1985 household surveys are only available for Tunisia and Egypt.
} 
income disparities given the political process and the balance of political power in those societies. $^{49}$

\section{South Asia}

South Asia has been a region of low inequality for developing world standards, though rising since the early 1990s. In India, further discussed in a separate box, the consumption Gini moved from 30.8 in 1993 to 33.9 in 2010. Bangladesh displayed relatively low inequality throughout the 1980s (Gini equal to 26.1 in 1984), but the situation worsened since the beginning of the 1990s: the Gini climbed to 32.1 by 2010. Khan (2008) argues that incomes from non-farm sources and the high concentration of land tenure have all been disequalizing forces, while the positive effects of the moreevenly distributed farm income were offset partly by its declining share in total income.

Scholars do not always agree about the distributive changes in Pakistan; PovcalNet helps defining the picture by providing consumption Ginis of 33.2 for 1990, 28.7 for 1996 and 30.0 for 2008. The high economic growth during the 1980 s contributed to a sharp decline in poverty, but accompanied by a mild increase in inequality. The fall in economic growth during the 1990s resulted in a rise in poverty while inequality decreased modestly. According with Akmal (2008) in Pakistan there is an institutional structure that excludes a large proportion of the population from the process of economic growth as well as governance.

Sri Lanka experienced rising inequalities between 1985 (Gini of 32.5) and 2007 (Gini 40.3) -among the highest increase in the region during the period of free market reforms, integration to the world markets and high growth-, with a reversal of the trend towards 2010 (Gini of 38.3) and persistent regional disparities due to conflict. Nepal presents similar dynamics. Gosh (2012) notes that rising inequality reflects two components: first, growing vertical inequality within the modern industrial sector driven by the returns to skill; and second, increasing disparities between the industrial fast-growing sector and the traditional agricultural activities.

\section{India}

Chakravarty (1987) argues that even if policymakers in India adopted a development strategy based on central planning over the forty years following independence, "there was a tolerance towards income inequality, provided it was not excessive and could be seen to result in a higher rate of growth than would be possible otherwise." One of the explicit goals of the socialist program was to limit the economic power of the elite in the context of a mixed economy. From the mid-1980s, however, India gradually

\footnotetext{
49 "In many MENA countries, from the Maghreb to the Arabian peninsula, power is wielded by rather narrow groups... Seen from this perspective, the most puzzling thing about inequality in the Middle East is how low it is" (Robinson, 2009).
} 
adopted market-oriented economic reforms. Initially, these were accompanied by an expansionist fiscal policy involving allocations to rural areas, in order to counterbalance the negative redistributive effects of the liberalization. The speed of reforms accelerated during the early 1990s; as in many developing countries influenced by the Washington consensus, the focus shifted away from state intervention towards liberalization, privatization and globalization.

Most analysis on inequality in India over the last three decades are based on the observations from the expenditure surveys conducted in 1983, 1987/8, 1993/94, 2004/05 and 2009/10 for urban and rural areas, which have allowed for an analysis pre and post reforms (see Figure 4.10 below). Inequality has increased significantly in the post-liberalization years, and this was much more pronounced in the urban areas; on the contrary, estimates of absolute poverty measures have systematically fallen since 1983. Mazundar (2012) summarizes the main drivers of these changes: (i) the lead in employment and output growth has been taken not by manufacturing but by the tertiary sector, which displays higher inequality in pay; ${ }^{50}$ (ii) much of the labor reallocated from agriculture is absorbed in the informal sector, where earnings are only slightly higher than the poverty line; (iii) although numerous social insurance schemes have been established, their actual impact has been limited and regressive as they have disproportionately benefited workers in the small formal sector; (iv) the modest and selective increase in social sector spending is constantly threatened by the budget deficit; $(v)$ the education polices implemented over the years have been biased towards the promotion of tertiary education and have neglected basic primary and lower secondary education.

From a different perspective, Banerjee and Piketty (2010) looked at the tax-based shares of top incomes. Their results suggests that the gradual liberalization of the Indian economy made it possible for the top $1 \%$ to substantially increase their share of total income, from $4.7 \%$ in 1980 to $8.9 \%$ in 1999 . While in the 1980 s the gains were shared by everyone in the top percentile, in the 1990 s it was only those in the top $0.1 \%$ who benefited the most. The authors stress that these results could be linked to the debate around the Indian growth paradox of the 1990s. According to the household expenditure survey conducted by the National Sample Survey (NSS), real per capital growth during the 1990s was fairly limited, in sharp contrast with the fast growth measured by national accounts. It was suggested that much of such growth could have gone to the rich, absent from surveys. Banerjee and Piketty (2010) conclude that top incomes could explain between 20 and $40 \%$ of the puzzle, which still leaves the bulk of the difference unaccounted for.

\footnotetext{
${ }^{50}$ According to Mazundar (2012) the reasons for this pattern of growth are to be found not in the tertiary sector but in the Indian manufacturing sector, which has been characterized by a dualistic size distribution where middle-size firms are missing.
} 


\section{Sub-Saharan Africa}

Although recently there have been many improvements, the lack of a consistent body of household surveys undermine the assessment of income inequality in Sub-Saharan Africa. Time series data on inequality is severely lacking in most SSA countries, hindering the inferences about trends in the region. For example, in PovcalNet some SSA countries are missing (Equatorial Guinea, Eritrea, Mauritius, Somalia, Zimbabwe), while for thirteen of them there is only one observation in the database for the whole period 1981-2010. In fact, very few countries have reliable surveys in the 1980s, and it is not until the mid-1990s when inequality could be really traced with some confidence in the region.

Regional studies typically report a mixed picture, with both increases and decreases in inequality (e.g. ECA, 2004), a fact that could reflect the heterogeneity in the region, but also could be caused by noise in the country estimations (Christiansen et al., 2002; Okojie and Shimeles, 2006). Bigsten and Shimeles (2003) for instance report that for 17 African countries the trend in inequality shows significant variations over short periods, causing concern about measurement problems.

The available evidence seems to support some few broad facts about consumption inequality in the Sub-Saharan African countries. First, inequality is very high on average, possibly the highest in the world. This result is in stark contrast with the presumption of low inequality in SSA, held for a long time based on the predictions of Kuznets-like models and the absence of reliable data. ${ }^{51}$ Second, on average inequality does not seem to have changed much in the 1990s and 2000s. Data from PovcalNet and other sources suggest a slow downward pattern; but in any case the evidence is mixed and weak. Third, the heterogeneity among countries in terms of inequality levels and patterns is large, partly possibly due to various measurement errors. It is hard to identify a prototype of an inequality pattern in SSA, as in other regions such as LAC or ECA. The scarce literature on inequality in SSA is consistent with these observations. Go, Nikitin, Wang and Zou (2007) report that high income inequality levels in SSA have remained more or less constant over the last four decades. Okojie and Shimeles (2006) underline the fact that SSA is one of the most unequal regions in the world, and that disparities have remained persistent over time. In contrast, Sala-iMartin and Pinkovskiy (2010) picture a more optimistic scenario, reporting a significant downward pattern for inequality during the period of growth (1995 to 2006).

\section{South Africa}

Over the last thirty years there have been important studies of overall inequality and poverty in South Africa, and a heated debate about trends in post-apartheid

\footnotetext{
${ }^{51}$ Several studies have sought to explain the unexpected result of high inequality in Sub-Saharan Africa (Milanovic, 2003; Okojie and Shimeles, 2006; Moradi and Baten, 2005; and van de Walle, 2008).
} 
transition. ${ }^{52}$ South Africa has long been regarded as having one of the most unequal societies in the world. Consistent with this view, the country has the highest Gini coefficient of household consumption per capita (63.1 in 2010). During the early 1970s, the previously constant racial shares of income started to change in favour of the blacks, at the expense of the whites, in a context of declining per capita incomes (McGrath, 1983; McGrath and Whiteford, 1994). But while inter-racial inequality fell throughout the eighties and nineties, inequality within race groups increased (Simkins 1991; Whiteford and Van Seventer 2000). Leibbrandt et al. (2010) provide evidence from comparable households' surveys conducted in 1993, 2000 and 2008. These authors find that since the fall of apartheid inequality continued to increase steadily, both for the whole population and within each racial group. The high level of overall income inequality accentuated between 1993 and 2008, incomes becoming increasingly concentrated in the top decile. The overall Gini coefficient increased by four percentage points, from 66 to 70. The Gini coefficient for the African and Asian/Indian population rose more sharply. Van der Berg and Louw (2004) also conclude that rising black per capita incomes over the past three decades have narrowed the interracial income gap, although increasing inequality within the black and Asian/Indian population seems to have prevented any decline in aggregate inequality.

In explaining these changes, scholars agree in that the labor market played a dominant role, where a rise in the number of blacks employed in skilled jobs (including civil service and other high-pay government positions) coupled with increasing mean wages for this group of workers. Leibbrandt et al. (2010) indicate that in the initial postapartheid period participation rates increased faster than absorption rates with a consequent increase in unemployment across all deciles. Since 2000 the aggregate unemployment rate declined marginally driven by increased absorption of those individuals in the top deciles. In the lower deciles the early post-apartheid trend continued to 2008. Indeed, this lack of successful integration into the labor market is the reason that many of these households find themselves at the bottom of the income distribution. State transfers have increased their importance as an income source but not in a way that has narrowed the distribution of per capita income. They have, however compensated for the decreasing share of remittance income.

Since 1993 poverty has remained virtually constant, or fallen slightly. Leibbrandt et al. (2010) argue that while their impact on poverty incidence remains negligible overall, government social assistance grants (mainly the child support grant, the disability grant and the old-age pension) have been crucial in reducing poverty among the poorest households and the elderly. Two-thirds of income to the bottom quintile now comes from social assistance, even when many eligible individuals do not receive any

\footnotetext{
52 See, for example, McGrath (1983); McGrath and Whiteford (1994); Klasen (1997 and 2005); Nattrass and Seekings (1997); Terreblanche (2002); Dollery (2003); van der Berg and Louw (2004); Leibbrandt et al., (2009); Leibbrandt et al., (2010); and Aron et al., (2009).
} 
grant for instrumental reasons. Despite the increase in educational attainment, younger age cohorts have the highest incidence and shares of poverty and this has not improved notably over time, suggesting that the labor market has not been playing a strongly virtuous role as a driver of poverty alleviation over the post-apartheid period.

Increasing inequality and stable poverty are consistent with the rising trend in top income shares recorded between 2002 and 2010 by Alvaredo and Atkinson (2010), which could be associated to the favorable conditions in the world market for agricultural commodities, the increase in the value of minerals other than gold, and the developments in the financial sector.

\subsection{Inequality convergence}

As suggested above, there are signs of inequality convergence among countries in the developing world. As an example, the mean Gini coefficient for the 20 most unequal countries in our PovcalNet sample in 1981 fell 11\% in the following three decades, while it increased $58 \%$ for the 20 most egalitarian economies.

Bénabou (1996) was the first to present empirical evidence for cross-country convergence in income inequality with data from 1970 to 1990 drawn from the Deininger and Squire dataset. He found evidence consistent with the predictions of a neoclassical growth model that yields convergence of the entire income distribution and not just the first moment. Evidence on inequality convergence was also found in studies that used improved data: Ravallion (2003) based on PovcalNet, Bleaney and Nishiyama (2003) based on WIID, and Dhongde and Miao (2013) using both datasets. With variations, a typical inequality convergence study estimates

$$
G_{i t}-G_{i 1}=\left(\alpha+\beta G_{i 1}\right)(t-1)+e_{i t} \quad \text { for } t=2, \ldots, T ; i=1, \ldots, N \text {, }
$$

where $G_{i t}$ is the Gini coefficient for country $i$ in year $t$ and $e_{i t}$ is an heteroscedastic error term. The parameter $\beta$ measures the link between the change and the initial Gini, and therefore $\beta<0$ indicates inequality convergence. The intercept adds a notion of the time required to attain convergence: a higher value for $\alpha$ is associated to a slower convergence process. Models could be estimated with the Gini coefficient in levels or logs. In his early study Bénabou (1996) found a $\beta$ coefficient of -0.039 for a small sample of around 30 countries. Naturally, estimates of $\beta$ vary according to the data used, the period covered, the time horizons considered, and the regression model applied. Ravallion (2003) estimated a value of -0.028 in the 1990s, Bleany and Nishiyama (2003) a value of -0.0125 between 1965 and 1990, and Dhongde and Miao (2013) a value of -0.022 from 1980 to 2005. This literature has also found that the impact of the initial Gini coefficient on the inequality change diminishes over longer time horizons, and that the speed of inequality convergence is higher than the speed of convergence in per capita income. 
We add to this literature our own estimates, taking advantage of the PovcalNet panel of 76 countries from 1981 to 2010 used in this section. Table 4.2 shows the OLS and IVE estimates of $\alpha$ and $\beta$ for different initial years. ${ }^{53}$ The parameter $\beta$ is negative and significant in all the specifications, suggesting evidence for inequality convergence. The estimated coefficients are in the range of those estimated in the literature.

Table 4.2

Inequality convergence

Models of the change in the Gini coefficient

\begin{tabular}{|c|c|c|c|c|c|c|}
\hline & \multicolumn{3}{|c|}{ Initial year 1981} & \multicolumn{3}{|c|}{ Initial year 1990} \\
\hline & Intercept $(\alpha)$ & Slope $(\beta)$ & $R^{2}$ & Intercept $(\alpha)$ & Slope $(\beta)$ & $R^{2}$ \\
\hline \multicolumn{7}{|l|}{ Gini Index } \\
\hline OLS & 1.098 & -0.026 & 0.49 & 0.908 & -0.023 & 0.35 \\
\hline & $(18.90)^{\star *}$ & $(20.38)^{\star \star}$ & & $(11.20)^{\star \star}$ & $(10.97)^{\star \star}$ & \\
\hline IVE & 1.271 & -0.031 & 0.47 & 0.855 & -0.021 & 0.35 \\
\hline & $(17.91)^{\star \star}$ & $(17.61)^{\star \star}$ & & $(9.83)^{\star \star}$ & $(9.90)^{\star \star}$ & \\
\hline Difference & 0.173 & -0.005 & & -0.053 & 0.002 & \\
\hline Hausman Test & $(4.26)^{\star \star}$ & $(4.03)^{\star \star}$ & & $(1.69)^{\star}$ & $(2.61)^{\star \star}$ & \\
\hline \multicolumn{7}{|l|}{ Log Gini Index } \\
\hline OLS & 0.118 & -0.032 & 0.65 & 0.105 & -0.029 & 0.27 \\
\hline & $(28.41)^{\star \star}$ & $(28.11)^{\star \star}$ & & $(15.53)^{\star \star}$ & $(15.14)^{\star \star}$ & \\
\hline IVE & 0.135 & -0.037 & 0.63 & 0.104 & -0.028 & 0.27 \\
\hline & $(25.79)^{\star *}$ & $(24.75)^{\star \star}$ & & $(14.07)^{\star \star}$ & $(13.66)^{\star \star}$ & \\
\hline Difference & 0.017 & -0.005 & & -0.001 & 0.001 & \\
\hline Hausman Test & $(5.30)^{\star \star}$ & $(5.01)^{\star \star}$ & & $(0.49)$ & $(0.48)$ & \\
\hline
\end{tabular}

Note: robust $\mathrm{t}$ statistics in parentheses; ${ }^{*}$ significant at $5 \%$; ${ }^{* *}$ significant at $1 \%$; the heteroskedasticityconsistent covariance matrix estimator is used (HC1). IVE estimates use the initial value as the instrument for the inequality measure in the second survey. The number of observations is 456 in the first panel, and 281 in the second.

While the evidence for inequality convergence in the last decades seems wellestablished, the reasons driven that pattern are not clear. As mentioned before, Bénabou (1996) finds the evidence on convergence consistent within the framework of a neoclassical growth model. In contrast, the evidence for unconditional inequality convergence is interpreted by Ravallion (2003) as the result of policy and institutional convergence since around 1990, when socialist planned economies became more market-oriented, and non-socialist economies adopted market reforms.

\subsection{Absolute inequality}

While relative inequality has been the preferred concept in empirical work in development economics, absolute views of inequality certainly have some intuitive appeal (Amiel and Cowell, 1999; Atkinson and Brandolini, 2004). Interestingly, the trends in the two concepts over the last decades have been different in the developing world. ${ }^{54}$ The fact that most countries experienced economic growth, while at the same time relative inequality did not fall, implied widening absolute income differences. On

\footnotetext{
${ }^{53}$ Caselli et al. (1996) and Dhongde and Miao (2013) discuss biases that may arise in an OLS model.

${ }^{54} \mathrm{See}$, as an example, the analysis of Atkinson and Lugo (2010) for Tanzania.
} 
average, the absolute difference in monthly consumption per capita between the top and bottom $10 \%$ of each country increased over the two decades from US\$415 (PPP adjusted) in 1990, to US\$497 in 2002, and US\$646 in 2010. In more than $90 \%$ of the countries in the sample that absolute difference was higher in 2010 than in 1990.

The contrast between the recent trends in absolute and relative inequality in the developing countries is illustrated in Figure 4.7. While relative inequality rose in the late 1980 s and early 1990s, absolute inequality declined, driven by a reduction in mean income. The strong growth in the developing world since mid-1990s is reflected in the substantial hike in the degree of absolute inequality. Although some equalizing forces operated in the 2000s that reduced the relative gaps, they were not enough to narrow the absolute gaps in a context of economic growth. Based on these facts, Ravallion (2004) argues that the disagreements over whether inequality in the world has gone up or down may partly be due to differing views about the importance of absolute versus relative conceptions of inequality.

\section{Figure 4.7}

\section{Absolute and relative Gini coefficients \\ Unweighted means, developing countries, 1981-2010}

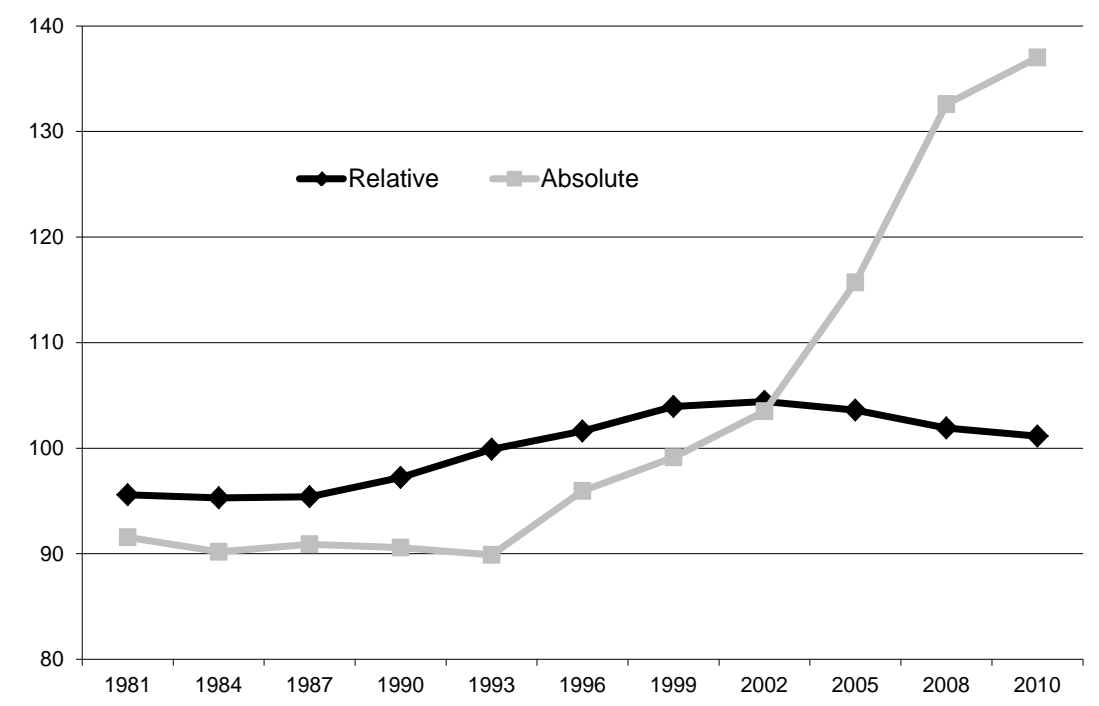

Source: own estimates based on PovcalNet (2013).

Note: normalized to $100=$ mean over the period 1981-2010.The Gini coefficients are computed over the distribution of household consumption per capita.

\subsection{Aggregate welfare}

The typical way of assessing the economic performance of a country is by means of its per capita income or output. However, this practice is valid only when the evaluator's welfare function is utilitarian. Except in this extreme case, measuring aggregate welfare involves not only knowing the mean but also other elements of the income distribution, in particular the degree of inequality. Although social welfare functions are naturally arbitrary, since they depend on the analyst's value judgments, it is 
common in the literature to work with anonymous, Paretian, symmetric and quasiconcave functions. For simplicity, here we consider the abbreviated welfare function proposed by Sen (1976), $W_{s}=\mu .(1-G)$, where $\mu$ is the mean of the distribution and $G$ is the Gini coefficient. Figure 4.8 shows the unweighted mean of $W_{s}$ for the developing countries in the period 1990-2010 computed from household survey data. In general, aggregate welfare has followed changes in per capita consumption. The fall in mean consumption in the early 1990s (mostly due to the negative performance in ECA) was reinforced by the increase in inequality, driving welfare down by around 15\%. Between 1993 and 2002 mean consumption went up but the change was counterbalanced by a similar increase in the Gini, keeping welfare roughly constant. The 2000s witnessed a robust increase in mean consumption, along with some fall in inequality, implying a 40\% increase in aggregate welfare between 2002 and 2010. According to these calculations the mean aggregate welfare in the developing countries was 22\% higher in 2010 than in 1990, implying an annual growth rate of around $1 \%$.

Figure 4.8

Aggregate welfare

Sen welfare function, unweighted mean, developing countries, 1990-2010

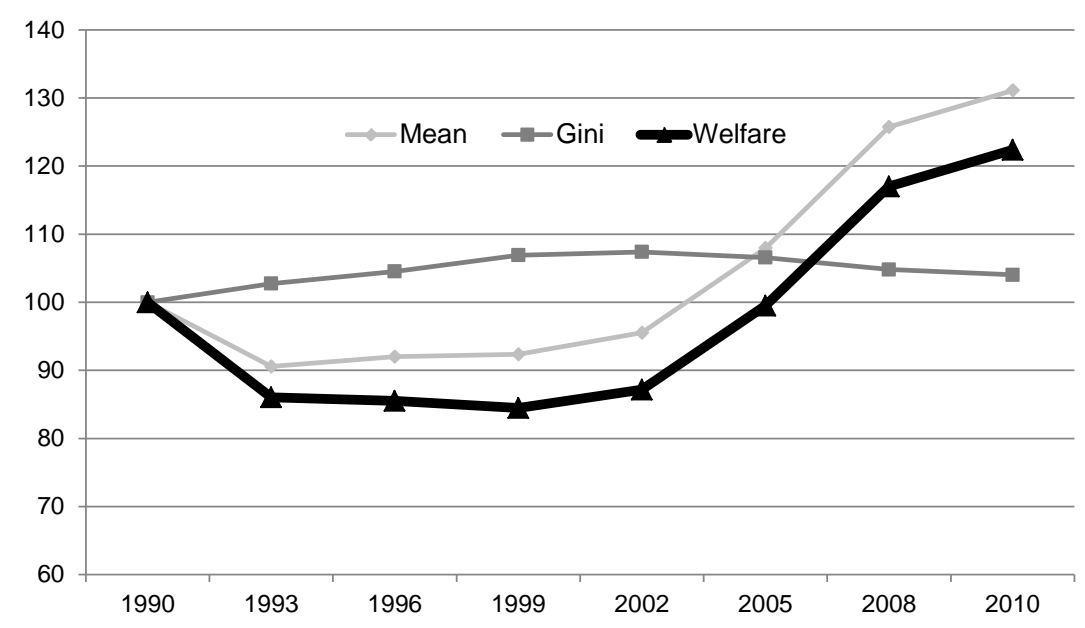

Source: own estimates based on PovcalNet (2013).

Note: normalized to 100=value in 1990 .

In order to calculate welfare it is necessary to have estimates of the mean income and some inequality measure. Ideally, both parameters should be estimated from the same source, typically a household survey, as we have done so far. Some authors have taken a different approach, anchoring the mean to a variable from National Accounts, such as per capita GDP or aggregate household consumption expenditures. For several reasons changes in mean income from household surveys tend to differ significantly from changes in per capita GDP (Deaton, 2003, 2005; Anand and Segal, 2008). Some of these differences are natural since per capita income and GDP are different concepts, but some are rooted in measurement errors both in household surveys and in National Accounts. Some authors pay the price of the potential inconsistency of using two 
different data sources (i) in order to avoid departing from the typical growth and development literature that is based on National Accounts data, (ii) as a way to alleviate the underreporting issue in household surveys, and (iii) to avoid problems related to the unavailability of surveys for many years in several countries (Ahluwalia et al., 1979; Bourguignon and Morrison, 2002; Sala-i-Martin, 2006; Bhalla, 2002).

In Figure 4.9 we report the results of computing the unweighted average of aggregate welfare across developing countries using alternative mean income variables. According to these estimates mean welfare in the developing world grew at an annual 1\% from 1990 to 2010 using mean consumption per capita from household surveys, 1.6\% using per capita GNI from WDI, and 2.1\% using per capita GDP from Penn World Tables (PWT) (Heston et al., 2012). ${ }^{55}$ These discrepancies are worrying and call for increasing efforts to understand and reduce the gaps among data sources.

\section{Figure 4.9}

\section{Aggregate welfare for alternative mean variables}

\section{Sen welfare function, unweighted mean, developing countries, 1990-2010}

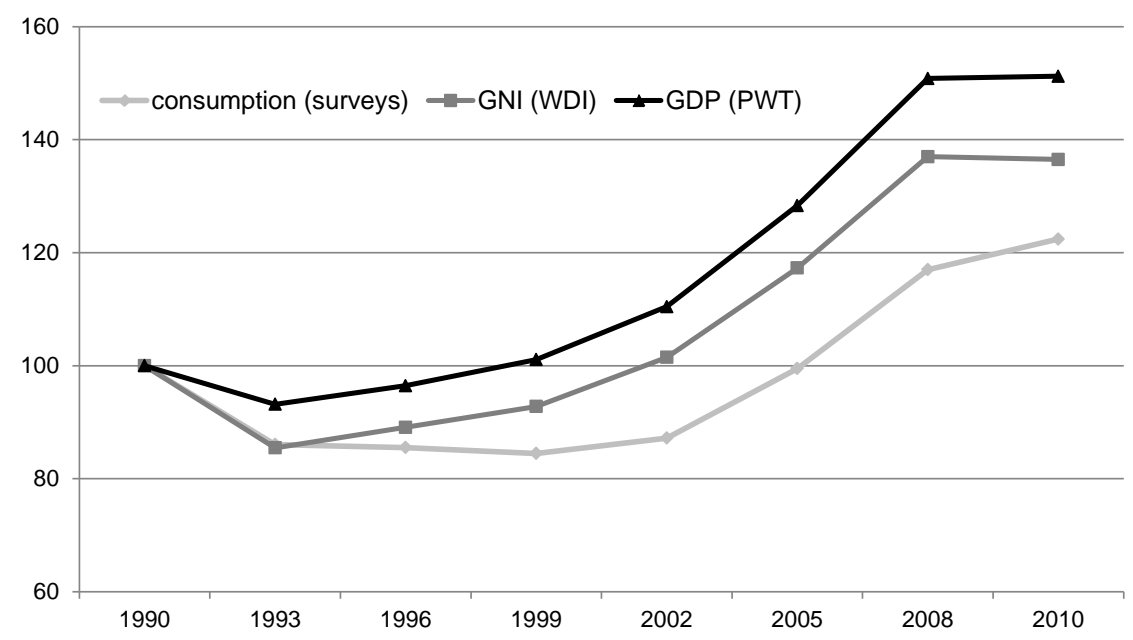

Source: own estimates based on PovcalNet (2013), WDI and PWT.

Note: mean anchored to per capita consumption (PovcalNet), GNI per capita (WDI) and GDP per capita (PWT). Normalized to 100=value in 1990.

The population-weighted mean of the welfare measure grew at a much higher rate, due to the positive performance of several large countries. ${ }^{56}$ The growth rate between 1990 and 2010 was $2.3 \%$ using household survey data, $3 \%$ anchoring mean income to per capita GNI from WDI, and 3.3\% when using the Penn World Tables.

\footnotetext{
55 In fact, this difference comes from the combination of higher growth recorded in the National Accounts in the 1990s compared to household surveys, and the opposite result in the 2000s. For instance, while per capita GDP slightly fell between 2008 and 2010, mean consumption in household surveys increased at annual $2 \%$.

${ }^{56}$ Some authors have computed global welfare, ignoring the division of the world in countries. The evidence suggest an increase in aggregate welfare in the developing world in the last decades (Pinkovskiy and Sala-i-Martin, 2009; Atkinson and Brandolini, 2010; Pinkovskiy, 2013).
} 


\subsection{Trends from tax records}

At the moment of writing (2013), the WTID offers estimates of the tax-based shares of top incomes for a small number of developing countries: Argentina, Colombia, India, Mauritius and South Africa. ${ }^{57}$ Malaysia is available from Atkinson (forthcoming), and will be included in the WTID as soon as the proper documentation is finished. Preliminary results for Ecuador are available from Alvaredo and Cano (forthcoming). ${ }^{58}$ Ongoing research analyzes the cases of Brazil, Chile, Ecuador and Uruguay. Consequently, evidence in this respect is still fragmentary, not only because this particular research program is rather recent in what concerns the developing world, but also because of the unavailability of tax data.

The results for the top $1 \%$ income share are presented in Figure 4.10, together with survey-based Gini coefficients. Several elements are worth mentioning. First, both sources are not directly comparable for the reasons discussed in section 3 . The top share estimates are in general before taxes, while survey Ginis are net of taxes; in addition the units of analysis usually do not match. Second, there is substantial heterogeneity in this group, both in levels and dynamics, compared to the evidence discussed in chapter 16 for developed countries. It should be borne in mind that the differences in the tax systems across countries imply different income concepts, so that top share levels should be read with this caveat in mind. Third, Leigh (2007), who analyzes 13 developed countries, and find that there is a strong and significant relationship between top income shares and broader inequality measures, concludes that "panel data on top income shares may be a useful substitute for other measures of inequality over periods when alternative income distribution measures are of low quality, or unavailable". Figure 4.10 seems to agree with the results in Leigh (2007) in some cases but not in others. For example, the evolutions of the Gini and the top 1\% share in Colombia are particularly diverging, while the dynamics in Mauritius is remarkably similar.

Top shares and broader, synthetic inequality measures can very well display different trends. The problem arises when the top group plays a major role in the changes in inequality and survey data fail to capture high incomes.

\footnotetext{
${ }^{57}$ The results for China (1986-2003) and Indonesia (1982-2004) in the WTID are based on household surveys and not on tax records. The fact that top income share estimates are lower than in the most egalitarian developed countries shows that they are likely to be underestimated. In the case of China, the rising trend is robust and can be taken as an indicator of the true dynamics of concentration at the top. Piketty and Qian (2009) show that top income shares increased at a very high rate during the period, which is consistent with the evidence discussed in section 4. The top decile share rose from about 17 per cent in 1986 to almost 28 per cent in 2003-that is, by more than 60 per cent. The top 1 per cent income share more than doubled between 1986 and 2001, from slightly more than 2.6 per cent in 1986 to 5.9 per cent in 2003.

${ }^{58}$ We do not review the results for former colonial territories being prepared as part of an on-going project carried out by Atkinson (British colonies), and Alvaredo, Cogneau and Piketty (French colonies). This project has assembled data for some forty colonies covering the periods before and after independence. Unfortunately, the series stop before 1970 in most cases due to unavailability of recent data.
} 
Figure 4.10

Top 1\% income share and Gini coefficients

Argentina, Colombia, Malaysia, Mauritius, India and South Africa
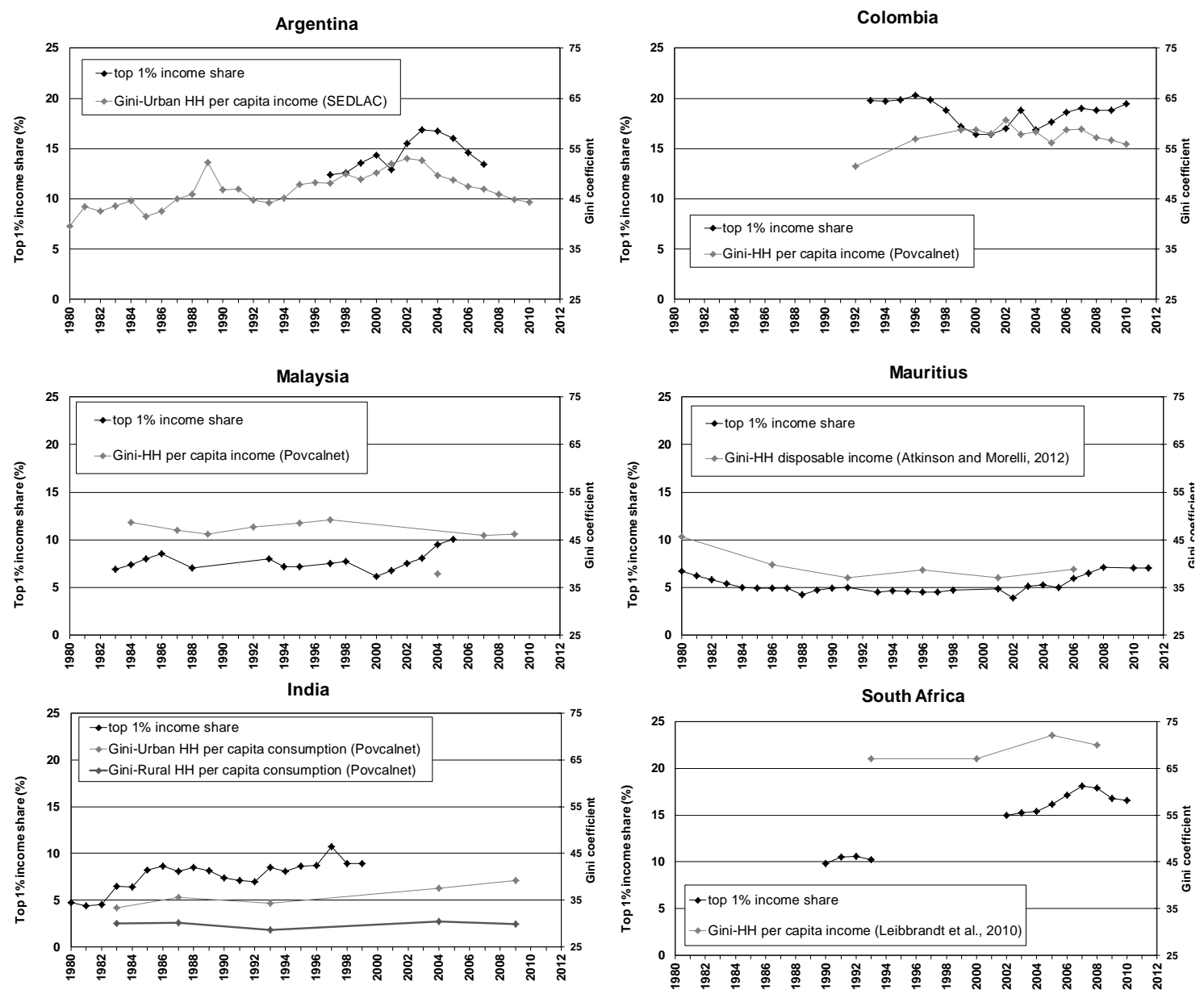

Source: own estimates based on WTID.

Note: Gini coefficient for Malaysia 2004 identified as outlier.

\subsection{Exploring inequality changes}

Explaining changes in the income distribution is a very difficult and challenging task that lies well beyond the objectives of this chapter. In this section we briefly review some methodologies to study the determinants of the income distribution changes and lay out some of the main results regarding developing countries. ${ }^{59}$ Certainly, there has been sustained progress in our understanding of the factors that shape the income distributions, but yet the image that emerges from reviewing the literature is still that of a patchwork of numerous hypotheses without conclusive empirical support.

\footnotetext{
59 Bourguignon et al. (2008) and Ferreira (2010) are excellent references for methodological issues in recent research on inequality determinants.
} 
Decompositions are one of the most widely used techniques to characterize income distribution changes. Typically, an income model is estimated, and a counterfactual distribution is simulated modifying some elements of the estimated income model (e.g. parameters or the distribution of observable factors), while keeping the rest fixed. The difference between the actual and the simulated distribution captures the firstround partial-equilibrium effect of the change under study. ${ }^{60}$ The method generates entire counterfactual distributions, and hence can capture the heterogeneity of impacts throughout the distribution. The decompositions have been typically used to shed light on the impact of changes in the returns to education, in the demographic, sectorial, occupational and educational composition of the population, and in labor and social policies. The decompositions do not allow for the identification of causal effects, and suffer from the usual problems of equilibrium-inconsistency and path dependence. Nevertheless, these types of exercises are informative about the relative strength of several direct determinants that may be driving the distributive changes, and therefore could be useful in identifying areas in which to focus the research efforts.

Ideally, income distribution changes should be studied in a general equilibrium framework, since they are the result of complex processes that involve all sorts of effects and interactions throughout the economy. Computable general equilibrium (CGE) models have been applied to study changes in the income distributions around the developing world. These exercises, however, depend critically on parameters and functions that are difficult to estimate, and rely on many simplifying assumptions. The more recent macro-micro approach combines a CGE model (the macro component) with a microsimulation (the micro component). CGE models provide a framework to assess consistency of policy alternatives, but lack the necessary disaggregation for the analysis of distributional issues, which is provided by the microsimulations. The macro and micro components of this methodology communicate through aggregate variables such as employment levels and wage rates that are generated by the CGE model and used as inputs in the microsimulations (Bourguignon et al., 2008; Bourguignon and Bussolo, 2012). In a related approach, rather than building a full general equilibrium model of the economy, researchers rely on a reduced-form relationship between a set of observed exogenous variables (such as changes in tariff rates) and a set of sectorlevel variables (such as industry-skill wage premia), that serve as inputs in the microsimulations. ${ }^{61}$

A very different strand of the literature involves the estimation of cross-country regressions, typically with panel data, where an aggregate measure of overall inequality, such as the Gini coefficient, is linked to various potential causal factors (e.g.

\footnotetext{
${ }^{60}$ See Bourguignon et al. (2005); Barros et al. (2006) and Bourguignon et al. (2008), for methodological proposals; Bourguignon et al. (2005) for applications to Asia and Latin America, and Inchauste et al. (2012) for a recent application to poverty reduction in Bangladesh, Peru and Thailand. Fortin et al. (2011) and Essama Nssah (2012) are useful surveys of the economic literature on decompositions.

${ }^{61}$ Ferreira et al. (2010) use this approach to estimate the effect of a trade liberalization episode on the distributions of wages and household incomes in Brazil.
} 
Li et al., 1998; Anderson, 2005). Naturally, endogeneity problems are endemic to this approach, which is useful to characterize the structure of correlations among variables, but less successful in identifying causal links.

Most of the literature takes a less ambitious but probably more productive road, and focus on the partial-equilibrium impact of specific shocks and policy changes, using different identification strategies depending on the characteristics of the shock/policy and the data available. Examples of these methodologies include (i) a typical supply and demand approach, where the impact of indicators of trade, technology or other factors on the relative wage between skilled and unskilled workers is estimated, controlling for relative supply; (ii) the cost function approach, where the impact of several indicators on the share of skilled wages in total wage bill is estimated, using flexible cost functions (usually a translog cost production function); and (iii) mandated wage regressions. ${ }^{62}$ When experiments with random assignment are available, causal links are more clearly identified. For instance, the conditional cash transfer program Progresa in Mexico was initially implemented with a random assignment of treated and control rural villages, which allowed a rigorous impact evaluation. Taking advantage of that design, Todd and Wolpin (2006) estimate a full structural model of behavior, including education, fertility and labor supply decisions, a model that can be used to simulate the distributive impact of policies and shocks. ${ }^{63}$

The bulk of the distributive analysis in developing countries has focused mainly on the labor market and on public and private transfers, while largely setting aside the role played by other sources of income, such as capital, land rents and business profits. The neglect of these other factors is essentially due to the fact that household surveys fail to capture these income sources properly. ${ }^{64}$ This shortcoming has, for instance, severely limited the study of the impact of the natural resources exploitation on inequality, a relevant topic in several developing countries. ${ }^{65}$ Most studies narrow the analysis to particular indicators of the labor market, such as the wage gap between skilled and unskilled labor (the wage premium) or the returns to education. For instance, Bourguignon et al. (2005) show that increases in returns to schooling were large contributors to increasing inequality in East Asia and Latin America in the 1990s.

In what follows we review some general debates on the determinants of recent inequality changes.

Growth and development. As shown in Section 3.5 there is a significant negative relationship between inequality and measures of development, such as GNI per capita, in a cross-section of countries. From this evidence Ferreira and Ravallion (2009)

\footnotetext{
${ }^{62}$ See Anderson (2005).

63 See also Parker and Skoufias (2001) and Gertler (2004) for impact evaluations studies of the Mexican conditional cash transfer program.

${ }^{64}$ For instance, according to SEDLAC data, on average in Latin America in 2010 the share of labor income in total household income was $82.3 \%$, the share of transfers (including pensions) $13.9 \%$, and the rest of the sources just $3.8 \%$.

${ }^{65}$ See Caselli and Michaels (2013).
} 
conclude that "high inequality is a feature of underdevelopment". However, the short or medium run relationship between inequality and development has proved to be elusive. There appears to be no evidence in the last decades of a significant correlation between the growth rate of an economy and the change in the inequality level (Ravallion and Chen, 1997; Ravallion, 2001; Dollar and Kraay, 2002; Ferreira and Ravallion, 2009). ${ }^{66}$ Ravallion (2007), for example, analyzed 290 episodes in 80 countries in 1980-2000 and found a correlation coefficient non-significant at the $10 \%$ level between the changes in the log of the Gini coefficient and changes in the log of mean income in real terms between successive household surveys. The analysis of more recent data from PovcalNet leads to the same conclusion. Using 473 spells in the period 1981-2010 we find a non-significant coefficient of -0.0094. A similar result applies when restricting the sample to observations after 1990 or 2000 , or when considering longer spells. ${ }^{67}$ The data suggests that among both growing and contracting economies, inequality increased about as often as it fell. In the last decades economic growth has been distribution-neutral on average in the developing countries. $^{68}$

Globalization. Much of the recent public and academic debate on inequality changes has been related to the rise in globalization. In the latest decades most developing countries have experienced increasing openness to international trade, capital markets flows and foreign direct investment. The theoretical channels linking these changes to inequality are multiple and complex, which accounts for the lack of conclusive empirical results (Wood, 1997; Rama, 2003; Winters et al., 2004; Anderson, 2005; Goldberg and Pavcnik, 2007; Harrison et al., 2011). While studies in cross sections of developing countries are inconclusive in relation to the impact of globalization upon inequality, several longitudinal estimates concerning countries taken separately or in small groups reveal a positive correlation between openness and the relative demand for skilled labor (Anderson, 2005; Goldberg and Pavnick, 2007; Harrison et al., 2011; Chusseau and Hellier, 2012). Trade openness may affect the income distribution through various channels. The traditional Stolper-Samuelson effect predicts a reduction in the skill premium in unskilled-labor-abundant developing countries, a prediction that does not appear to be confirmed by the facts (Goldberg and Pavnick, 2007; Feenstra, 2008). While some of the research has pointed then to non-trade factors - such as skill-biased technological change and labor institutions - to explain rising wage gaps, in recent years new mechanisms have been explored through which trade can increase income inequality. These mechanisms include heterogeneous firms

\footnotetext{
${ }^{66}$ A related literature finds no support for a Kuznets curve with longitudinal data (Bruno, 1998; Fields, 2002; Hellier and Lambrecht, 2012).

${ }^{67}$ The relationship becomes negative, although just slightly significant, when using the change in log real per capita GDP (Penn World Tables) or per capita GNI (WDI) as measures of growth.

${ }^{68}$ Ravallion (2004) argues that, on average, growth is not associated with increases in relative inequality but absolute inequality, and it is these higher absolute gaps between "rich" and "poor" that generate the perception of an unequal growth processes.
} 
and bargaining, trade in tasks, labor frictions and incomplete contracts (Harrison et al., 2011). In addition, competition among developing countries may increase inequality in middle-income countries (e.g. Latin America) competing with low-income economies. ${ }^{69}$ Also, the growing size of the developing world, as new countries enter the world markets, may foster inequality by augmenting the world endowment of unskilled labor. The literature finds that the mechanisms through which globalization affects income distribution are country, time, and case specific, and therefore the impacts of trade liberalization need to be examined in conjunction with other concurrent policy reforms (Goldberg and Pavnick, 2007). In addition, and due to various limitations, the literature is mostly focused on the static link between globalization and income distribution that typically operates through changes in relative prices and wages, rather than on the dynamic, more indirect link from trade to growth, and then to poverty and inequality.

Technology and education. Skill-biased technological change has been a popular explanation for the rise in inequality in the developed countries. Changes in technology, such as the use of computers, increase the relative demand for skilled workers driving the skill premium up. This hypothesis is also plausible in the developing world, where globalization increased the transfers of more skill-intensive technologies from the North, and fostered imports of capital goods, typically complementary of skilled labor. Several studies find that openness-driven technological transfers tend to increase inequality in emerging countries (Conte and Vivarelli, 2007). The increase in the wage skill premium may be temporary, as the introduction of new technologies requires a transitional period during which skilled workers are employed to adapt the firm to the new technology (Pissarides, 1997; Helpman and Trajtenberg, 1998). The empirical applications usually show evidence on the short and medium-run effects of the reforms, failing to capture the long-run impact. The generalized fall in inequality in the 2000s in the developing world might be in part attributed to the petering out of the unequalizing initial impact of the liberalizing reforms and technological shocks experienced by many countries in the 1990s.

The increase in education may counteract the effect of skill-biased technological change in the Tinbergen's race between education and technology. ${ }^{70}$ In fact, education has expanded in the developing world at high rates during the last decades, mitigating the impact of other factors that tend to increase the wage premium. ${ }^{71}$ However, the link between education and income inequality may not be that straightforward. Given

\footnotetext{
${ }^{69}$ The increase in inequality in Latin America has also been explained arguing that it is a region relatively abundant in natural resources, while in the onset of liberalization Asian countries were relatively abundant in unskilled labor (Wood, 1997).

${ }^{70}$ According to Tinbergen (1975) changes in earnings inequality are the outcome of a "race" between technological progress raising the demand for skills, and the expansion of education raising the supply of skills.

${ }^{71}$ See Gasparini et al. (2011) for Latin America.
} 
the convexities in the returns to education, even an equalizing increase in schooling may generate an unequalizing change in the distribution of earnings. Bourguignon, Ferreira and Lustig (2005) have labeled this phenomenon "the paradox of progress", a situation where an educational expansion is associated to higher inequality. ${ }^{72}$

Market reforms. Several developing countries have implemented market-oriented reforms in the last decades, reducing regulations and privatizing firms. The paradigmatic case includes the former socialist planned economies in ECA, but the transition from centrally planned to market-oriented economies was also experienced by several African and Asian countries, including China. The evidence suggests a significant increase in inequality over the transition period. That surge has been linked to the process of privatizations, that implied an increase in the earnings dispersion in comparison to the more compressed wage structure of the state-own firms, and the institutional and regulatory reforms that have increased competition in product and factor markets and decreased the bargaining power of labor. ${ }^{73}$ Other non-socialist economies also adopted market-friendly reforms; Ravallion (2003) argues that in some cases (e.g. Brazil) pre-reform controls benefited the rich and kept inequality high, and then reforms help lowering inequality, while in some others (e.g. India) the controls (and the reforms) had the opposite effect.

Fiscal and social policy. Developing countries are characterized by relatively low levels of taxation, heavy reliance on regressive revenue instruments, and low coverage and benefit levels of transfer programs (World Bank, 2006). This structure limits the redistributive potential of fiscal policy and in some cases even exacerbates the market income disparities. ${ }^{74}$ While average tax ratios for advanced economies exceed 30 per cent of GDP, ratios in developing economies (excluding emerging Europe) generally fall in the range of 15-20 per cent of GDP (Baltagi et al., 2012). Tax collection is not only lower but also more regressive than in developed countries. The difficulties in collecting more progressive taxes are related to the high levels of self-employment and sizeable informal sectors, which limit the capacity of the tax authorities to verified taxpayers' income and assets. On the spending side, in most developing economies social spending is relatively low, and participation in social insurance schemes is restricted to high-income workers in the formal sector and to public sector employees. ${ }^{75}$ All these factors combine for a low redistributive impact of the fiscal

\footnotetext{
72 Inequality may also increase after an education expansion, given that wage dispersion is larger at higher educational levels (Alejo, 2012).

${ }^{73}$ See Cornia (1996), Milanovic (1998), Ferreira (1999), Cornia and Reddy (2001), and Milanovic and Ersado (2010).

${ }^{74}$ For instance, Lustig (2012) finds that in Latin America when indirect taxes are taken into account, the net income of the poor and the near poor can be lower than it was before taxes and cash transfers.

${ }^{75}$ ILO (2010) reports that in the early 2000s the share of the population above the legal retirement age receiving a pension in developing economies was, on average, around 40 per cent, as compared to 90 per cent in European economies.
} 
policy. For instance, Goñi et al. (2008) and Lustig (2012) find that the tax and transfer system in Latin America decreased the market Gini by only 2 percentage points, a meager impact compared to the 20-points impact estimated in 15 European economies.

Since the mid-1990s there have been some encouraging signs of improvement, especially in terms of increasing coverage and better targeting of social policies. The recent expansion of conditional cash transfer programs (CCTs) implies a promising approach for enhancing the distributive impact of public spending in developing economies. CCTs typically transfer income to poor households, conditional on households making certain investments on their children's human capital - education, health and nutrition. Such programs have been adopted in many developing economies, including some Sub-Saharan African countries, although on a smaller scale (Fiszbein and Shady, 2009; Garcia and Moore, 2012). CCTs became particularly popular in LAC: by 2010 there were 18 countries in Latin America and the Caribbean applying CCTs, covering $20 \%$ of total LAC population, and spending on average $0.40 \%$ of GDP (Cruces and Gasparini, 2012). Soares et al. (2009) estimate that the CCTs in Brazil and Mexico reduced the Gini for disposable income by 2.7 percentage points, accounting for about a fifth of the decrease in that index between the mid-1990s and the mid2000s.

Macroeconomic crises. The scale of the recent crisis has placed the distributional impact of macroeconomic shocks back on the agenda. Banking crises, crashes in stock and real estate markets and GDP collapses are events with potential large effects on the income distribution. Atkinson and Morelli (2011) were the first in addressing this issue from an empirical, historical and global perspective. They investigated the effect of crisis on inequality as well as the impact of inequality on the probability of economic crises, by analyzing the history of banking, consumption and GDP collapses over a 100year period in 25 countries, out of which only 6 are developing economies. These authors observed the variation in distributional variables taking a 5-year window before and after the crisis date, and classified each one according to whether inequality was increasing, constant or decreasing before and afterwards. ${ }^{76}$ Table 4.3, panel $A$, reproduces their results specifically regarding GDP collapses. ${ }^{77}$ They identified 103 crises, but for only one third there is information on inequality changes. The shadowed diagonal shows combinations where the trajectory was unchanged; above the diagonal are cases where the trajectory "bent" downward; below the diagonal are cases where the trajectory "bent" upward. As it is readily apparent, one cannot draw firm conclusions: (i) the raw totals show that most crisis did not involve changes in

\footnotetext{
76 In the case of the Gini coefficient, a change is considered significant when it is higher than 0.7 percentage points (that is, $1 / 3$ of 2 Gini points).

${ }^{77}$ A collapse is identified as a cumulative percentage drop in per capita GDP (from peak to trough) of at least $9.5 \%$ for 1911 to 1950 and of 5\% for the post-1950 period. Their results are somewhat different when they look at banking crisis and consumption collapses, but not more conclusive.
} 
inequality ex-post; (ii) the number of cases above the diagonal is low and not very different from the cases below the diagonal, which means that GDP crisis are not necessarily associated with a specific direction in the change of inequality; (iii) the inverted $V$ shape (inequality increasing and then decreasing) is not prevalent. Atkinson and Morelli (2011) conclude that "economic crises differ a great deal in whether or not they were preceded by rising inequality, and, in any case, where there was such a rise, causality is not easy to establish." When banking crisis are analyzed instead of GDP drops, the cases in which inequality tend to increase following a crisis are in majority.

We replicated their methodology for the years 1980-2010 to take into account the set of developing countries, and the results are shown in panel B of Table 4.3. ${ }^{78}$ Even if our list is not exhaustive and could be considerably improved, we identified at least 67 crises episodes. As in general they occurred during the 1980 s or early 1990s, it is not surprising that in most cases inequality changes before the crises remain unknown due to data unavailability. There is a tendency for inequality to rise after a GDP collapse (10 cases), but again the numbers are too small to draw conclusions, and this could just be the continuation of a previous tendency. This is not necessarily in contradiction with Atkinson and Morelli (2011) due to at least two reasons: (i) GDP crisis may well be more correlated with financial crisis in the developing world, and (ii) such conclusion is highly influenced by the experience of the transition economies after the fall of the Berlin Wall. It should also be noted that several of the canonical Latin American exchange rate crisis of the 1980s and 1990s, with the exception of Argentina and Brazil (included in Atkinson and Morelli, 2011) do not fall within our classification of a collapse. In this sense, there is much work to be done about the magnitude of a crisis and its sensitivity on the two-way relationship with inequality. In any case, the pattern in Latin America points to an increase in inequality before the crashes (regressive inflation tax, rise in unemployment due to openness to trade and loss of competitiveness from exchange rate mismanagement), then followed by short-term reductions after stabilization programs. ${ }^{79}$

\footnotetext{
${ }^{78}$ Given the higher volatility of per capita GDP in developing countries, we have kept the threshold of 9.5\% drop to identify crisis for 1980-2010. The data come from the World Bank Development Indicators. Changes in Gini coefficient are taken from PovcalNet.

${ }^{79}$ The case studies are numerous; see for example Forbes (2011) and Lustig (1990).
} 
Table 4.3

Inequality and GDP collapses

Panel A (Atkinson and Morelli, 2011)

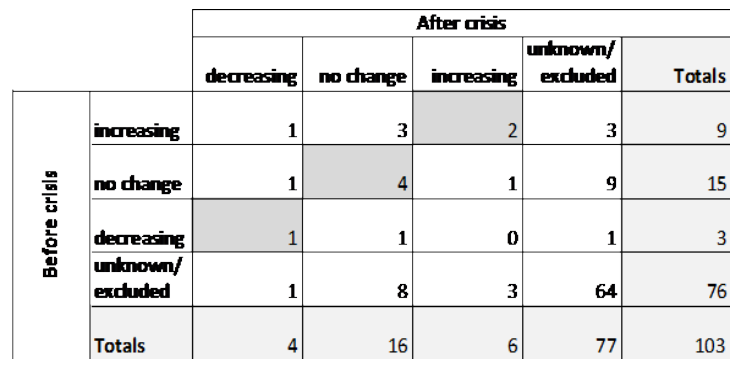

Panel B (developing countries 1980-2010)

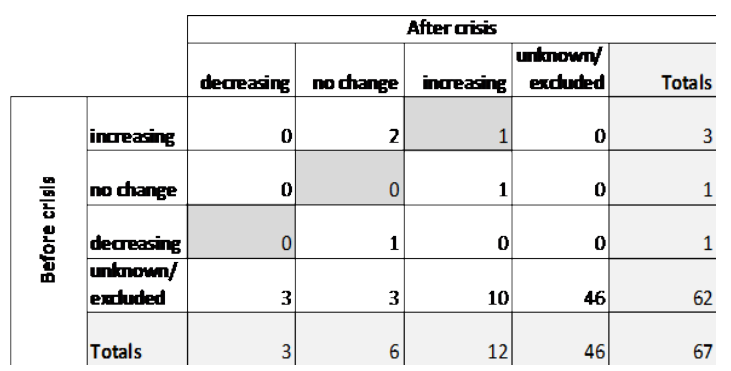

Source: own calculations based on PovcalNet (2013) and WDI.

Others. Of course this brief review does not exhaust the multiple factors behind distributive changes in the developing world; in fact, arguably any shock or policy could affect the income distribution. For instance, demographic factors, such as the decline in fertility, the rise in life expectancy and the growing importance of assortative mating and single-parent households have been identified as relevant sources of inequality changes. Labor policies are a key target for research, as well. Several studies find that the weakening of labor institutions such as unions and the declining real value of minimum wages were responsible for the increase in earnings inequality in several developing countries, especially in the 1990s, while more ambitious labor policies contributed to the reduction in inequality in the 2000s. Migration and sector changes are also determinants of inequality changes, studied at least since the seminal contributions by Lewis (1954) and Kuznets (1955). Changes in inequality are associated to the geographic and sectorial pattern of growth (Loayza and Raddatz, 2010). Ferreira and Ravallion (2009), for instance, report that in Indonesia a large share of the increase in inequality was associated with migration from wage employment in agriculture to urban self-employment. Milanovic (2012) argues about the key role of migration in global inequality.

\section{Poverty: levels}

The vast literature on poverty measurement suggests that there are neither normative nor objective arguments to set an unambiguous threshold below which everybody is poor and above which everyone is non-poor (Deaton, 1997). Despite this central conceptual ambiguity, reducing poverty is a deliberate policy objective for governments around the world. The international community has embraced this goal as reflected in the first Millennium Development Goal of halving poverty by 2015. In this section we focus on measures of poverty in the income/consumption space using international poverty lines in terms of US dollars adjusted for purchasing power parity (PPP). This choice implies taking a one-dimensional, monetary, static, absolute view of poverty, that certainly has many limitations and drawbacks, but it is still the best available paradigm to summarize deprivations in the world. 
The \$1-a-day per person at PPP is a poverty standard meant to define an international norm to gauge at the inability to pay for food needs. ${ }^{80}$ The $\$ 1$ line, proposed in Ravallion et al. (1991) and used in World Bank (1990), was chosen as being representative of the national poverty lines found among low-income countries. The line was recalculated in 1993 PPP terms at \$1.0763 a day (Chen and Ravallion, 2001), and more recently in 2005 PPP at \$1.25 a day (Ravallion et al., 2009). The PPP adjustment is based on the 2005 round of the International Comparison Program (World Bank, 2008). ${ }^{81}$ The $\$ 1.25$ line is usually deemed too low for middle-income countries; for that reason it is typical to compute poverty with the \$2-a-day standard, which is close to the median of the official poverty lines chosen by the developing countries. Although these international lines have been criticized, their simplicity and the lack of reasonable and easy-to-implement alternatives have made them the standard for international poverty comparisons. ${ }^{82}$ While the measurement of poverty with national lines takes into consideration that societies differ in the criteria used to identify the poor, the international lines are unavoidable instruments to compare absolute poverty levels and trends across countries, and provide regional and world poverty counts.

The World Bank is the main institution that regularly produces information on poverty measurement in the developing world drawn from original microdata from household surveys. ${ }^{83}$ In 2013, the World Bank released an update of the developing world's poverty estimates for 1981-2010. The new poverty estimates combine the PPP exchange rates for household consumption from the 2005 International Comparison Program with data from more than 850 household surveys across 127 developing countries. In this section we rely heavily on that dataset (PovcalNet).

The problem of the choice of the welfare variable discussed for inequality in section 3 applies to the measurement of poverty, as well. While poverty estimates in PovcalNet refer to consumption deprivation, in most countries in Latin America and a few others in the rest of the world they are constructed from income data. After computing consumption and income poverty in 22 household surveys of 7 Latin American countries using the $\$ 2$ standard, we find that on average the ratio consumption/income poverty is 0.97 with only small differences across countries. Given this piece of evidence we decided not to perform an adjustment for income poverty figures in the analysis that follows.

\footnotetext{
${ }^{80}$ For simplicity, the sign $\$$ is used to refer to US dollars.

${ }^{81}$ See the discussions on the PPP adjustments in Deaton and Dupriez (2008), Deaton and Heston (2010) and Ravallion (2010).

${ }^{82}$ For the debate on the international measurement of poverty, see Reddy and Pogge (2010), Deaton (2010) and chapter 12 by Anand and Segal in this volume. Gentilini and Sumner (2012) compute global poverty using the national poverty lines officially set in each country instead of using international poverty standards.

${ }^{83}$ Ahulwalia et al. (1979) was an early attempt to measure poverty in the developing countries.
} 


\subsection{Income poverty in the developing world}

Although poverty is a ubiquitous characteristic of the developing economies, its severity widely varies across countries. Figure 5.1 shows the poverty headcount ratio in most of the developing countries in the world, using the \$2-a-day poverty line. The figure reveals the enormous differences among developing nations in terms of monetary deprivation. While there are economies where the proportion of the population living with less than 2 dollars a day is below $2 \%$, in several countries that proportion exceeds $80 \%$. The problem of absolute income poverty has a radically different scale in some countries compared to others, even in the developing world.

\section{Figure 5.1}

\section{Poverty headcount ratio}

Developing countries, 2010

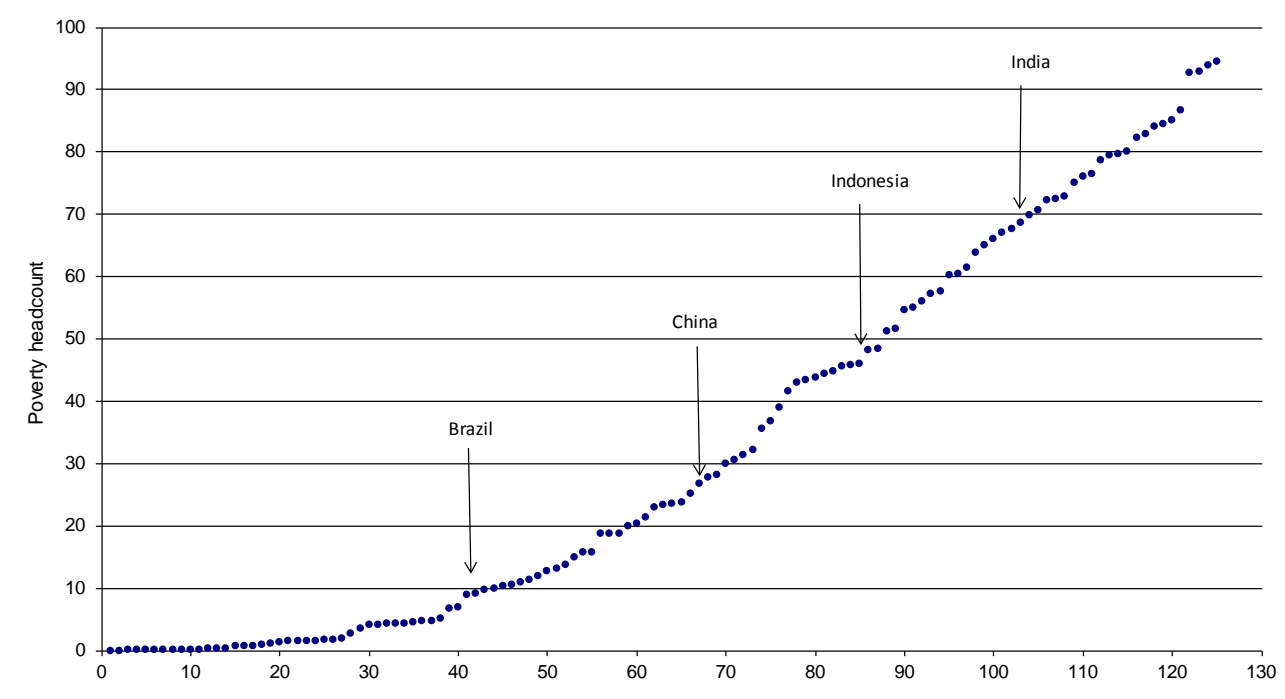

Source: own calculations based on PovcalNet (2013).

Note: poverty computed over the distribution of consumption/income per capita with the PPP-adjusted \$2-a-day line.

In 2010, 41 per cent of the population in the developing world lived with less than \$2 a day. The unweighted mean headcount ratio was significantly lower: in a typical developing country 33 per cent of the population was poor according to that criterion. The difference between the weighted and unweighted mean is not determined by China, as the incidence of poverty in that country is similar to the developing world mean, but by India (and to a lesser extent Indonesia and Pakistan), where the deprivation measures are substantially higher. In fact, when ignoring India both the weighted and unweighted headcount ratios become very close (33.3 and 32.7). The median poverty rate is also lower than the mean (23.5 for the \$2 line). Table 5.1 reports these results for other indices and poverty lines. Interestingly, when using the $\$ 1.25$ line the weighted mean is lower than the unweighted mean for the poverty gap 
and the squared poverty gap, a result driven by the relatively low value of these indicators in China and Indonesia.

\section{Table 5.1}

Poverty measures

Developing countries, 2010

\begin{tabular}{lcccc}
\hline \hline & & \multicolumn{3}{c}{ unweighted } \\
\cline { 3 - 6 } & weighted & mean & std.dev & median \\
\hline \$1.25 poverty line & & & & \\
Headcount & 21.4 & 19.6 & 22.9 & 9.3 \\
Poverty gap & 6.5 & 7.5 & 10.7 & 2.9 \\
Squared poverty gap & 3.0 & 4.0 & 6.5 & 1.0 \\
\hline \$2 poverty line & & & & \\
Headcount & 41.0 & 33.0 & 30.1 & 23.5 \\
Poverty gap & 15.8 & 14.5 & 16.4 & 7.1 \\
$\quad$ Squared poverty gap & 8.1 & 8.3 & 10.9 & 4.0 \\
\hline \$ p poverty line & & & & \\
Headcount & 66.7 & 54.8 & 33.6 & 59.3 \\
Poverty gap & 35.9 & 29.6 & 24.0 & 25.4 \\
Squared poverty gap & 22.9 & 19.5 & 18.5 & 13.2 \\
\hline
\end{tabular}

Source: own calculations based on PovcalNet (2013).

Note: poverty computed over the distribution of consumption/income per capita.

The picture of poverty in the developing world is not significantly affected by changing the poverty indicator or the poverty line. The correlations across countries when using alternatively the headcount $(H)$, the poverty gap $(P G)$ and the squared poverty gap (SPG) with a given poverty line are all higher than 0.9. For a fixed indicator the correlations are higher than 0.95 when changing the poverty line. The correlations are only slightly lower when changing both the indicator and the line (e.g. 0.85 for SPG with the $\$ 1$ line and $\mathrm{H}$ with the $\$ 2$ line).

The top ten steps in the poverty ladder, using the headcount ratio with the \$2 line, are all occupied by Sub-Saharan African countries. ${ }^{84}$ The following ten features also eight SSA economies, in addition to a Caribbean country (Haiti), and a South Asian nation (Bangladesh). However, given its size, India is the country with the largest number of poor people. While around 840 million people in that country live with less than $\$ 2$ a day, the number in the second nation in that ranking, China, is less than a half (359). Both countries are home of $52 \%$ of the poor in the world, while the following four countries - Nigeria, Bangladesh, Indonesia and Pakistan - represent 19\%. Of course, these exact figures are valid only for a specific definition of income poverty, but the main results are robust to changes in indices and poverty lines. ${ }^{85}$

\footnotetext{
${ }^{84}$ Rwanda, Mozambique, Malawi, Nigeria, Tanzania, Zambia, Madagascar, Burundi, Congo Dem. Rep. and Liberia.

${ }^{85}$ The share of India and China in the world poor is $47 \%$ with the $\$ 1.25$ line, $52 \%$ with the $\$ 2$ line and $51 \%$ with the $\$ 4$ line.
} 
As expected, the relationship between mean consumption and poverty is very tight (Figure 5.2). A simple model of the headcount ratio (\$2 line) on log mean consumption per capita estimated in a cross section of developing countries for 2010 accounts for more than $70 \%$ of the variation in the data.

\section{Figure 5.2}

Poverty headcount ratio and log consumption per capita Developing countries, 2010

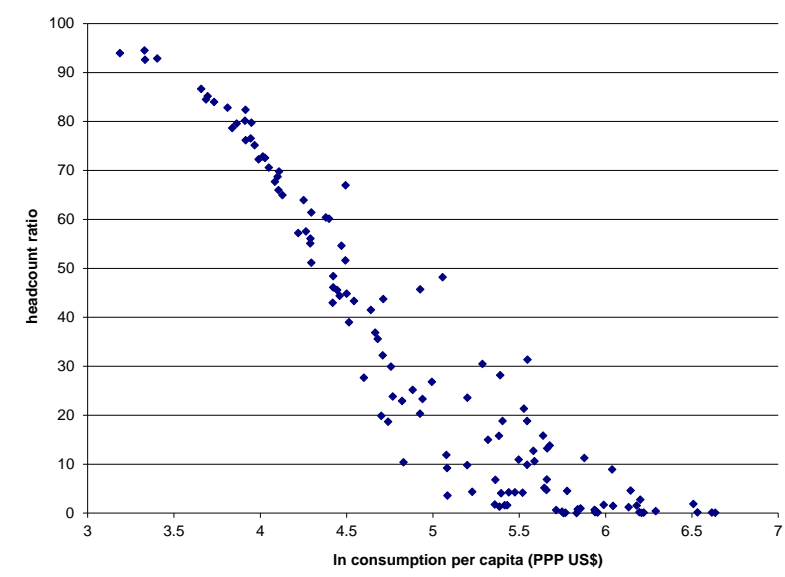

Source: own calculations based on PovcalNet (2013).

Note: poverty computed over the distribution of consumption/income per capita with the PPP-adjusted $2 \$$-a-day line.

The cross-country relationship between poverty and inequality is much looser (Figure 5.3). The correlation coefficient between the headcount (\$2 line) and the Gini is 0.17 (barely significant at 5\%). The relationship is somewhat tighter with other poverty indices, but still in all cases the correlation coefficients are lower than 0.3. The magnitude of the correlations is similar when considering different income shares as measures of inequality. 


\section{Figure 5.3}

\section{Poverty headcount ratio and Gini coefficient}

Developing countries, 2010

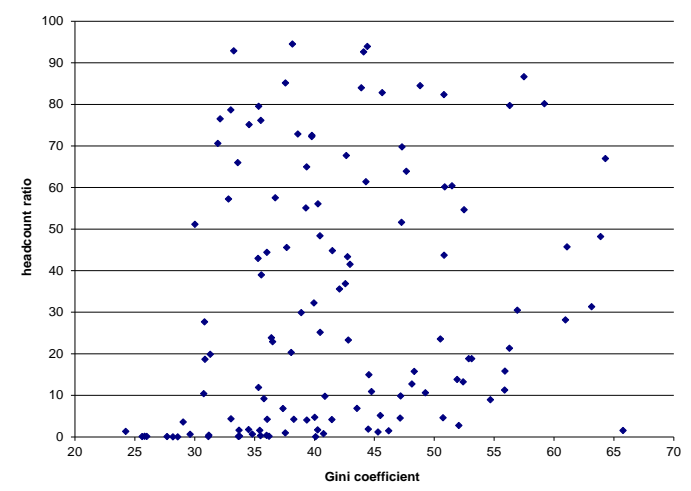

Source: own calculations based on PovcalNet (2013).

Note: poverty computed over the distribution of consumption/income per capita with the PPP-adjusted \$2-a-day line.

Table 5.2 shows some simple regressions aimed at characterizing the relationship between poverty, mean income and inequality in a cross-section of developing countries. The results of course do not have any causal implication, and then are not helpful to orient policy, but nonetheless are illustrative of the empirical relationship among these three variables. An increase (cross-country) of $1 \%$ in mean consumption is associated to a fall of around $2 \%$ in the headcount ratio, while a drop of $1 \%$ in the Gini coefficient is associated to a reduction of around 3.5\% in poverty measured by the headcount. The results are similar when measuring deprivation with the squared poverty gap.

Table 5.2

Regressions of poverty measures

Developing countries, 2010

\begin{tabular}{|c|c|c|c|c|c|c|c|c|}
\hline & \multicolumn{4}{|c|}{ log headcount ratio } & \multicolumn{4}{|c|}{ log squared poverty gap } \\
\hline & (i) & (ii) & (iii) & (iv) & (v) & (vi) & (vii) & (viii) \\
\hline \multirow[t]{2}{*}{$\ln y$} & -2.0 & -2.0 & -2.1 & -2.0 & -2.1 & -2.0 & -2.2 & -2.1 \\
\hline & $(0.114)^{* * *}$ & $(0.085)^{* * *}$ & $(0.086)^{* * *}$ & $(0.086)^{* * *}$ & $(0.127)^{* * *}$ & $(0.092)^{* * *}$ & $(0.084)^{* * *}$ & $(0.091)^{* * *}$ \\
\hline \multirow[t]{2}{*}{ In Gini } & & 3.32 & & & & 3.76 & & \\
\hline & & $(0.329)^{* * *}$ & & & & $(0.349)^{* * *}$ & & \\
\hline \multirow[t]{2}{*}{ Share d1 } & & & -0.74 & & & & -0.91 & \\
\hline & & & $(0.073)^{* * *}$ & & & & $(0.071)^{* * *}$ & \\
\hline \multirow[t]{2}{*}{ Share d1-d6 } & & & & -0.12 & & & & -0.13 \\
\hline & & & & $(0.011)^{* * *}$ & & & & $(0.012)^{* * *}$ \\
\hline \multirow[t]{2}{*}{ Constant } & 12.6 & 0.1 & 14.8 & 16.1 & 11.0 & -3.1 & 13.8 & 15.1 \\
\hline & $(0.577)^{* * *}$ & $(1.30)$ & $(0.484)^{* * *}$ & $(0.561)^{* * *}$ & $(0.64)^{* * *}$ & $(1.39)$ & $(0.473)^{* * *}$ & $(0.586)^{* * *}$ \\
\hline $\mathrm{R} 2$ & 0.72 & 0.85 & 0.85 & 0.85 & 0.68 & 0.84 & 0.87 & 0.85 \\
\hline
\end{tabular}

Source: own calculations based on PovcalNet (2013).

Note: poverty computed over the distribution of consumption/income per capita with the PPP-adjusted \$2-a-day line. In y=log mean household consumption/income per capita; share d1= share of decile 1 in the household consumption/income per capita distribution; share d1-d6=cumulative share of deciles 1 to 6 . Robust standard deviations are shown under the coefficients. ${ }^{* * *}$ significant at $1 \%$ level. 


\subsection{Poverty by region}

Poverty has a clear regional component: Table 5.3 reveals that Eastern Europe and Central Asia is always the region with the lowest income poverty, followed by Middle East and North Africa and Latin America and the Caribbean. Poverty in South Asia is substantially larger than in Eastern Asia when weighting by population, but roughly similar when ignoring weights. All income poverty measures are substantially higher in Sub-Saharan Africa than in the rest of the developing world.

Table 5.3

Poverty indicators by region

Developing countries, 2010

\begin{tabular}{|c|c|c|c|c|c|c|}
\hline & $\begin{array}{c}\text { East Asia \& } \\
\text { Pacific }\end{array}$ & $\begin{array}{c}\text { Eastern } \\
\text { Europe \& } \\
\text { Central Asia }\end{array}$ & $\begin{array}{c}\text { Latin } \\
\text { America \& } \\
\text { Caribbean }\end{array}$ & $\begin{array}{c}\text { Middle East } \\
\& \text { North } \\
\text { Africa }\end{array}$ & South Asia & $\begin{array}{c}\text { Sub-Saharan } \\
\text { Africa }\end{array}$ \\
\hline \multicolumn{7}{|l|}{ Weighted } \\
\hline \multicolumn{7}{|l|}{$\$ 1.25$ line } \\
\hline Headcount & 12.5 & 1.0 & 5.5 & 2.4 & 31.0 & 48.5 \\
\hline Poverty gap & 2.8 & 0.3 & 2.9 & 0.6 & 7.1 & 20.9 \\
\hline Squared poverty gap & 0.9 & 0.2 & 2.1 & 0.2 & 2.4 & 11.8 \\
\hline \multicolumn{7}{|l|}{$\$ 2$ line } \\
\hline Headcount & 29.7 & 2.4 & 10.4 & 12.0 & 66.7 & 69.9 \\
\hline Poverty gap & 9.7 & 0.7 & 4.7 & 2.8 & 23.4 & 35.7 \\
\hline Squared poverty gap & 4.2 & 0.3 & 3.2 & 1.0 & 10.5 & 22.4 \\
\hline \multicolumn{7}{|l|}{ Unweighted } \\
\hline \multicolumn{7}{|l|}{$\$ 1.25$ line } \\
\hline Headcount & 17.9 & 1.6 & 8.6 & 3.5 & 17.6 & 41.5 \\
\hline Poverty gap & 5.1 & 0.5 & 4.0 & 0.9 & 3.9 & 16.6 \\
\hline Squared poverty gap & 2.3 & 0.2 & 2.6 & 0.3 & 1.3 & 8.8 \\
\hline \multicolumn{7}{|l|}{$\$ 2$ line } \\
\hline Headcount & 38.4 & 5.2 & 15.6 & 13.5 & 43.5 & 62.2 \\
\hline Poverty gap & 13.8 & 1.5 & 7.0 & 3.5 & 14.1 & 30.2 \\
\hline Squared poverty gap & 6.7 & 0.6 & 4.4 & 1.4 & 6.1 & 18.1 \\
\hline
\end{tabular}

Source: own calculations based on PovcalNet (2013).

Note: poverty computed over the distribution of consumption/income per capita.

Figure 5.4 unveils the considerable heterogeneity within each geographic region. When using the $\$ 2$ line, the poverty headcount ratio ranges in EAP from 1.4 (Malaysia) to 70.6 (Timor-Leste), in ECA from 0.1 (Slovenia) to 35.6 (Georgia), in LAC from 1.2 (Uruguay) to 80.1 (Haiti), in MENA from 1.6 (Jordan) to 45.6 (Yemen), in SA from 6.8 (Maldives) to 76.5 (Bangladesh), and in SSA from 1.5 (Seychelles) to 94.5 (Liberia). Figure 5.5 displays a map of the poverty levels in the world that illustrates the regional differences, as well as the within-region heterogeneities. 


\section{Figure 5.4}

Poverty headcount ratio

Developing countries, 2010

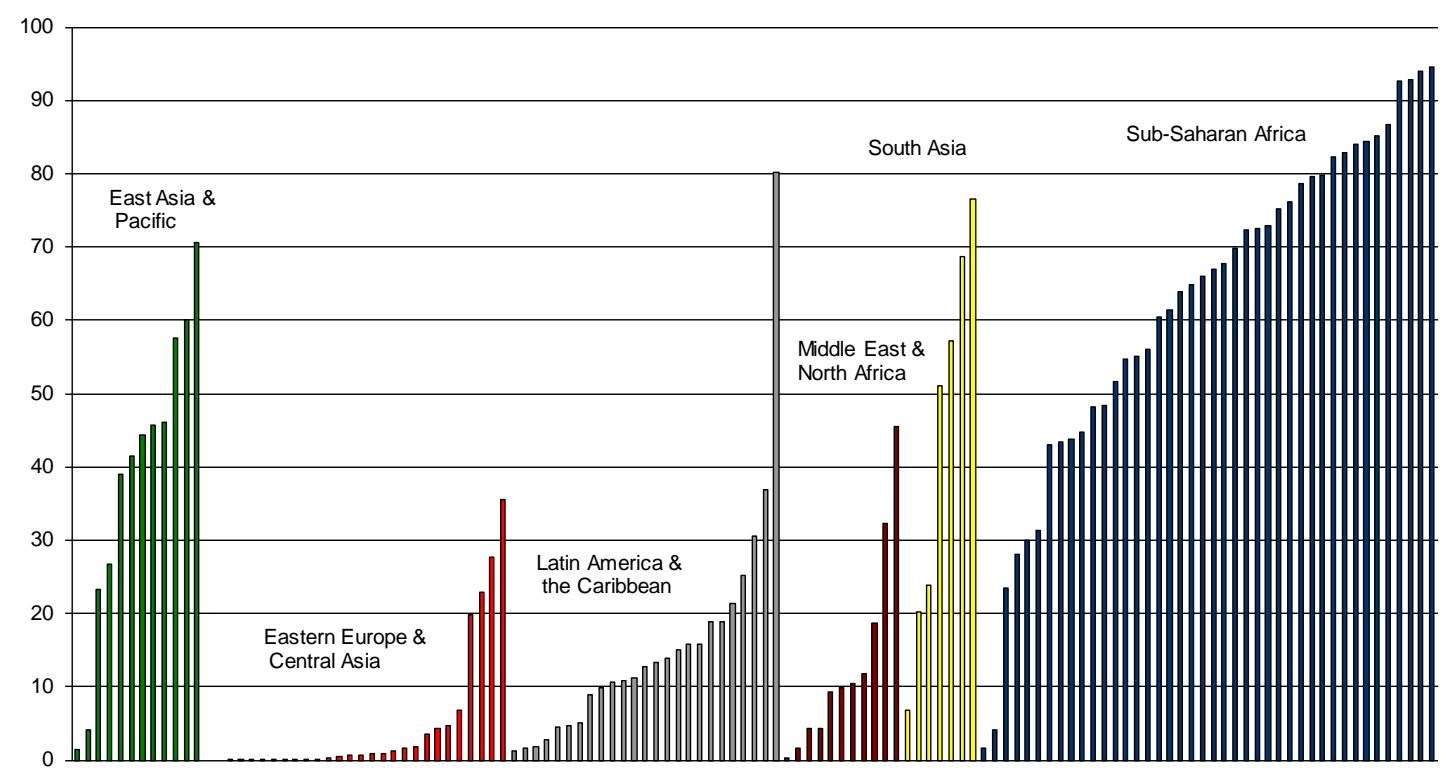

Source: own calculations based on PovcalNet (2013).

Note: poverty computed over the distribution of consumption/income per capita with the PPP-adjusted \$2-a-day line.

There is a considerable degree of spatial correlation of poverty measures across countries. The Moran scatterplot is a way to illustrate that spatial correlation (Figure 5.6). The horizontal axis shows the normalized headcount ratio of a country ( $\$ 2$ line), while the vertical axis depicts a weighted average of its neighbors' normalized poverty rates, where neighborhood is defined in terms of geographical proximity. The graph suggests a strong positive correlation between a country poverty incidence rate and that of its neighbors (the Moran correlation coefficient is 0.507 , significant at $1 \%$ ). Almost $80 \%$ of the countries are either in the HH cells (high poverty for the country and its neighbors) or in the LL cells. 


\section{Figure 5.6}

\section{Spatial correlation of poverty rates \\ Moran's scatterplot \\ Developing countries, 2010}

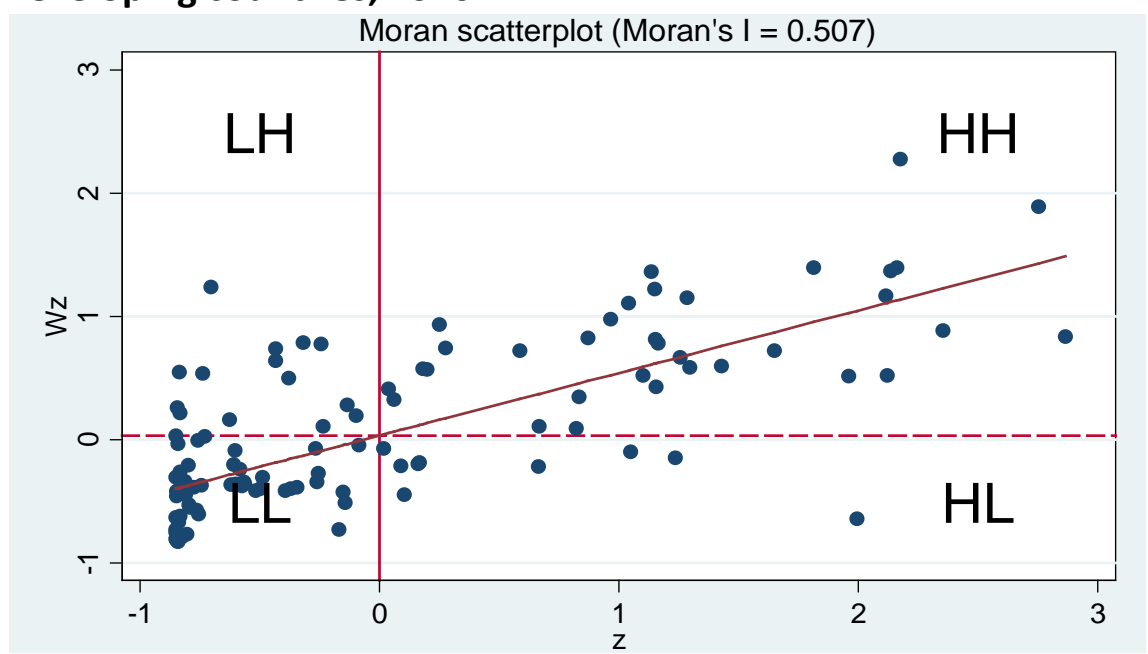

Source: own calculations based on PovcalNet (2013).

Note: poverty computed over the distribution of consumption/income per capita with the PPP-adjusted $\$ 2-a-d a y ~ l i n e . ~ z$ is the normalized poverty headcount ratio (the value minus the mean, divided by the standard deviation), $W z$ is the weighted average of the normalized poverty headcount ratios of a country's neighbors, where the weights $W$ are defined in terms of contiguity.

The poverty gap indicator has an intuitive-appealing interpretation: when normalized by the poverty line and the total population of a country, it gives the total cost needed to end poverty, in the particular case in which cash transfers could be perfectly targeted to poor people in the amount just needed to reach the poverty line, and no changes in behavior take place. Table 5.4 shows the unweighted mean across countries of the cost of eliminating poverty as percentage of GDP under this scenario in each region. Although the context is clearly unrealistic, the figures give a rough idea of the magnitude of the task of fighting poverty in each region of the developing world in relation to the available economic resources. While eliminating poverty with the $\$ 2$ line in this scenario would require on average less than 1 GDP point in the economies of ECA and between 1 and 2 points in MENA and LAC, the size of the effort is larger in Asia and orders of magnitude greater in Sub-Saharan Africa. 
Table 5.4

The cost of eliminating poverty

Total poverty gap as percentage of GDP

Unweighted means by region, 2010

\begin{tabular}{lcc}
\hline \hline & \multicolumn{2}{c}{ Poverty lines } \\
\cline { 2 - 3 } Region & $\$ 1.25$ & $\$ 2$ \\
\hline East Asia and Pacific & 0.6 & 2.9 \\
Eastern Europe and Central Asia & 0.1 & 0.3 \\
Latin America and the Caribbean & 0.7 & 1.7 \\
Middle East and North Africa & 0.2 & 1.0 \\
South Asia & 1.2 & 6.6 \\
Sub-Saharan Africa & 8.1 & 23.0 \\
\hline
\end{tabular}

Source: own calculations based on PovcalNet (2013).

Note: poverty computed over the distribution of consumption/income per capita.

International surveys, such as the Gallup Poll, provide an opportunity to alleviate some of the typical comparability problems of household surveys, since survey design and questionnaires are identical across countries. However, as discussed above, these surveys have still small samples, and measurement errors are presumably large, given that only one income question is included. The correlation between headcount ratios computed with the Gallup Poll and PovcalNet is 0.32 , significant at $2 \%$, while the rank Spearman correlation is 0.61 , significant at $1 \%$.

Figure 5.7 shows the cumulative density function in some regions of the world, based on Gallup data. There is first-order stochastic dominance of the Western Europe distribution over the rest, while the South Asian distribution is dominated by the rest. The curves of ECA and EAP cross each other, although they do so at high-income levels.

\section{Figure 5.7}

\section{Distribution functions}

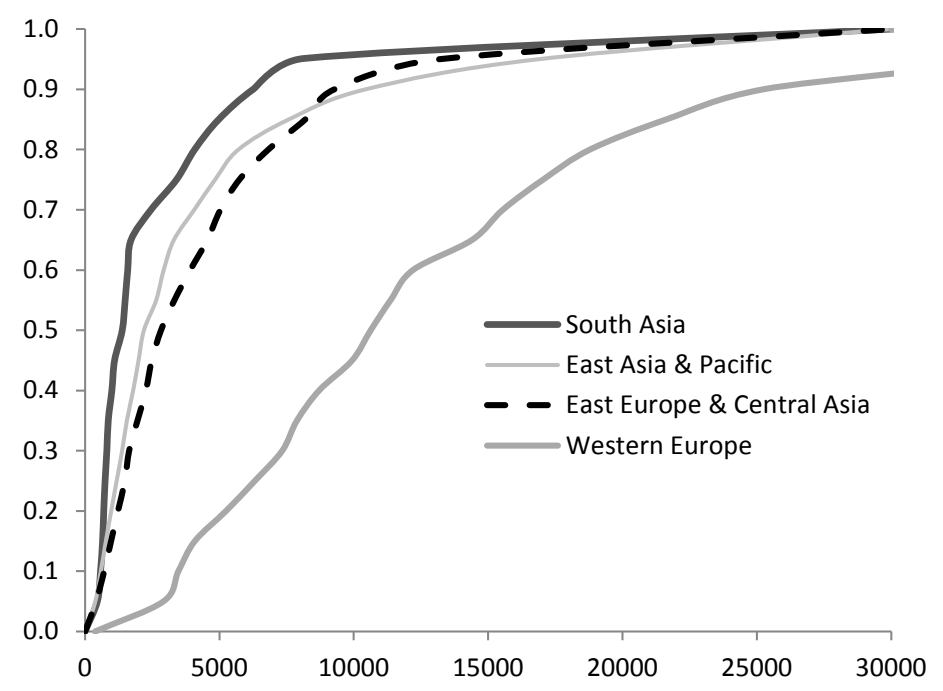

Source: own estimates based on microdata from Gallup World Poll 2006. Note: cumulative distribution functions of per capita household income. 


\section{Poverty: trends}

In the last decades the developing world has made undeniable progress toward the goal of ending absolute poverty. The evidence suggests that the first goal of the Millennium Development Goals - to halve extreme poverty from 1990 to 2015 - was already met in $\mathbf{2 0 1 0}$ for the aggregate of developing countries. However, the strong decline in global absolute poverty hides substantial heterogeneities across economies and over time. In this section we document and characterize trends in income poverty in the countries of the developing world since the early 1980s to 2010, and trace those changes to economic growth and distributional changes. ${ }^{86}$

The literature on international poverty trends can be divided into two main strands. The first one makes comparisons based exclusively on household survey microdata. This ambitious road that requires access to surveys for many countries over time has been taken by several initiatives at the regional level, and by the World Bank at a global scale, mainly through the work of Martin Ravallion and Shaohua Chen. The second strand combines estimates of the national income distributions with GDP or aggregate consumption data drawn from National Accounts to anchor the mean. Bourguignon and Morrison (2002), Bhalla (2002), Karshenas (2003) and Sala-i-Martin (2006) are examples of this literature. In this section we mainly document the results of the first approach.

\subsection{Trends in income poverty}

Data from PovcalNet reveals a widespread fall in absolute income poverty in the developing countries over the last three decades (Figure 6.1). Only for a few nations poverty in 2010 was not lower than in 1981; that set includes some economies in Eastern Europe, Central Asia and Sub-Saharan Africa, and only a few in Latin America and the Caribbean. The poverty decline in the 2000s was even more generalized: in only 8 out of 121 countries did poverty increase between 1999 and 2010 (5 in SubSaharan Africa).

\footnotetext{
${ }^{86}$ Chapter 12 in this volume also covers the issue of global poverty in the developing world. In our chapter the interest is more focused on the country trends, and then we make more use of unweighted statistics.
} 


\section{Figure 6.1}

\section{Poverty headcount ratio \\ Developing countries \\ Poverty 1981-2010}

Poverty 1999-2010
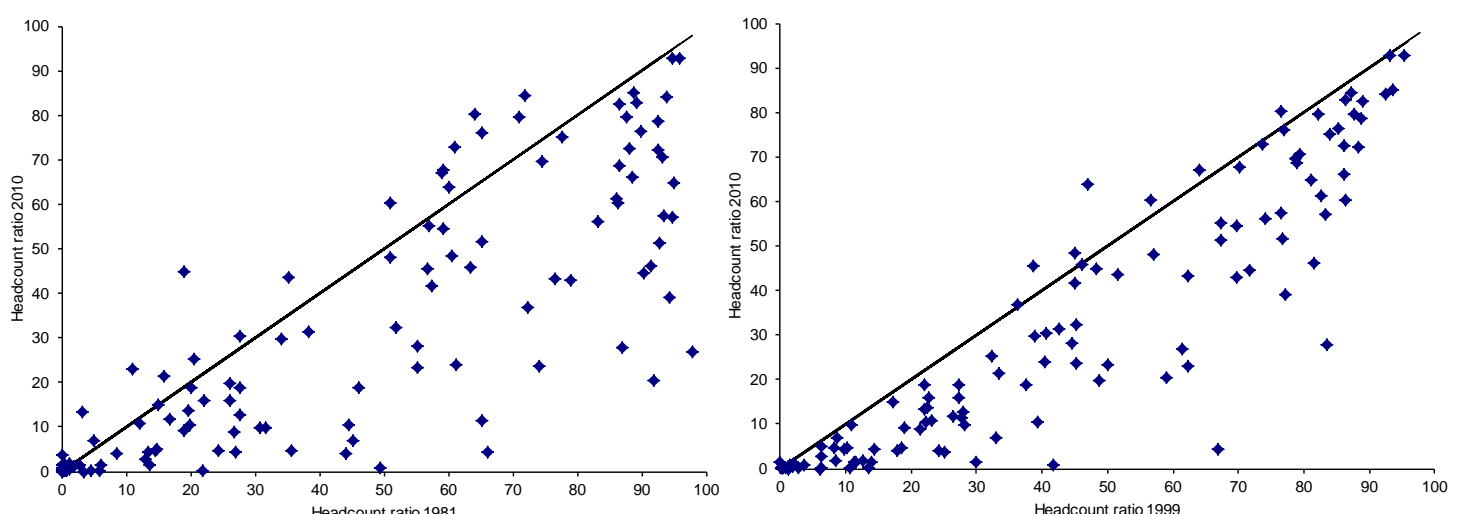

Source: own calculations based on PovcalNet (2013).

Note: poverty computed over the distribution of consumption/income per capita with the PPP-adjusted \$2-a-day line.

The proportion of the population in the developing world living with less than $\$ 1.25$ per day decreased from $52 \%$ in 1981 to $20.8 \%$ in 2010, which implies a trend decline of around one point per year (Figure 6.2). ${ }^{87}$ This is a remarkable achievement that should not be overlooked. It would be hard to find other episodes in history where the extent of extreme poverty was reduced so massively in such a short period of time.

\section{Figure 6.2}

\section{Poverty headcount ratio}

Weighted and unweighted means, developing countries, 1981-2010

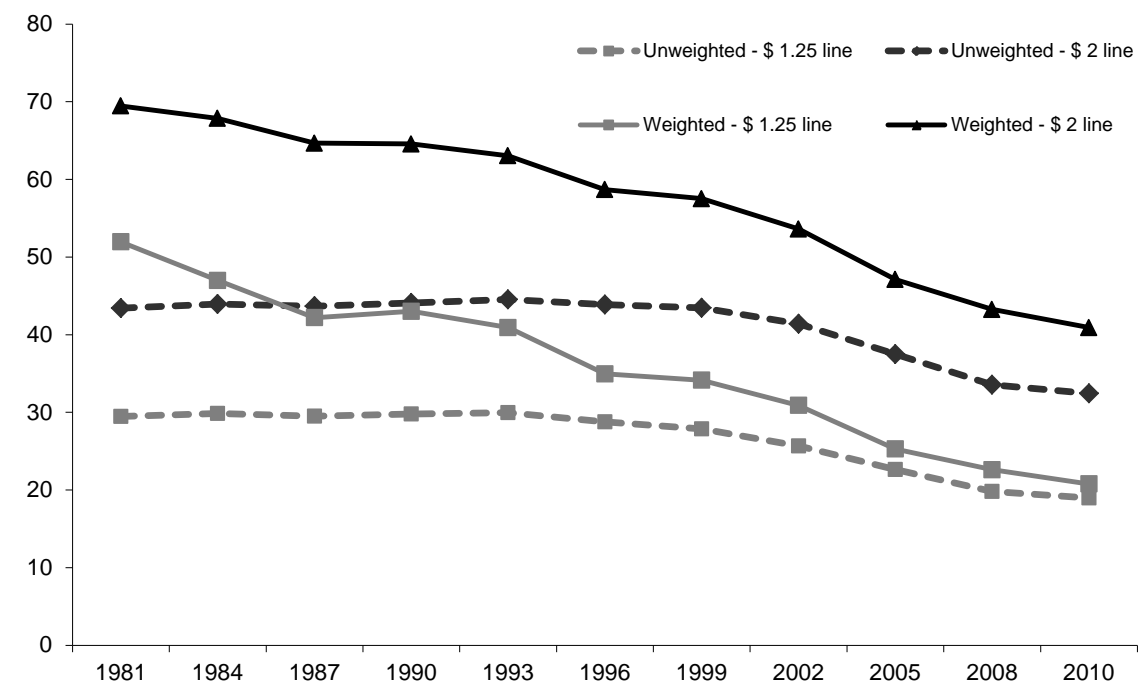

Source: own calculations based on PovcalNet (2013).

\footnotetext{
${ }^{87}$ The cumulative distribution function of 2010 lies always below the functions corresponding to all previous years. The first-order stochastic dominance assures that the result of lower poverty in 2010 is robust to the choice of poverty line and valid for a broad class of poverty measures (Atkinson, 1987).
} 
Note: poverty computed over the distribution of consumption/income per capita.

However, this extraordinary result should be put in perspective. First, even after this global social improvement one of every five persons in the developing world still lives in extremely deprived conditions (less than $\$ 1.25$ a day), while four out of ten people have household per capita consumption levels lower than a frugal \$2 per day.

Second, the positive performance of China is key for the global result. Ignoring China, the poverty decline is less impressive: the headcount ratio fell 16 instead of 31 points in three decades (Table 6.1). ${ }^{88}$ In fact, when ignoring China it is not clear that the developing world could meet the MDG for poverty reduction in 2015. While the population-weighted mean of the poverty incidence rate dropped 31 points between 1981 and 2010, the unweighted mean declined about 10 points, and the median went down just 8 points. The extreme poverty rate $(\$ 1.25)$ of a typical developing country was reduced from $29.5 \%$ in 1981 to $19 \%$ in 2010, which represents a fall of around a third of a point per year, a figure less impressive than the corresponding one for the global poverty rate (one point a year). In fact, this decline took place only since the late-1990s. A typical developing country did not experience any improvement for almost two decades: the unweighted poverty rate for the developing world was $29.5 \%$ in $1981,29.8 \%$ in 1990 and $28.8 \%$ in 1996 . From then on poverty declined more consistently, especially between 2002 and 2008, when for a typical developing economy the rate of poverty reduction was almost one point a year.

\footnotetext{
${ }^{88}$ When ignoring China the distribution of 2010 still dominates (first-order stochastic dominance) 1981 although the distance between the two cumulative distributions is smaller. The curve for 1999 lies below 1981 and 1990 but only for poverty lines lower than \$3 a day.
} 
Table 6.1

Change in poverty measures (points)

Developing countries, 1981-2010

\begin{tabular}{|c|c|c|c|c|c|c|c|c|c|}
\hline Poverty measure & $\begin{array}{l}1981- \\
1990\end{array}$ & $\begin{array}{c}1990- \\
1999\end{array}$ & $\begin{array}{l}1999- \\
2010\end{array}$ & $\begin{array}{l}1981- \\
2010\end{array}$ & Poverty measure & $\begin{array}{l}1981- \\
1990\end{array}$ & $\begin{array}{c}1990- \\
1999\end{array}$ & $\begin{array}{l}1999- \\
2010\end{array}$ & $\begin{array}{l}1981 \\
2010 \\
\end{array}$ \\
\hline Headcount - \$1.25 line & & & & & Poverty gap - \$1.25 line & & & & \\
\hline Unweighted & & & & & Unweighted & & & & \\
\hline Mean & 0.3 & -1.9 & -8.9 & -10.5 & Mean & 0.2 & -1.6 & -4.2 & -5.7 \\
\hline Median & 4.9 & 0.0 & -12.9 & -8.0 & Median & 0.3 & 0.3 & -4.0 & -3.4 \\
\hline Weighted & & & & & Weighted & & & & \\
\hline Mean & -9.0 & -8.9 & -13.4 & -31.2 & Mean & -6.4 & -3.7 & -4.8 & -14.9 \\
\hline Without China & -2.8 & -3.1 & -10.0 & -15.9 & Without China & -1.6 & -1.5 & -3.7 & -6.8 \\
\hline Headcount - \$2 line & & & & & Poverty gap - \$2 line & & & & \\
\hline Unweighted & & & & & Unweighted & & & & \\
\hline Mean & 0.7 & -0.6 & -11.0 & -11.0 & Mean & 0.3 & -1.5 & -6.5 & -7.7 \\
\hline Median & -0.3 & -3.4 & -17.1 & -20.7 & Median & 2.3 & 0.8 & -9.2 & -6.1 \\
\hline Weighted & & & & & Weighted & & & & \\
\hline Mean & -4.9 & -7.1 & -16.6 & -28.5 & Mean & -6.6 & -5.4 & -8.8 & -20.8 \\
\hline Without China & -1.2 & -1.1 & -10.9 & -13.1 & Without China & -1.7 & -1.8 & -6.4 & -9.9 \\
\hline Headcount - \$4 line & & & & & Poverty gap - \$4 line & & & & \\
\hline Unweighted & & & & & Unweighted & & & & \\
\hline Mean & 0.9 & 2.2 & -11.4 & -8.3 & Mean & 0.4 & -0.4 & -9.0 & -9.0 \\
\hline Median & 2.1 & -2.1 & -16.3 & -16.3 & Median & -0.4 & -1.4 & -12.3 & -14.1 \\
\hline Weighted & & & & & Weighted & & & & \\
\hline Mean & -1.7 & -1.3 & -14.0 & -17.0 & Mean & -8.4 & -4.6 & -12.1 & -25.1 \\
\hline Without China & -1.2 & 1.7 & -8.3 & -7.8 & Without China & -1.4 & -0.5 & -7.8 & -9.7 \\
\hline
\end{tabular}

Source: own calculations based on PovcalNet (2013).

Note: poverty computed over the distribution of consumption/income per capita.

The fall in poverty appears less startling when using higher poverty lines. While the headcount ratio with the $\$ 1.25$ line fell $60 \%$ from 1981 to 2010, it declined $41 \%$ when measured with the $\$ 2$ line and $20 \%$ with the $\$ 4$ line. In fact, while the MDG goal of halving \$1-a-day poverty from the value in 1990 was already met in 2010, the assessment is different when using the \$2 line: the headcount ratio in 2010 was about $2 / 3$ of the value in 1990.

The performance of the developing world in terms of poverty reduction also looks much less spectacular when considering poverty counts, instead of the typical measures that are invariant to the size of the population. In fact, for the majority of the developing countries (63\%) the number of poor people was higher in 2010 than in 1981. Even during the booming 2000s the poverty count increased in $30 \%$ of the nations. The number of poor people was in the late 2000 s only slightly lower than in the early 1980s (2,585 million in 1981 and 2,394 million in 2010); ignoring China the poverty count actually increased in 422 million (from 1,613 to 2,035). Some authors have suggested that the difference in the assessment of world poverty when alternatively using the headcount ratio or the number of poor people may be behind some of the controversies in the public debate about globalization and the social performance of the world in the last decades. ${ }^{89}$

Since the calculation of global poverty with microdata is very cumbersome, and requires having a large number of comparable household surveys, some authors

${ }^{89}$ See Reddy and Pogge (2010), Chen and Ravallion (2012) and Cockburn et al. (2012). 
estimate the changes in poverty with National Accounts data, anchoring the mean of the income distribution to output or domestic consumption taken from National Accounts, using secondary distributive data and making assumptions about the functional form of the income distribution, typically the lognormal parameterization (Ahluwalia et al., 1979; Chotikapanich et al., 1997; Bhalla, 2002; Sala-i-Martin, 2006; Pinkovskiy and Sala-i-Martin, 2009). ${ }^{90}$ This methodology allows ambitious calculations in terms of coverage, but it faces some obvious caveats as changes in National Accounts aggregates may be misleading proxies for changes in household per capita income, and the secondary distributive data in which the estimates are usually based are mined with several comparability problems. ${ }^{91}$

According to the estimates by Pinkovskiy and Sala-i-Martin (2009) (PSM) using a sample of 191 countries, and distributive data from the WIID, world poverty rates (\$2 line) went down from $45.2 \%$ in 1970 to $37.8 \%$ in $1981,24.9 \%$ in $1990,16.8 \%$ in 1999 , and $13 \%$ in 2006 . That pattern implies a fall substantially faster than what is estimated with household surveys data alone in the 1980s and 1990s, but slower in the 2000s. ${ }^{92}$ For instance, while the magnitude of the poverty incidence rates in PSM for the \$3 line is similar than in PovcalNet with the $\$ 1.25$ line, the declines have been different: in PSM the headcount ratio fell at annual $2.6 \%$ and $3.5 \%$ in the $1980 \mathrm{~s}$ and $1990 \mathrm{~s}$, respectively, while the rates were $2.1 \%$ and $2.5 \%$ with PovcalNet data. Instead, in the 2000s poverty fell at annual $3.1 \%$ in PSM and at annual $4.4 \%$ in PovcalNet.

\subsection{Decomposing poverty changes}

Researchers frequently use decompositions of changes in poverty into growth and redistribution effects in order to characterize poverty trends. ${ }^{93}$ The growth effect refers to the poverty change between two years that would have occurred if the mean income had changed as it did, but the shape of the distribution had stayed fixed. On the other hand, the redistribution effect records the poverty change between two years that would have occurred if the shape of the distribution had changed in the way it did, but the mean had remained fixed. Of course, this is just a mechanical exercise, as indicators of economic growth, and changes in inequality and poverty are just three different ways of aggregate information on income dynamics, and therefore they are all jointly determined by the general equilibrium of the economy. In that sense the decompositions are helpful to illustrate the way incomes have changed and affected

\footnotetext{
${ }^{90}$ It should be noticed that the World Bank poverty estimates also use National Accounts (NAS) data, although to a limited extent. For instance, for countries with only one household survey, poverty is estimated by applying the NAS consumption estimates to the available distribution data, assuming the Lorenz curve remains fixed.

${ }^{91}$ An intermediate alternative is proposed by Karshenas (2003), who calibrates survey means using National Accounts statistics. Calibrated survey means are read off the fitted curve for the mean of household survey consumption conditional on the NAS mean.

92 Dhongde and Minoiu (2010) explore several factors behind the different results in Chen and Ravallion (2010) and Pinkovskiy and Sala-i-Martin (2009).

93 See Datt and Ravallion (1992), Kakwani and Subbarao (1990), Kakwani (2000) and Mahmoudi (2001) for different proposals.
} 
poverty, but they are silent on the fundamental factors underlying poverty changes, and on the policies recommended to reduce deprivations more effectively.

The change in the growth-inequality-poverty triangle was very different in the 2000s compared to the previous decade. Table 6.2 illustrates this difference showing the unweighted mean of the growth and redistribution effects of changes in poverty for a sample of 76 developing countries with information on deciles shares in PovcalNet. ${ }^{94}$ The mild fall in the poverty headcount ratio (\$2 line) in the 1990s can be decomposed into a poverty-decreasing growth effect that outweighed a poverty-increasing redistribution effect. On average (unweighted) mean consumption grew at an annual 0.2 per cent, and the Gini increased about 0.3 points per year, implying a very modest decline in poverty. In contrast, in the 2000s both effects contributed to a falling poverty. A robust increase of mean consumption (more than 3 per cent a year) and a slow fall in inequality (around 0.1 Gini points a year) combined to yield a substantial reduction in indicators of material deprivation. The growth effect was particularly large, accounting for 90 per cent of the fall in the headcount ratio (\$2 line). This result does not mean that distributional changes are not important, but instead that they have not been the main drivers of poverty reduction in the past.

\section{Table 6.2}

Decomposition of poverty changes

Developing countries, 1990-2010

\begin{tabular}{lccc}
\hline \hline & Actual & \multicolumn{2}{c}{ Effects } \\
\cline { 3 - 4 } & change & Growth & Redistribution \\
\hline $1990-1999$ & -0.3 & -1.5 & 1.2 \\
$1999-2010$ & -10.1 & -9.0 & -1.1 \\
$1990-2010$ & -10.5 & -10.4 & -0.1 \\
\hline
\end{tabular}

Source: own calculations based on data from PovcalNet.

Note: the columns show unweighted means across a sample of 76 developing countries of the change in poverty headcount ratio (\$2 line), and the growth and redistribution effects from the poverty change decomposition.

\subsection{The cost of closing the poverty gap}

Although still a challenging problem, eliminating absolute extreme income poverty is an increasingly affordable target. Based on PovcalNet data we computed the population-weighted poverty gap index in the developing world as a share of global GDP. This fraction, that indicates the fiscal effort required to end poverty in a scenario of perfect targeting, absent behavioral responses, has been substantially falling over time as poverty decreased and global GDP went up. The resources needed to close the poverty gap with the $\$ 1.25$ line as a share of global GDP declined from $1.3 \%$ in 1981 to

\footnotetext{
${ }^{94}$ Since the decompositions could be carried out changing the base year, the table shows the averages over the two exercises. To obtain the results we use lineal approximations to the Pen curve based on information on mean consumption per capita by decile from PovcalNet.
} 
$0.2 \%$ in 2010 (the corresponding values for the $\$ 2$ line are $3.6 \%$ and $1 \%$ ). ${ }^{95}$ As a share of the GDP in the developing world the cost of closing the poverty gap fell from $1.9 \%$ in 1981 to $0.4 \%$ in 2010 ( $5.4 \%$ and $1.8 \%$ for the $\$ 2$ line).

Kanbur and Sumner (2011) highlight the fact that while in 1990 over 90 per cent of the world's extremely poor people (\$1.25) lived in countries classified as low-income countries (LICs), by the late 2000 s this share dropped to less than 30 per cent. From the fact that most of the world's poor live in middle-income countries with the domestic financial capacity to end at least extreme poverty, Sumner (2012) concludes that poverty reduction is increasingly becoming a domestic issue of national distribution and domestic political economy, rather than primarily an aid and international issue. Table 6.3 suggests than on average (unweighted) across developing countries the redistributive national effort to end extreme poverty fell from $8.2 \%$ of GDP in 1981 to $4 \%$ in 2010 . The median value is much lower, and has fallen from $1.9 \%$ in 1981 to $0.5 \%$ in 2010 . The third column shows the share of countries where the cost of eliminating extreme income poverty is less than 1 GDP point. That share substantially increased in the 2000s, from $41.3 \%$ in 1999 to $55.4 \%$ in 2010 . Similarly, the share of countries for which closing the poverty gap is fiscally very burdensome (in the table more than 3 GDP points) fell from more than $50 \%$ in 1990 to about $30 \%$ in 2010. Sumner (2012) reports similar trends, although a lower proportion of countries with poverty gap/GDP less than $1 \%$. Ravallion (2010) also notes that most middleincome countries would require very small additional taxation to end poverty.

Table 6.3

Poverty gap as share of GDP

Mean, median, share of countries with gap/GDP less than $1 \%$ and greater than $3 \%$ Developing countries, 1981-2010

\begin{tabular}{|c|c|c|c|c|c|c|c|c|}
\hline & \multicolumn{4}{|c|}{ Poverty line \$1.25 } & \multicolumn{4}{|c|}{ Poverty line $\$ 2$} \\
\hline & & & $\%$ less & $\%$ more & & & $\%$ less & $\%$ more \\
\hline & Mean & Median & 1 GDP point & 3 GDP points & Mean & Median & $1 \mathrm{GDP}$ point & 3 GDP points \\
\hline 1981 & 8.2 & 1.9 & 42.4 & 45.7 & 19.9 & 5.4 & 22.9 & 60.4 \\
\hline 1984 & 8.4 & 2.2 & 41.3 & 45.7 & 20.5 & 6.6 & 19.8 & 60.4 \\
\hline 1987 & 8.2 & 2.3 & 39.1 & 46.7 & 19.9 & 7.1 & 20.8 & 60.4 \\
\hline 1990 & 8.1 & 3.3 & 39.1 & 51.1 & 19.6 & 7.0 & 24.0 & 59.4 \\
\hline 1993 & 9.2 & 2.4 & 40.2 & 47.8 & 22.0 & 7.5 & 25.0 & 59.4 \\
\hline 1996 & 9.2 & 2.0 & 40.2 & 42.4 & 21.6 & 7.3 & 24.0 & 60.4 \\
\hline 1999 & 6.9 & 2.0 & 41.3 & 39.1 & 17.9 & 5.9 & 25.0 & 60.4 \\
\hline 2002 & 5.9 & 1.4 & 41.3 & 40.2 & 15.7 & 4.8 & 27.1 & 58.3 \\
\hline 2005 & 5.2 & 1.0 & 48.9 & 35.9 & 14.0 & 3.7 & 32.3 & 55.2 \\
\hline 2008 & 4.3 & 0.7 & 50.0 & 33.7 & 11.6 & 3.0 & 40.6 & 50.0 \\
\hline 2010 & 4.0 & 0.5 & 55.4 & 31.5 & 11.1 & 3.0 & 42.7 & 50.0 \\
\hline
\end{tabular}

Source: own calculations based on PovcalNet (2013).

Note: poverty computed over the distribution of consumption/income per capita. Unweighted statistics.

\footnotetext{
95 This computation assumes zero poverty in the high-income countries, when deprivation is measured with the international lines.
} 


\subsection{Regional trends}

The patterns in income poverty over time have been heterogeneous across the geographic regions of the developing world (Table 6.4). At least three facts are worth stressing: (i) the remarkable decline in poverty in Asia over the last three decades, (ii) the lack of significant progress in the rest of the regions in the 1980s and 1990s, and (iii) the generalized fall in poverty in the 2000s.

Arguably, the main fact about poverty dynamics in the last three decades has been the noteworthy decline in Asia. The share of people living with less than \$2 a day went down from $92.4 \%$ to $29.7 \%$ between 1981 and 2010 in East Asia and Pacific, and from $87.2 \%$ to $66.7 \%$ in South Asia. ${ }^{96}$ The performance of EAP is enhanced by the presence of China, but also the unweighted mean dramatically fell in this region (from $70.4 \%$ in 1981 to $38.4 \%$ in 2010). The fall in the unweighted mean was similar in South Asia (from $80.3 \%$ to $43.5 \%$ ). Almost all countries in Asia experienced drops in income poverty over the period 1981-2010. The reductions were on average larger in the 2000 s than in the previous decades. For instance, in South Asia the unweighted mean fell 5.6 points in the 1980s, 10.9 in the 1990 s and 20.4 in the 2000 s.

In the rest of the developing world the performance was weak and even negative in the 1980s and 1990s. Income poverty rose in Latin America in the 1980s, in Eastern Europe and Central Asia in the 1990s, and in Sub-Saharan Africa in both decades. In contrast, all regions experienced falling poverty in the 2000s. The reductions were large, and in general outweighed the weak performance of the previous decades. For instance, on average (unweighted) income poverty (\$2 line) went down $72 \%$ in ECA, $43 \%$ in MENA, $34 \%$ in LAC and $12 \%$ in SSA. The proportion of countries where the headcount ratio fell more than $5 \%$ in the 2000 s is above $90 \%$ in all these regions, with the exception of SSA, where the corresponding proportion is $66 \%$.

\footnotetext{
${ }^{96}$ The contrast between East Asia and the rest of the developing world is evident in terms of progress towards the first goal of the MDGs. EAP already met the goal in the early 2000s, far ahead of the rest.
} 
Table 6.4

Poverty headcount ratio, developing world 1981-2010

Weighted and unweighted means

\begin{tabular}{|c|c|c|c|c|}
\hline & 1981 & 1990 & 1999 & 2010 \\
\hline \multicolumn{5}{|l|}{ Unweighted mean; \$1.25 line } \\
\hline East Asia and Pacific & 53.4 & 44.3 & 33.3 & 17.9 \\
\hline Eastern Europe and Central Asia & 4.0 & 4.5 & 7.5 & 1.4 \\
\hline Latin America and the Caribbean & 13.2 & 14.4 & 13.7 & 8.6 \\
\hline Middle East and North Africa & 10.3 & 7.2 & 6.8 & 3.5 \\
\hline South Asia & 59.7 & 51.3 & 37.8 & 17.6 \\
\hline Sub-Saharan Africa & 49.3 & 54.0 & 52.2 & 41.5 \\
\hline \multicolumn{5}{|l|}{ Unweighted mean; \$2 line } \\
\hline East Asia and Pacific & 70.4 & 65.8 & 56.2 & 38.4 \\
\hline Eastern Europe and Central Asia & 10.1 & 10.2 & 17.0 & 4.8 \\
\hline Latin America and the Caribbean & 24.3 & 25.9 & 23.8 & 15.6 \\
\hline Middle East and North Africa & 28.6 & 24.0 & 23.5 & 13.5 \\
\hline South Asia & 80.3 & 74.7 & 63.9 & 43.5 \\
\hline Sub-Saharan Africa & 67.1 & 71.5 & 71.0 & 62.2 \\
\hline \multicolumn{5}{|l|}{ Population-weighted mean; \$1.25 line } \\
\hline East Asia and Pacific & 77.2 & 56.2 & 35.6 & 12.5 \\
\hline Eastern Europe and Central Asia & 1.9 & 1.9 & 3.8 & 0.7 \\
\hline Latin America and the Caribbean & 11.9 & 12.3 & 11.9 & 5.5 \\
\hline Middle East and North Africa & 9.6 & 5.7 & 5.0 & 2.4 \\
\hline South Asia & 61.1 & 53.8 & 45.1 & 31.0 \\
\hline Sub-Saharan Africa & 51.4 & 56.5 & 57.9 & 48.5 \\
\hline \multicolumn{5}{|l|}{ Population-weighted mean; \$2 line } \\
\hline East Asia and Pacific & 92.4 & 81.0 & 61.7 & 29.7 \\
\hline Eastern Europe and Central Asia & 8.3 & 6.9 & 12.1 & 2.3 \\
\hline Latin America and the Caribbean & 23.7 & 22.5 & 22.0 & 10.4 \\
\hline Middle East and North Africa & 30.0 & 23.4 & 21.9 & 12.0 \\
\hline South Asia & 87.2 & 83.6 & 77.8 & 66.7 \\
\hline Sub-Saharan Africa & 72.2 & 75.9 & 77.5 & 69.9 \\
\hline
\end{tabular}

Source: own calculations based on PovcalNet (2013).

The contrast between Asia and the rest of the developing world in terms of poverty reduction is even more dramatic when the calculations are carried out anchoring the mean of the income distribution to GDP from National Accounts. Figure 6.3 shows regional estimates taken from Pinkovskiy and Sala-i-Martin (2009), where the sharp declines in poverty in East and South Asia stand out. According to these estimates there would be poverty convergence across the regions of the developing world, with the exception of Sub-Saharan Africa. 


\section{Figure 6.3}

\section{Poverty headcount ratio \\ Developing countries, 1970-2006}

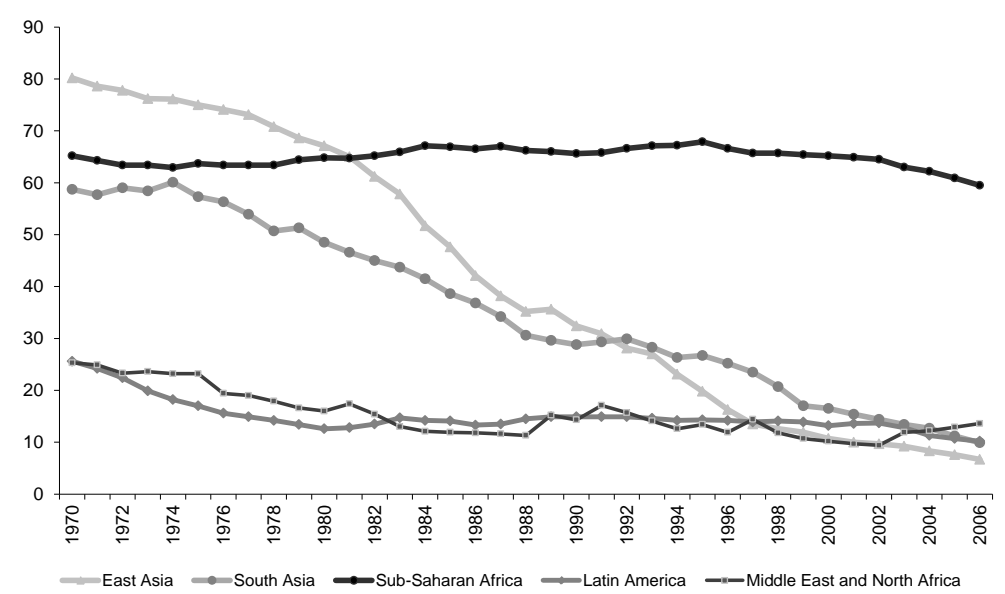

Source: Pinkovskiy and Sala-i-Martin (2009).

Note: poverty line $\$ 2$ a day.

Regions have been different in terms of the growth-inequality-poverty triangle (Table 6.5). The growth effect was strong in Asia dwarfing a much smaller (and sometimes poverty-increasing) redistribution effect. The increase in poverty in ECA in the 1990s is associated with both negative growth and inequality rise, while the fall in poverty in the following decade is mostly accounted by neutral positive growth. In Latin America growth contributed in both decades, but only in the 2000s did the redistribution effect become poverty-reducing. Finally, in Africa (MENA and SSA) the growth effect in the 2000 s was the major contributing factor to the fall in poverty.

\section{Table 6.5}

Decomposition of poverty changes Developing countries

\begin{tabular}{llcc}
\hline \hline & Actual & \multicolumn{2}{c}{ Effects } \\
\cline { 3 - 4 } & change & Growth & Redistribution \\
\hline EAP & & & \\
$1990-1999$ & -10.5 & -10.7 & 0.2 \\
$1999-2010$ & -19.4 & -19.2 & -0.2 \\
$1990-2010$ & -30.0 & -30.3 & 0.3 \\
\hline ECA & & & \\
$1990-1999$ & 8.6 & 6.1 & 2.5 \\
$1999-2010$ & -11.5 & -10.5 & -1.0 \\
$1990-2010$ & -2.9 & -3.9 & 1.0 \\
\hline LAC & & & \\
$1990-1999$ & -3.2 & -5.3 & 2.1 \\
$1999-2010$ & -7.9 & -5.3 & -2.6 \\
$1990-2010$ & -11.1 & -10.2 & -0.9 \\
\hline
\end{tabular}

\begin{tabular}{lccc}
\hline \hline & Actual & \multicolumn{2}{c}{ Effects } \\
\cline { 3 - 4 } & change & Growth & Redistribution \\
\hline MENA & & & \\
$1990-1999$ & -1.5 & -0.6 & -1.0 \\
$1999-2010$ & -10.1 & -8.0 & -2.1 \\
$1990-2010$ & -11.6 & -8.4 & -3.3 \\
\hline SA & & & \\
$1990-1999$ & -9.0 & -10.9 & 2.0 \\
$1999-2010$ & -13.2 & -12.0 & -1.1 \\
$1990-2010$ & -22.1 & -23.3 & 1.2 \\
\hline SSA & & & \\
$1990-1999$ & -1.8 & -1.4 & -0.4 \\
$1999-2010$ & -5.9 & -6.0 & 0.0 \\
$1990-2010$ & -7.7 & -7.8 & 0.0 \\
\hline
\end{tabular}

Source: own calculations based on data from PovcalNet.

Note: the columns show unweighted means across a sample of 76 developing countries of the change in the poverty headcount ratio ( $\$ 2$ line), and the growth and redistribution effects from the poverty change decomposition. 
In the rest of this section we take a closer look at the changes in poverty reported by the literature in each geographic region of the developing world.

\section{East Asia and Pacific}

As mentioned above, East Asia and Pacific has achieved an impressive record in terms of poverty reduction. The fall in the indicators of material deprivation has been strong, sustained over the two last decades and widespread across countries. ${ }^{97}$ The poverty headcount ratio with the \$2 line fell from $92.4 \%$ in 1981 to $81 \%$ in $1990,61.7 \%$ in 1999 and $29.7 \%$ in $2010 .^{98}$

China's progress against absolute poverty was a key factor behind this dynamics (World Bank, 2009; Ravallion and Chen, 2007; Minoiu and Reddy, 2008). Rural areas accounted for the bulk of the gains to the poor, although migration to urban areas helped; rural economic growth was far more important to national poverty reduction than urban economic growth; agriculture played a far more important role than the secondary or tertiary sources of GDP, mainly from the efficiency gains after the decollectivization of agriculture. Ravallion and Chen (2007) claim that, though they cannot offer a rigorous test against alternative explanations, "the halving of the national poverty rate in the first few years of the 1980s was largely attributable to picking these blow-lying fruits of agrarian reform". Provinces starting with relatively high inequality saw slower progress against poverty, due both to lower growth and a lower growth elasticity of poverty reduction. While in 1990 the incidence of poverty in China was roughly 25 points higher than in the rest of the developing world, by the end of the 2000s, it had fallen more than 10 points below the average. ${ }^{99}$

Between 1990 and 2010 the headcount ratio fell from $60 \%$ to $12 \%$ in China $(\$ 1.25$ line), and from $54 \%$ to $18 \%$ in Indonesia, the two most populated countries in the region. The rest of the economies experienced similar patterns. The headcount ratio dropped from $58 \%$ to $15 \%$ in Cambodia, from $12 \%$ to $0.4 \%$ in Thailand, and from $73 \%$ to $14 \%$ in Vietnam.

The reductions were less spectacular, but anyway significant in the Pacific countries (Micronesia, Philippines, Papua New Guinea, Timor-Leste). According to Asian Development Bank (2012) using the national poverty lines, poverty declined in all economies except Mongolia, Micronesia, Samoa, Timor-Leste, Tonga and Tuvalu. With

\footnotetext{
${ }^{97}$ See Ahuja et al. (1997) and Nissanke and Thorbecke (2010) as examples of a vast literature.

98 According to World Bank (2012), poverty in East Asia and Pacific "will continue to decline, and the share of people living on \$2/day will reach 24.5 per cent by the end of 2013."

${ }^{99}$ During the early and mid-1990s poverty declined substantially, but then in the late 1990s to the early 2000s the downward trend stalled. Li et al. (2013) argue that further reductions in poverty became more challenging due to several factors, for example, the fact that a high proportion of the remaining poverty was geographically dispersed and transient, and also because poverty had become less responsive to macroeconomic growth (World Bank, 2009). Policies adopted after 2002, such as the minimum living guarantee program, the new rural cooperative medical system, and the new rural pension system, have addressed some of these factors.
} 
respect to the poverty reduction target of the Millennium Development Goals, of the ten economies for which data are available, 6 have achieved the poverty target, and Cambodia is very close to reaching it by 2015. Lao PDR, Philippines, and Timor-Leste are progressing more slowly toward that goal.

\section{Eastern Europe and Central Asia}

The evidence clearly suggests that poverty in Eastern Europe and Central Asia increased during the 1990s and decreased during the 2000s. The collapse of output in many of these countries following the dismantling of the Soviet Union, along with hyperinflation that wiped out savings, resulted in a dramatic drop in living standards for the majority of people and the emergence of poverty as a major issue. However, according to Simai (2006) poverty in the region was not a new phenomenon: most of the countries began their transformation with extensive hidden unemployment and at least one-tenth of its population below the subsistence level. The transition also involved setbacks in non-monetary dimensions of wellbeing. Past achievements in social welfare came under pressure, the most striking being the reduction in life expectancy: in 1995, life expectancy for males in the Russian Federation was just 58 years, 10 years less than that of men in China (UN, 2004).

Table 6.4 reminds the reader that poverty rates in these countries have always been much lower than in the other developing regions, irrespective of the line considered and of the weighted or unweighted averages, and despite the fact that low-income CIS (Georgia, Uzbekistan, Moldova, Armenia, Kygryz Republic, Tajikistan) display figures well above the regional mean. When growth resumed after the Russian crisis in 1998, poverty started to fall. ${ }^{100}$ It was not until 2004 that the region as a whole returned to the level of GDP recorded in 1990 (World Bank, 2005). Much of the poverty reduction initially occurred in the populous middle-income countries (Kazakhstan, Russian Federation, Ukraine), but eventually it spread almost everywhere. Scholars have identified four main explanations for the poverty dynamics: (i) the positive growth in output and wages; (ii) the decline in inequality, with incomes of poorer households increasing faster than average in some countries (CIS) but not in others (Poland, Romania); (iii) the increasing role of public transfers, with benefits improving in coverage and adequacy; and (iv) private remittances, which in many cases far exceeded public funding.

\section{Latin America and the Caribbean}

Poverty estimates in Latin America, available since the 1970s, were always mostly based on income, not consumption. ${ }^{101}$ Despite the fact that statistics were initially

\footnotetext{
${ }^{100}$ For an analysis of the growth elasticities of poverty reduction, see World Bank (2005), chapter 2.

101 In the Caribbean poverty is estimated based on consumption expenditures, but surveys are still scarce, so poverty changes are difficult to monitor.
} 
weak, there is agreement among researchers that during the 1970s economic growth pushed poverty down in the region (Altimir, 1979, 1996). In contrast, the "lost decade" of the 1980s was characterized by recurrent crises and output stagnation, that brought about a weak social performance. Latin American economic growth resumed in the 1990s, but in the context of growing inequalities, a combination that resulted in a modest decline in poverty (Londoño and Székely, 2000). The exceptional economic conditions in the 2000s and the consolidation of more ambitious social policies implied a sharp drop in poverty indicators in that decade. Gasparini et al. (2013) estimate that the income poverty headcount ratio ( $\$ 2.5$ line) fell from $36 \%$ in the early 1970 s to $27.3 \%$ in 1980 , slowly increased to reach $27.8 \%$ in 1992 , mildly decreased to $24.9 \%$ in 2003 , and was reduced dramatically to $16.3 \%$ by $2009 .{ }^{102}$ The number of poor people in the region is estimated to have fallen from 119 million in 1992 to 89 million in 2009 (Gasparini et al., 2013). Other indicators of income poverty and of various types of material deprivation are consistent with these results. Data from SEDLAC confirms that the reduction in poverty continued in the period 2009-2013, despite a deceleration in the GDP growth rates. The improvements in social indicators in the 2000s have been linked to at least two factors: on the one hand, most of the region's economies experienced robust growth together with upswings in employment and labor income; on the other, all countries boosted social spending and put ambitious social protection systems into place or expanded the scope of their existing systems (López Calva and Lustig, 2010; Cruces and Gasparini, 2012).

The performance in terms of poverty reduction has been heterogeneous across the regions in Latin America. While Central America experienced a slow decline in income deprivation over the last two decades, in the rest of the regions the rapid poverty fall of the 2000s contrasts with the sluggish or even negative performance of the 1990s. SEDLAC data indicate that using the international poverty line of $\$ 2.5$, the average (unweighted) poverty rate in Southern South America increased from $17.7 \%$ in 1992 to $18.5 \%$ in 2003 , and then dropped to $9.1 \%$ by 2010 . In the same period the average poverty rate in the Andean region first rose from $30.2 \%$ to $33 \%$, and then declined to 17.5\%. In contrast, poverty in Central America fell more uniformly over the two decades: $33.3 \%$ in 1992, 28.6\% in 2003 and $23.1 \%$ in 2010.

More than half of the population in Latin America lives in Brazil or Mexico. After a decline in the early 1990s, income poverty in Brazil remained stable for about a decade: the poverty incidence rate with the $\$ 2.5$ line was $27.8 \%$ in 1995 and $27.1 \%$ in 2003. After that plateau, the country experienced a fast and sustained reduction in income poverty, reaching $13.9 \%$ in 2010 . The Mexican economy was hit by a serious crisis in the mid-1990s (the so-called Tequila crisis) that raised income poverty from $17.8 \%$ in 1992 to $43.4 \%$ in 1995 (SEDLAC data, \$2.5 line). From that peak, income poverty initiated a consistent decline to reach a value of $12 \%$ in 2006 , with no gains in the second half of the 2000s.

\footnotetext{
102 Estimates are based on SEDLAC statistics, Londoño and Székely (2000), Wodon et al. (2001) and official poverty estimates from all countries in Latin America.
} 


\section{Middle East and North Africa}

As discussed in section 4 it is useful to divide the last four decades in MENA into three periods. The first one, spanning until the mid-1980s, was characterized by strong economic growth: the average per capita income growth for the region between 1975 and 1984 was over $4.5 \%$. Adams and Page (2003) argue that given MENA's relatively equal income distribution, this economic growth had a powerful impact on reducing poverty in the region. However, assessing that progress is difficult since pre-1985 household surveys are only available for Tunisia and Egypt. Iqbal (2006) reports that in Tunisia poverty fell from 51\% in 1965 to $16 \%$ in 1985, while Egypt's achievement was also impressive, with poverty declining from 82\% to 53\% between 1975 and 1985. Page (2007) estimates a fall in the incidence of poverty ( $\$ 2$ line) in the region from $57 \%$ in the late 1970 s to $22 \%$ in the early 1990 s.

The second period, covering the late 1980s and most of the 1990s, was characterized by a sluggish economic performance, in part due to low prices for hydrocarbons, declining remittances and aid flows, as well as a low payoff to the reforms that were implemented. On average for the developing MENA countries, real per capita incomes went up by less than $1.5 \%$ per year. The proportion of those living with less than $\$ 2$ per day stayed roughly unchanged around 22\% for a decade (PovcalNet). Iqbal (2006) reports that "by 2001, approximately 52 million people were poor, an increase in absolute numbers of approximately 11.5 million people, compared with the situation in 1987". The 1990s were a lost decade for economic growth and poverty reduction in the developing economies of the MENA region (Page, 2007).

The downward pattern in poverty appeared to have resumed in the 2000s. The incidence of poverty ( $\$ 2$ line) fell from $22 \%$ in 1999 to $12 \%$ in 2010 . According to PovcalNet data the number of people living with less than $\$ 2$ a day increased by 7 million in the 1990s, and then was reduced by 20 million in the 2000s (from 60 to 40 million). While in the 1990s poverty went down in a third of the MENA countries, in the 2000s it went down in all economies, with the possible exception of Yemen.

\section{South Asia}

South Asia achieved impressive economic growth in the past fifteen years. Since 1996 until the recent global crisis, GDP growth in the region exceeded 5 percent per year. As a consequence, poverty rates were considerably reduced. In Bangladesh, India and Nepal, absolute poverty (headcount ratio, $\$ 1.25$ line) fell by 18,15 and 43 percentage points, respectively, between 1996 and 2010. In Pakistan, it fell by 22 percentage points between 2002 and 2010 (yet, one in 10 children still dies before his fifth birthday and only 57 percent of children complete primary school). Devarajan and Nabi (2006) optimistically expected the region to have single-digit poverty rates in 2015 if growth rates accelerated to 10 percent per year. This has indeed happened already in Sri Lanka (where poverty dropped from 17\% in 1996 to $4 \%$ in 2010) as well as in 
Maldives (where, according to the 2006 census, about 1 per cent of the population was living on less than $\$ 1$ a day).

Growth has been instrumental in reducing poverty rates, but, as Ghani (2010) pointed out from a gloomier perspective, poverty rates were not falling fast enough to reduce the total number of poor people. Those living on less than \$1.25 a day increased from 549 million in 1981 to 595 million in 2005. In India, where around three-quarters of these poor live, the number increased from 420 million in 1981 to 455 million in 2005 (Ravallion et al. 2009). The situation seems to have slightly improved according to the most recent observations, but the question remains: why has India not performed as well as China in this dimension? One explanation may be related to the already mentioned Indian paradox: survey-based households' income growth has been much lower than National Accounts-based GDP growth.

\section{Sub-Saharan Africa}

The economic and social performance of Sub-Saharan African countries has been frustrating. Five decades after most nations gained independence, poverty is still at very high levels in SSA, in fact the highest in the world. Fortunately, it seems that finally, after years of impoverished economic performance, the last decade shows some signs of improvement. Based on figures from PovcalNet, the incidence of poverty increased between 1981 and 1999 from 51\% to 58\% for the \$1.25 per day line, and from $72 \%$ to $77 \%$ for the $\$ 2$ line (the unweighted statistics are not very different). ${ }^{103}$ Because of the increase in population the number of people living with less than $\$ 1.25$ a day almost doubled in Sub-Saharan Africa during those years, from 205 million to 377 million. These results are even more disappointing when compared to the rest of the developing world. The share of the world's poor living in Sub-Saharan Africa rose from $11 \%$ in 1981 to $22 \%$ in 1999. Artadi and Sala-i-Martin (2003) find that the SSA poverty rate was stable in the 1970 s, around a value of $49 \%$, and soared in the 1980 s and early 1990s reaching $60 \%$ in 1995 , following the deterioration of the aggregate per capita income of Sub-Saharan economies. They report a nearly $50 \%$ reduction in the worldwide poverty rate between 1980 and 2000, that contrast with a $27 \%$ increase in SSA.

Following the dismal performance of the 1980s and early 1990s, SSA witnesses some economic and social progress. Poverty declined considerably from their heights of the mid-1990s; in fact the reduction in extreme poverty from that date to the late 2000s was similar than in the rest of the developing world, excluding China. Chen and Ravallion (2012) stressed the fact that for the first time since 1981 the share of people in Sub-Saharan Africa living below $\$ 1.25$ a day was less than $50 \%$. Changes in poverty have been closely linked to economic growth. According to Fosu (2010), poverty has declined in SSA by about 0.5 percentage points per year since the mid-1990s, quite

\footnotetext{
${ }^{103}$ According to the $\$ 4$ line, more than 90 per cent of the SSA population is actually considered poor.
} 
comparable with South Asia's record. Sala-i-Martin and Pinkovskiy (2010) estimate that African poverty has been falling steadily since 1995. According to these authors the African poverty rate in 2006 was 31.8\%, 30 per cent lower than in 1995, and 28 per cent lower than in 1990 . The decline in poverty in the 2000s has been quite extended: as reported above, 2/3 of the SSA countries in PovcalNet have experienced reductions larger than 5\%. Sala-i-Martin and Pinkovskiy (2010) find that "poverty fell for both landlocked as well as coastal countries; for mineral-rich as well as mineral-poor countries; for countries with favorable or with unfavorable agriculture; for countries regardless of colonial origin; and for countries with below or above median slave exports per capita during the African slave trade. Hence, the substantial decline in poverty is not driven by any particular country or set of countries". However, Fosu (2009) highlights the considerable heterogeneity across country experiences. For example, while high economic growth in Botswana has been transformed to only a minimal decline in poverty, Ghana has succeeded in translating its relatively modest growth to considerable poverty reduction. Fosu (2009) attributes this contrast to the difference in the levels of income inequality between the two countries.

Despite the encouraging signs of progress in the fight against poverty in Sub-Saharan Africa, Chen and Ravallion (2012) alert that the lags in survey data availability and problems of comparability and coverage, rise up concerns about how robust this positive trend will prove to be.

\subsection{Poverty convergence}

Given the heterogeneity among economies in terms of social improvement, a natural question is whether countries starting out with a high incidence of material deprivation tend to be the ones with higher rates of poverty reduction. Figure 6.4 suggests some signs of poverty convergence in absolute terms but not in proportionate terms. ${ }^{104}$ The 1981 poverty level (\$2 line) is negatively correlated with the annualized change over the period 1981-2010, but not with the proportionate change (annualized log difference). In the first panel the regression line has a slope of -0.009 with a $t$-ratio of -4.51 , based on a robust (White) standard error. This result means that on average the absolute fall in poverty has been larger in countries with higher poverty incidence, but since the difference across countries is small, there is absence of poverty convergence in proportionate terms.

\footnotetext{
${ }^{104}$ The analysis is restricted to countries with initial poverty above $5 \%$.
} 


\section{Figure 6.4}

\section{Poverty convergence among developing countries}

\section{1-2010}

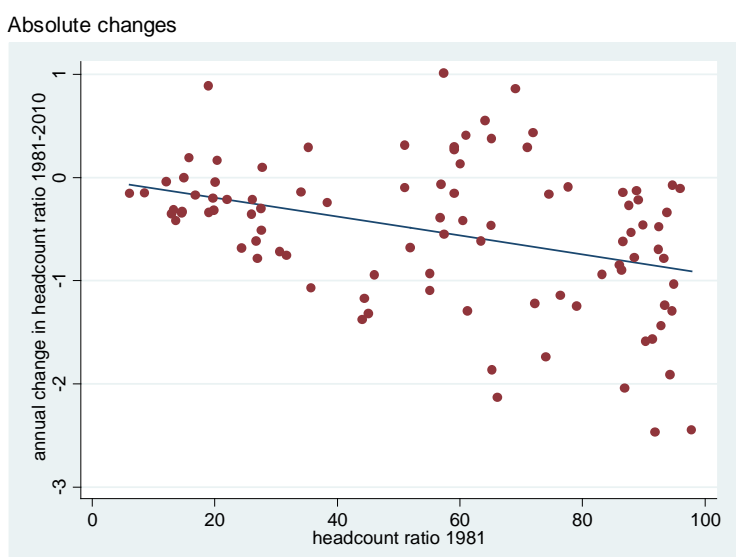

Proportionate changes

Source: own calculations based on PovcalNet (2013).

Note: poverty computed over the distribution of consumption/income per capita with the PPP-adjusted \$2-a-day per person line.

The results for other poverty indices, lines and time periods are similar (Table 6.6). The coefficients for the absolute change in poverty are negative but small, while the coefficients for the proportionate change are in general positive, but in most cases non-significant. ${ }^{105}$

Table 6.6

Poverty convergence among developing countries Coefficients of initial poverty on a poverty change regression

\begin{tabular}{|c|c|c|c|c|c|c|c|}
\hline \multirow[b]{2}{*}{ Index } & \multirow[b]{2}{*}{ Poverty line } & \multicolumn{2}{|c|}{$1981-2010$} & \multicolumn{2}{|c|}{$1990-2010$} & \multicolumn{2}{|c|}{ 1999-2010 } \\
\hline & & $\begin{array}{l}\text { Absolute } \\
\text { changes }\end{array}$ & $\begin{array}{c}\text { Proportionate } \\
\text { changes }\end{array}$ & $\begin{array}{l}\text { Absolute } \\
\text { changes }\end{array}$ & $\begin{array}{c}\text { Proportionate } \\
\text { changes }\end{array}$ & $\begin{array}{l}\text { Absolute } \\
\text { changes }\end{array}$ & $\begin{array}{c}\text { Proportionate } \\
\text { changes }\end{array}$ \\
\hline \multirow[t]{2}{*}{ Headcount } & $\$ 1.25$ & -0.017 & 0.001 & -0.018 & 0.010 & -0.016 & 0.023 \\
\hline & & $(0.002)^{\star \star \star}$ & $(0.004)$ & $(0.003)^{\star \star \star}$ & $(0.004)^{\star}$ & $(0.004)^{\star \star \star}$ & $(0.006)^{\star \star \star}$ \\
\hline \multirow[t]{2}{*}{ Headcount } & $\$ 2$ & -0.009 & 0.006 & -0.008 & 0.016 & -0.008 & 0.028 \\
\hline & & $(0.002)^{\star \star \star}$ & $(0.004)$ & $(0.002)^{\star \star \star}$ & $(0.004)^{\star \star}$ & $(0.004)^{\star \star}$ & $(0.007)^{\star \star \star}$ \\
\hline \multirow[t]{2}{*}{ Poverty gap } & $\$ 1.25$ & -0.021 & -0.007 & -0.026 & -0.001 & -0.024 & 0.014 \\
\hline & & $(0.002)^{\star \star \star}$ & $(0.004)$ & $(0.003)^{\star \star \star}$ & $(0.005)$ & $(0.005)^{\star \star \star}$ & $(0.007)^{\star \star}$ \\
\hline \multirow[t]{2}{*}{ Poverty gap } & $\$ 2$ & -0.016 & 0.001 & -0.018 & 0.010 & -0.016 & 0.024 \\
\hline & & $(0.002)^{\star \star \star}$ & $(0.004)$ & $(0.003)^{\star \star \star}$ & $(0.005)^{\star}$ & $(0.004)^{\star \star \star}$ & $(0.008)^{\star \star \star}$ \\
\hline \multirow[t]{2}{*}{ Squared poverty gap } & $\$ 1.25$ & -0.024 & -0.013 & -0.032 & -0.008 & -0.030 & 0.006 \\
\hline & & $(0.002)^{\star \star \star}$ & $(0.004)^{\star \star}$ & $(0.004)^{\star \star \star}$ & $(0.006)$ & $(0.007)^{\star \star \star}$ & $(0.006)$ \\
\hline \multirow[t]{2}{*}{ Squared poverty gap } & $\$ 2$ & -0.020 & -0.005 & -0.024 & 0.002 & -0.022 & 0.014 \\
\hline & & $(0.002)^{\star \star \star}$ & $(0.004)$ & $(0.003)^{\star \star \star}$ & $(0.004)$ & $(0.005)^{\star \star \star}$ & $(0.005)^{\star \star \star}$ \\
\hline
\end{tabular}

Source: own calculations based on PovcalNet (2013).

Note: standard errors in parenthesis.

${ }^{*}=$ significant at $10 \%, * *=$ significant at $5 \%, * * *=$ significant at $1 \%$.

105 The first panel in Figure 6.4 suggests an increase in the dispersion of absolute changes at higher values of the initial poverty level. A quantile regression analysis confirms that the slope of the regression line is negative and significant for the lower quantiles (the high-performers in terms of poverty reduction), and statistically non-significant for the higher quantiles. The systematic difference in the slopes across quantiles suggests that poverty convergence depends on factors beyond the initial poverty level. 
Ravallion (2012) argues that the lack of poverty convergence (in proportionate terms), despite evidence for mean convergence and for the poverty-reduction impact of growth, suggests that the dynamic processes for growth and poverty reduction depend directly on the initial level of poverty. He shows evidence on two adverse effects of being a country with high poverty levels: first, these countries tend to grow at a slower pace, controlling for the initial mean, and second a high poverty rate implies lower "productivity" of economic growth in terms of poverty reduction (lower povertygrowth elasticity).

\subsection{Poverty and growth}

The dynamics of poverty are closely related to income growth. The economic literature has gathered abundant evidence supporting the fact that absolute poverty tends to fall with economic growth. ${ }^{106}$ Moreover, the longer the growth spells under consideration, the larger the share of the variance in poverty that is accounted for by the growth component (Ferreira, 2010). Figure 6.5 illustrates this relationship by showing poverty along with two alternatives measures of mean income: per capita gross national income (GNI) constructed from National Accounts, and per capita consumption obtained from household surveys. The figure shows the unweighted mean of these variables among developing countries in the period 1981-2010. On average, the economic performance of the developing countries was weak in the 1980s and early 1990s, hindering the perspectives of poverty reduction. Since the mid-1990s economic growth resumed in most countries in the developing world, a process that accelerated in the 2000s, leading to a sustained decrease in all measures of income poverty. At the end of the decade that pattern was slowed down, but not halted, by the poor economic performance of several developing countries associated to the international crisis.

\footnotetext{
106 See Chen and Ravallion (1997), World Bank (2000), Ravallion (2001, 2007, 2012), Fields (2002), Bourguignon (2003), Besley and Burguess (2003), Kraay (2006), Fosu (2011) as examples of a large literature.
} 


\section{Figure 6.5}

\section{Per capita GNI, per capita consumption and poverty headcount ratio}

Unweighted mean, developing countries, 1981-2010

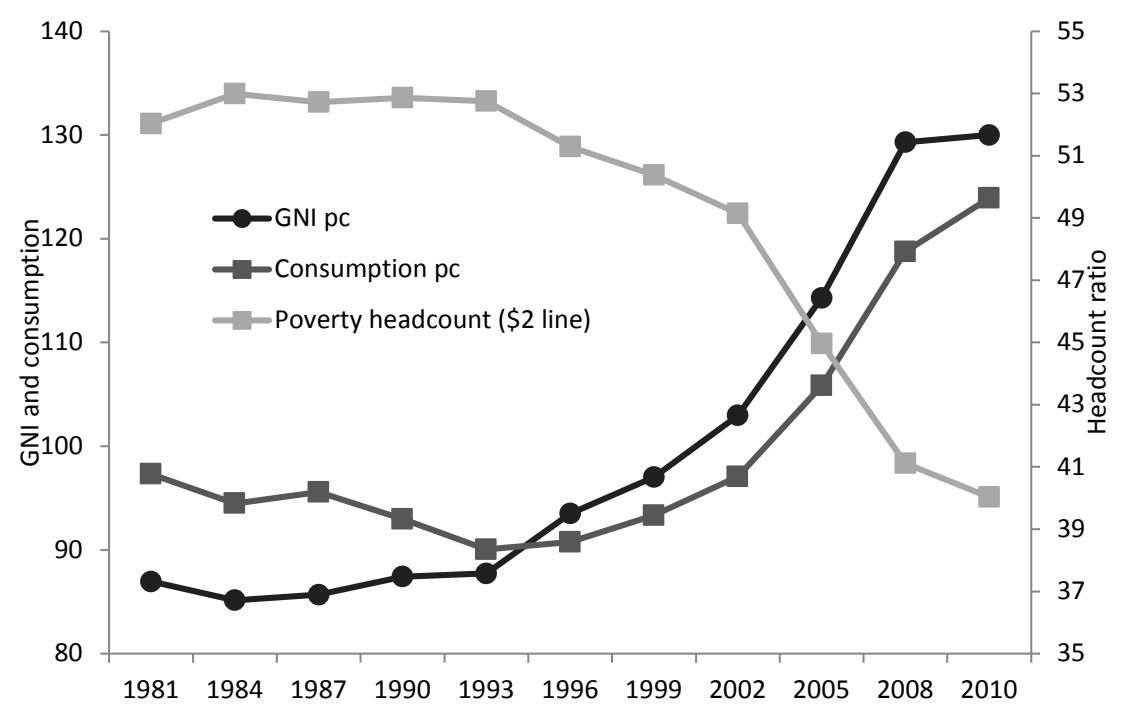

Source: own calculations based on PovcalNet (2013).

Note: per capita gross national income in constant 2005 PPP dollars, per capita consumption from household surveys in constant 2005 dollars. Unweighted averages across developing countries, series displayed with mean=100. Headcount poverty ratio \$2-a-day line, unweighted averages across developing countries.

Figure 6.6 is another illustration of the relationship between poverty reduction and economic growth. The figure shows that the change in poverty is closely negatively related to economic growth, either in per capita consumption expenditures drawn from household surveys or in GNI from NAS. Notice that in both panels the fitted line approximately crosses the $(0,0)$ point.

\section{Figure 6.6}

\section{Growth and poverty reduction in the developing countries, 1981-2010}

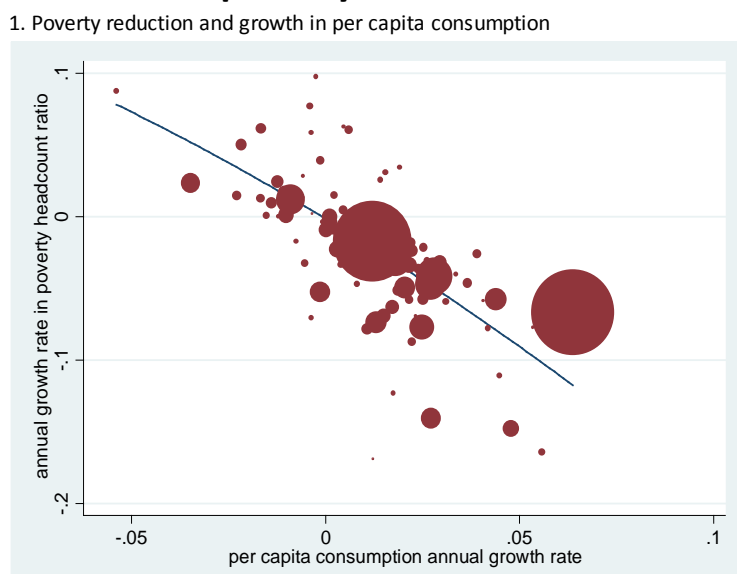

2. Poverty reduction and growth in per capita GNI

Source: own calculations based on PovcalNet (2013).

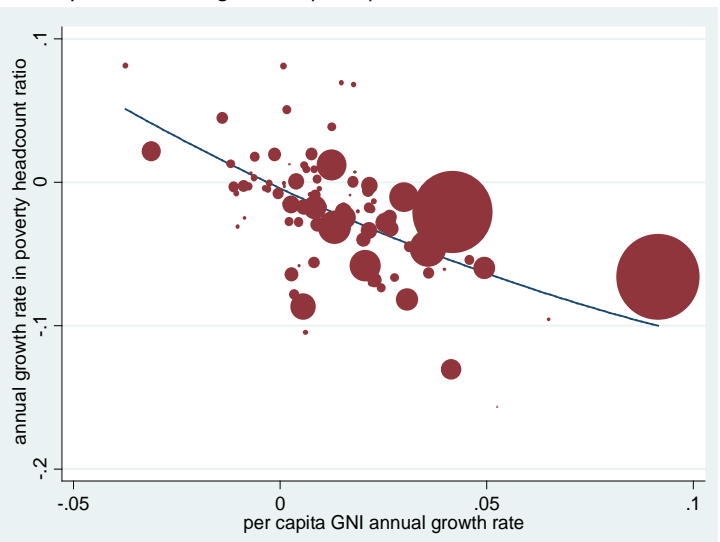

Note: the horizontal axis shows the annual growth rate between 1981 and 2010 in per capita consumption from household surveys in constant 2005 dollars (panel 1) and in per capita gross national income in constant 2005 PPP dollars (panel 2); the vertical axis shows the annual growth change in the poverty headcount ratio ( $\$ 1.25$ line) in the same period. The size of each circle is proportional to the country population in 2010. 
Since the positive correlation between poverty reduction and growth is a wellestablished result, research in this area is mainly focused on estimating the magnitude of the corresponding elasticity, an issue that may have relevant policy implications. "If (the elasticity) is reasonably high, then poverty reduction strategies almost exclusively relying on economic growth are probably justified. If it is low, however, ambitious poverty reduction strategies might have to combine both economic growth and some redistribution" (Bourguignon, 2003). The growth elasticity of poverty reduction is typically estimated by regressing the annualized proportional change in a poverty indicator against the annualized growth rate of mean income (per capita income or consumption from surveys, or per capita GDP, GNI, or aggregate private consumption from NAS) in a sample of growth spells. In a regression without controls the resulting coefficient is the total elasticity, as opposed to a partial elasticity that can be obtained by holding inequality and other factors constant.

Based on a dataset for 67 countries over the period from 1981 to 1994, and using the \$1 line, Ravallion and Chen (1997) find a central estimate for the poverty-growth elasticity of -3.1. Values estimated by other authors are somewhat lower (in absolute terms): around -2 in World Bank (2000), -1.6 in Bourguignon (2003), -2.6 in Adams (2004), and -1.8 in Ferreira and Ravallion (2009). More recently, Ravallion (2012) reports an elasticity of -1.4 for the $\$ 1.25$ line. The elasticity is lower when using the growth rate of consumption per capita from NAS (-0.8), and also lower when using a higher poverty line. The confidence intervals around the regression coefficient are typically wide. Ravallion (2007) reports that the 95\% confidence interval implies that for a poverty level of $40 \%$, an annual growth rate of $2 \%$ is consistent with poverty reductions ranging from $1 \%$ to $7 \%$.

Estimates of the total growth elasticity of poverty reduction over the period 1981-2010 obtained with the latest version of PovcalNet data are shown in Table 6.7. ${ }^{107}$ All the elasticities are negative and significant at $1 \%$. The growth elasticity of poverty reduction, as measured by the proportion of individuals below $\$ 1.25$ a day, is around 1.5. The results in Table 6.7 confirm that elasticities are lower in absolute value when considering a higher poverty line. The result of lower elasticities using GNI from National Accounts holds but only until the 2000s, suggesting a change in the relative trends between consumption reported in household surveys and output estimated in NAS. In general, the absolute value of the elasticities estimated with both sources have increased in the 2000s compared to previous decades, suggesting that growth was better translated to the poor in that period of falling inequality. For instance, while the elasticity, using the $\$ 1.25$ line and consumption per capita, was -1.53 for the period 1981-2010, it amounted to -1.83 when restricting the analysis to the 2000 s.

\footnotetext{
107 The sample includes 725 spells in 76 countries for which consistent information for the whole period is available. Results do not significantly vary when we restrict the analysis to more recent periods which allows a larger sample of countries.
} 
Table 6.7

Total poverty-growth elasticities

Developing countries

\begin{tabular}{|c|c|c|c|c|c|c|c|}
\hline \multirow{2}{*}{ Index } & \multirow{2}{*}{ Poverty line } & \multicolumn{3}{|c|}{ Consumption per capita } & \multicolumn{3}{|c|}{ GNI per capita } \\
\hline & & $1981-2010$ & $1990-2010$ & $1999-2010$ & $1981-2010$ & $1990-2010$ & $1999-2010$ \\
\hline \multirow{3}{*}{ Headcount } & 1.25 & -1.53 & -1.56 & -1.83 & -1.46 & -1.51 & -2.16 \\
\hline & 2 & -1.39 & -1.41 & -1.68 & -1.17 & -1.19 & -1.91 \\
\hline & 4 & -1.30 & -1.38 & -1.10 & -0.78 & -0.81 & -1.21 \\
\hline \multirow{3}{*}{ Poverty gap } & 1.25 & -1.75 & -1.77 & -1.87 & -1.44 & -1.47 & -2.09 \\
\hline & 2 & -1.50 & -1.47 & -1.85 & -1.35 & -1.30 & -1.83 \\
\hline & 4 & -1.41 & -1.47 & -1.39 & -0.95 & -0.98 & -1.54 \\
\hline \multirow{3}{*}{ Squared PG } & 1.25 & -2.18 & -2.25 & -1.87 & -1.50 & -1.52 & -1.87 \\
\hline & 2 & -1.60 & -1.52 & -1.86 & -1.44 & -1.29 & -1.91 \\
\hline & 4 & -1.40 & -1.43 & -1.54 & -1.04 & -1.04 & -1.71 \\
\hline
\end{tabular}

Source: own calculations based on PovcalNet (2013).

Note: all elasticities are significant at $1 \%$ level.

So far, we have reported total elasticities, which can be seen as summary measures of the co-movements of poverty and growth. The literature has tried to improve this characterization by adding other variables into the analysis, typically measures of inequality and development. The empirical evidence supports the intuition that higher inequality tends to reduce the absolute value of the elasticity, by shifting the gains from growth away from the poor (Ravallion, 1997, 2001; Kraay, 2006). ${ }^{108}$ For example, based on a sample of 65 countries during 1981-2005, and using the \$1 poverty line, World Bank (2005) reports that the poverty-growth elasticity is highest among lowinequality countries (with a value of approximately -4.0 for countries with Ginis in the mid-20s) and lowest among high-inequality countries (close to -1.0 for countries with a Gini coefficient around 60). The change in inequality is also found as a significant direct determinant of the elasticity. For instance, Ravallion (2001) finds that the median rate of reduction in the poverty headcount ratio ( $\$ 1$ line) among growing economies was $10 \%$ per year among countries with falling inequality, and $1 \%$ per year for those countries with rising inequality.

Using a sample of 114 growth spells from the mid-1980s to the mid-1990s in 26 developing countries Bourguignon (2003) finds an elasticity of -1.6 in the model without controls and -2 when controlling for the change in the Gini. The latter specification increases the $\mathrm{R}^{2}$ from 0.266 to 0.419 , suggesting that the heterogeneity in distributional changes is as much responsible for the variation in poverty changes across growth spells as the heterogeneity in the speed of growth. Bourguignon (2003) also finds positive and significant coefficients for the interaction terms between the growth rate and both (i) the initial level of inequality, and (ii) the level of development (proxied by the poverty line over mean income). He also reports negative coefficients for the interaction terms between the change in the Gini and those two variables. The

\footnotetext{
${ }^{108}$ Although the intuition is compelling, the result is theoretically ambiguous. See Ravallion (2007) for a proof, and Bourguignon (2003) for a case in which assuming log-normality yields an unambiguous result.
} 
first four columns in Table 6.8 in general confirm the results in Bourguignon (2003), using a larger dataset spanning three decades. ${ }^{109}$

\section{Table 6.8}

Regressions for annualized proportional change in the poverty headcount ratio Developing countries, 1981-2010

\begin{tabular}{|c|c|c|c|c|c|c|}
\hline & \multirow{3}{*}{$\begin{array}{c}\text { Unconditional } \\
\text { (1) }\end{array}$} & \multicolumn{5}{|c|}{ Conditional on } \\
\hline & & \multicolumn{3}{|c|}{ Inequality and development } & \multicolumn{2}{|c|}{ Poverty } \\
\hline & & (2) & (3) & (4) & (5) & (6) \\
\hline \multirow[t]{2}{*}{$g=$ growth rate in per capita consumption } & -1.391 & -1.467 & -2.879 & -2.910 & -2.111 & -2.073 \\
\hline & $(0.147)^{* * *}$ & $(0.144)^{* * *}$ & $(0.570)^{* * *}$ & $(0.590)^{* * *}$ & $(0.206)^{* * *}$ & $(0.188)^{* * *}$ \\
\hline \multirow[t]{2}{*}{ dGini = change in Gini coefficient } & & 1.488 & 1.566 & 3.195 & & \\
\hline & & $(0.265)^{* * *}$ & $(0.279)^{* * *}$ & $(1.206)^{* * *}$ & & \\
\hline \multirow[t]{2}{*}{$\mathrm{g} *$ initial Gini coeficient } & & & 0.022 & 0.023 & & \\
\hline & & & $(0.013)^{*}$ & $(0.014)^{*}$ & & \\
\hline \multirow[t]{2}{*}{ g*(poverty line/mean consumption) } & & & 0.903 & 0.879 & & \\
\hline & & & $(0.094)^{* * *}$ & $(0.101)^{* * *}$ & & \\
\hline \multirow[t]{2}{*}{ dGini* initial Gini coefficient } & & & & -0.019 & & \\
\hline & & & & $(0.027)$ & & \\
\hline \multirow[t]{2}{*}{ dGini * (poverty line/mean consumption) } & & & & -1.666 & & \\
\hline & & & & $(0.345)^{* * *}$ & & \\
\hline \multirow[t]{2}{*}{$\mathrm{g} *$ initial poverty rate } & & & & & 0.021 & 0.021 \\
\hline & & & & & $(0.003)^{* * *}$ & $(0.003)^{* * *}$ \\
\hline \multirow[t]{2}{*}{ log initial poverty rate } & & & & & & -1.559 \\
\hline & & & & & & $(0.927)^{*}$ \\
\hline \multirow[t]{2}{*}{ Intercept } & 0.150 & -0.008 & 0.187 & 0.064 & -0.255 & 4.108 \\
\hline & $(0.225)$ & $(0.203)$ & $(0.154)$ & $(0.208)$ & $(0.122)^{* *}$ & (2.655) \\
\hline Observations & 725 & 695 & 695 & 695 & 725 & 725 \\
\hline $\mathrm{R}^{2}$ & 0.414 & 0.502 & 0.583 & 0.610 & 0.508 & 0.516 \\
\hline
\end{tabular}

Source: own calculations based on PovcalNet (2013).

Note: sample of 76 countries with information for the period 1981-2010. Poverty indicator=headcount ratio, \$2-a-day line. Growth rates computed from per capita consumption in household surveys.

The results suggest the possibility of a double dividend from reducing inequality: first, given a growth rate, lower inequality is associated directly with less poverty, and second, less inequality means more poverty reaction to a given growth rate, that is an acceleration of poverty reduction for a given rate of economic growth. Ravallion (2007) illustrates the relevance of lower inequality for the perspectives of poverty reduction assuming a country with a poverty incidence rate of $40 \%$ and a growth rate of $2 \%$ per year: with an initial Gini coefficient of 30 it would take 11 years to reduce poverty by half, while with a Gini of 60 it would take 35 years.

In a more recent study Ravallion (2012) finds that the (absolute) growth elasticity of poverty reduction tends to be lower in countries with a higher initial poverty rate (see also the two last columns in Table 6.8). Ravallion (2012) finds a large attenuating effect of a higher initial poverty rate on the elasticity: at an initial poverty rate of $10 \%$ the elasticity is -2.2 , while it falls to -0.5 at a poverty rate of $80 \%$. The results are robust to

\footnotetext{
${ }^{109}$ Instead, unlike Bourguignon (2003) we fail to find a coefficient close to - 1 for the interaction between the growth rate and the theoretical value of the poverty-growth elasticity under the lognormal assumption.
} 
the inclusion of additional interaction effects with the initial Gini coefficient, the partial elasticity of poverty reduction holding the Lorenz curve constant, the primary school enrollment rate, life expectancy, the price of investment goods, and regional dummies.

Unfortunately, while the characterizations of the growth elasticity of poverty reduction discussed in this section are useful, the literature is still far from being able to clearly identify the structural factors that are behind the differences in the elasticities, and therefore is relatively silent about the specific policies that could foster a larger impact of economic growth on poverty.

\subsection{Relative poverty}

So far we have presented evidence on absolute poverty, an option that requires keeping the real value of the poverty line fixed over time. The alternative is relative poverty, where the line is adjusted to reflect changes in a general measure of economic well-being. Although the measurement of relative poverty has not been common in the developing world, sustained economic growth have triggered the update of absolute poverty lines in some countries (e.g. China and India), and foster discussions on relative poverty. The measurement of relative, instead of absolute, poverty, can be justified on two grounds (Sen, 1983; Chen and Ravallion, 2008). First, the very concept of poverty may depend on social norms that are likely different across countries and over the development process. Second, even for a fixed norm, an absolute line in the space of welfare may require a relative line in the space of consumption if individual welfare also depends on relative consumption with respect to the rest of the society where the person lives.

The typical relative poverty line is set as a constant proportion of the mean (or median) of the distribution, implying that poverty does not fall (increase) when all incomes grow (fall) at the same rate. This result is considered problematic by many authors who prefer weakly versions in which the cost of inclusion is not a constant proportion of mean income. For instance, following Atkinson and Bourguignon (2001), Ravallion and Chen (2012) propose a poverty line that is fixed up to a critical value of the mean, where it rises with elasticity less than one. In particular, Ravallion and Chen (2012) set the line for country $i$ at time $t$ as $z_{i t}=\max \left[\$ 1.25,\left(\$ 1.25+M_{i t}\right) / 2\right]$, where $M_{i t}$ is the country and date specific mean. Figure 6.7 reveals an overall trend decline in the incidence of weakly relative poverty in the developing world. The fall has been relatively meager, so that the number of poor by this measure actually increased from 2.3 billion in 1981 to 2.7 billion in 2008 . While the coefficient in an OLS regression between the proportionate rate of poverty reduction (annualized differences in the logs) and the rate of growth in the mean is -1.89 (standard error $=0.23$ ) for the absolute measure of poverty, it becomes -0.38 (standard error $=0.08$ ) for the relative measure. Only East Asia has experienced a marked reduction in the incidence of relative poverty: from $81 \%$ in 1981 to $42 \%$ in 2008 . In fact it is the only region in which the poverty 
count was reduced according to this measure. Weakly relative poverty measures rose or stayed unchanged in most regions in the 1990s, and slowly went down in the 2000s.

\section{Figure 6.7}

Poverty headcount ratio with absolute and weakly relative poverty lines Developing countries, 1981-2008

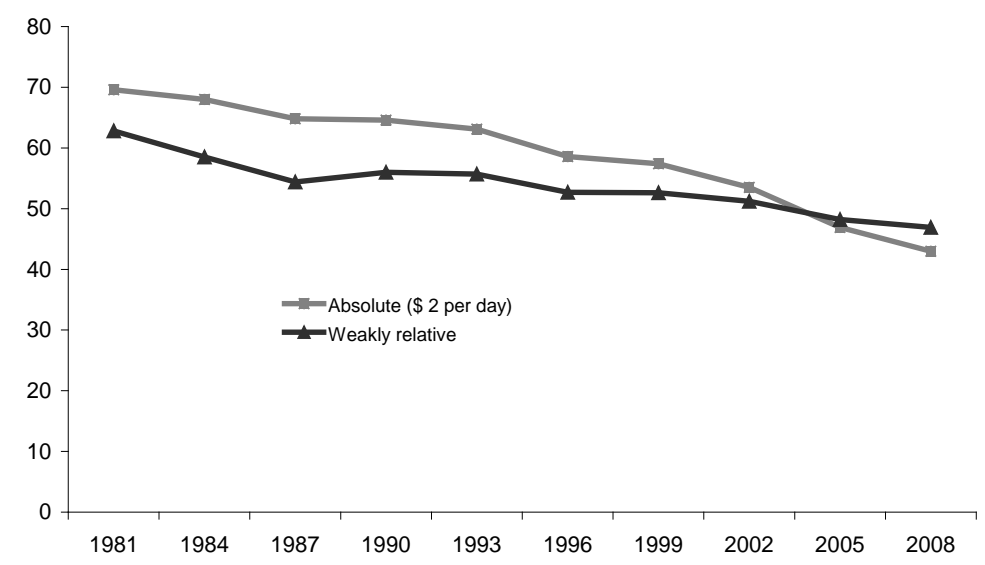

Source: Ravallion and Chen (2012).

In Table 6.9 we extend the estimates of Ravallion and Chen (2012) to 2010, and add estimates of strongly relative poverty ( 50 per cent of mean income) and anchored poverty, computed by "anchoring" the relative lines ( 50 per cent of mean income) to the values in 1990, updating them only by domestic price changes (see chapter 9 in this volume). Our view of poverty trends widely varies across methodologies: while the unweighted anchored poverty rate fell 32\% between 1990 and 2010, the strongly relative poverty rate went up $2 \%$. The differences are even larger when considering the population-weighted statistics.

Table 6.9

Absolute and relative poverty Developing countries, 1990-2010

\begin{tabular}{|c|c|c|c|c|c|c|c|c|}
\hline & \multicolumn{4}{|c|}{ unweighted } & \multicolumn{4}{|c|}{ weighted } \\
\hline & $\begin{array}{c}\text { absolute } \\
(\$ 2)\end{array}$ & $\begin{array}{c}\text { weakly } \\
\text { relative (RC) }\end{array}$ & $\begin{array}{l}\text { strongly } \\
\text { relative }\end{array}$ & anchored & $\begin{array}{c}\text { absolute } \\
(\$ 2)\end{array}$ & $\begin{array}{c}\text { weakly } \\
\text { relative (RC) }\end{array}$ & $\begin{array}{l}\text { strongly } \\
\text { relative }\end{array}$ & anchored \\
\hline 1990 & 40.6 & 46.5 & 28.0 & 28.0 & 64.7 & 54.1 & 19.7 & 19.7 \\
\hline 1993 & 39.8 & 47.9 & 29.0 & 32.9 & 62.7 & 53.7 & 21.1 & 19.1 \\
\hline 1996 & 38.6 & 47.4 & 29.1 & 32.1 & 58.0 & 51.4 & 22.0 & 17.1 \\
\hline 1999 & 38.3 & 47.5 & 30.1 & 31.9 & 56.7 & 50.2 & 22.9 & 16.9 \\
\hline 2002 & 36.7 & 46.9 & 30.1 & 29.6 & 52.5 & 49.5 & 23.7 & 15.2 \\
\hline 2005 & 32.3 & 45.0 & 29.5 & 24.8 & 45.6 & 46.5 & 23.7 & 12.3 \\
\hline 2008 & 28.7 & 43.2 & 29.0 & 19.9 & 42.1 & 46.1 & 24.9 & 9.9 \\
\hline 2010 & 27.7 & 42.4 & 28.6 & 18.9 & 39.4 & 45.6 & 26.6 & 9.5 \\
\hline
\end{tabular}

Source: own calculations based on data from PovcalNet (sample of 76 countries). Note: weakly relative poverty computed according to Ravallion and Chen (2012). Strongly relative lines set at $50 \%$ of mean income. Anchored poverty computed by "anchoring" the relative lines (50\% of mean income) to the values in 1990, and updating them only by domestic price changes. 


\section{Concluding remarks}

There has been a remarkable improvement in the availability of information for distributive analysis in the last decades due to increasing efforts by researchers, national governments and international organizations. To be sure, the picture of inequality and poverty in the developing world is substantially sharper now than in the late 1990s, when the first volume of this Handbook was written. There remain, however, enormous data limitations that make that picture only a very rough approximation of reality. Household surveys are lacking in some countries and are carried out very occasionally in others. Changes in methodology over time are frequent; a fact that generally implies improvement in the data collection, but that at the same time introduces comparability issues with previous surveys that are difficult to deal with. Household surveys have endemic problems in capturing some income and consumption items and in dealing with selective compliance and under-reporting issues. The gaps with National Accounts aggregates, usually variable over time, are a disturbing sign of measurement errors and conceptual issues. Comparability across countries is another big problematic issue, as there are few efforts among national agencies to standardize surveys or at least some criteria to gather and process information. Another issue of concern is the difficulty in obtaining statistical confidence intervals for the distributive statistics, either because agencies do not report them, do not provide information on sampling issues, or do not release the microdata. In sum, in order to be able to characterize and track distributive changes in the developing world with more accuracy we need more efforts to extend the coverage and frequency of household surveys, and improve their reliability and comparability across countries. There is still a long way to go to get an accurate assessment of poverty and inequality in the developing world.

From the data available, some general facts emerge. High poverty and inequality are pervasive characteristics of the developing world, but are not immutable features of these economies. The evidence suggests a robust decline in the levels of income absolute poverty in the developing world, driven mainly by East Asia in the 1980s and 1990s, but generalized to the rest of the developing countries in the 2000s. Income poverty has been reduced in most countries and in the world as whole, making the achievement of the first MDG possible. Despite these positive results there are reasons for concern. The task of fighting poverty continues to be very challenging: around 1.2 billion people survive with less than $\$ 1.25$ a day, an extremely low standard. Also, most of the people who succeeded in jumping the $\$ 1.25$ line in the last decades are still poor by the standards of middle-income developing countries, and remain highly vulnerable if economic conditions worsen. Moreover, due to economic growth, concerns about relative poverty may be increasingly important, and the evidence in that sense is less optimistic.

The evidence on income relative inequality suggests that on average the developing countries are somewhat more unequal than three decades ago. The patterns have been different by period and region. Relative income inequality rose in the late $1980 \mathrm{~s}$ 
and in the 1990s. The changes were larger in Eastern Europe and Central Asia, probably as a result of the transition from a central-planned to a more marketoriented economy; in East Asia, likely as a consequence of the economic take-off; and in Latin America probably as the result of recurrent macroeconomic crises and some structural transformations. Distributive changes in the 2000s become more equalizing in most of the developing world, but the changes were rather moderate and with considerable heterogeneity across countries. In fact, in this decade of widespread social improvement around a third of the countries did not experience falling inequality levels. Reducing inequality certainly remains a top concern in the developing countries of the world. 


\section{References}

Acar, S. and Dogruel, F. (2012). Sources of inequality in selected MENA countries. Structural Change and Economic Dynamics 23(3), pp. 276-285.

Asian Development Bank (2012). Key Indicators for Asia and the Pacific. 43 ${ }^{\text {rd }}$ edition.

Adams R. Jr. and Page, J. (2003). Poverty, inequality and growth in selected Middle East and North Africa countries, 1980-2000. World Development 31(12), pp. 2027-2048.

Ahluwalia, M., Cartner, N. and Chenery, H. (1979). Growth and poverty in developing countries. Journal of Development Economics 6(3), pp. 299-341.

Ahuja, V., Bidani, B., Ferreira, F., and Walton, M. (1997). Everyone's miracle? Revisiting poverty and inequality in East Asia. Directions in Development. The World Bank.

Alatas, V. and Bourguignon, F., (2000). The evolution of the distribution of income during Indonesian fast growth: 1980 -1996, Princeton University, Princeton (unpublished).

Alejo, J. (2012). Educación y Desigualdad: una metodología de descomposición basada en dos interpretaciones de la ecuación de Mincer. Evidencia para Argentina. Anales de la XLVII Reunión Anual de la Asociación Argentina de Economía Política, Trelew, Argentina.

Altimir, O. (1979). La Dimensión de la pobreza en América Latina. Cuadernos de la CEPAL 27.

Altimir, O. (1996). Cambios de la desigualdad y la pobreza en la América Latina. El Trimestre Económico 61(1).

Alvaredo, F. (2011). A Note on the Relationship between Top Income Shares and the Gini Coefficient; Economics Letters, 110(3): 274-277

Alvaredo, F., Atkinson, A. B., Piketty, T. and Saez, E. The World Top Incomes Database, http://topincomes.parisschoolofeconomics.eu, 25/03/2013.

Alvaredo, F. and Atkinson, A. B. (2010). Colonial Rule, Apartheid and Natural Resources: Top Incomes in South Africa 1903-2007. CEPR DP 8155; series updated in the World Top Incomes Database.

Alvaredo, F. and Cano, L. (forthcoming). High incomes in Ecuador.

Alvaredo, F. and Londoño Vélez, J. (2013). High Incomes and Personal Taxation in a Developing Economy: Colombia 1993-2013. Commitment to Equity-CEQ Working Paper n. 12.

Amiel, Y. and Cowell, F. (1999). Thinking about Inequality: Personal judgment and income distributions. Cambridge: Cambridge University Press.

Anand, S. and Segal, P. (2008). What do we know about global income inequality? Journal of Economic Literature 46(1), pp. 57-94. 
Anderson, E. (2005). Openness and inequality in developing countries: A review of theory and recent evidence. World Development 33(7), pp. 1045-1063.

Arif, G. and Farooq, S. (2011). Poverty, Inequality and Unemployment in Pakistan. Pakistan Institute of Development Economics and Islamic Development Bank working paper.

Aron, J., Kahn, B. and Kingdon, G. (2009) South Africa economic policy under democracy. Oxford University Press, Oxford.

Artadi, E. and Sala-i-Martin, X. (2003). The economic tragedy of the XXth Century: Growth in Africa. NBER Working Paper 9865.

Asian Development Bank (2012). Asian development outlook 2012. Confronting rising inequality in Asia. ADB.

Atkinson, A. (1987). On the measurement of poverty. Econometrica 55(4), pp. 749-764.

Atkinson, A. and Bourguignon, F. (2001). Poverty and inclusion from a world perspective. In Stiglitz and Muet (eds). Governance, equity and global markets. Oxford: Oxford University Press.

Atkinson, A. and Brandolini, A. (2001). Promise and pitfalls in the use of "secondary" data-sets: Income inequality in OECD countries as a case study. Journal of Economic Literature 39(3), pp. 771-199.

Atkinson, A. and Brandolini, A. (2004). Global world inequality: absolute, relative or intermediate?" Paper Presented for the 28th Generation Conference of the International Association for Research in Income and Wealth, Cork, Ireland.

Atkinson, A. and Brandolini, A. (2010). On analyzing the world distribution of income. World Bank Economic Review 24(1), pp. 1-37.

Atkinson, A. and Lugo, M. (2010). Growth, poverty and distribution in Tanzania.

Atkinson, A. B. and Micklewright, J. (1992). Economic transformation in Eastern Europe and the distribution of income. Cambridge Books, Cambridge University Press.

Atkinson, A. B. and Morelli, S. (2011). Economic crisis and inequality. Human Development Research Paper 2011/06, UNDP.

Atkinson, A. and Morelli, S. (2012). Chartbook of economic inequality: 25 countries, 1911-2010. Manuscript.

Atkinson, A. B., and Piketty, T. eds. (2007). Top Incomes over the Twentieth Century: A Contrast between Continental European and English-Speaking Countries. Oxford University Press.

Atkinson, A. B., and Piketty, T. eds. (2010). Top Incomes: A Global Perspective. Oxford and New York: Oxford University Press.

Banerjee, A. and Piketty, T. (2010). Top Indian Incomes 1922-2000; in Atkinson, A. B. and Piketty, T. (editors) Top Incomes: A Global Perspective, Oxford University Press, chapter 1, pp. 1-39. 
Bastagli, F., Coady, D. and Gupta, S. (2012). Income inequality and fiscal policy. IMF Staff Discussion Note, SDN/12/08, June.

Barros, R. P., Carvalho, M., Franco, S. and Mendoça, R. (2006). Uma análise das principais causas da queda recente na desigualdade de renda brasileira. Revista Econômica 8(1).

Baulch, B. and McCulloch, N. (2000). Simulating the impact of policy upon chronic and transitory poverty in rural Pakistan. Econometrics 0004003, EconWPA.

Benabou, R. (1996). Inequality and growth. In NBER Macroeconomics Annual 1996, Volume 11, NBER.

Besley, T. and Burgess, R. (2003). Halving global poverty. Journal of Economic Perspectives 17(3), pp. 3-22.

Bhalla, S. (2002). Imagine there's no country: poverty, inequality and growth in the era of globalization. Institute for International Economics.

Bibi, S. and Nabli, M. (2010). Equity and inequality in the Arab region. Policy Research Report 33, Economic Research Forum.

Bigsten, A. and Shimeles, A. (2003). Prospect for pro-poor growth strategies in Africa. WIDER Research Paper 42/2004.

Birdsall, N. and Nellis, J. (2003). Winners and losers: assessing the distributional impact of privatization. World Development, 31(10), pp. 1617-1633.

Bourguignon, F. (2003). The growth elasticity of poverty reduction: Explaining heterogeneity across countries and time periods. In Eichler and Turnovsky (eds). Inequality and Growth: Theory and Policy Implications. CESifo Seminar Series, London: MIT Press.

Bourguignon, F. and Bussolo, M. (2012). Income distribution and computable general equilibrium models: macro-micro modelling. In Dixon and Jorgenson (eds). Handbook of Computable General Equilibrium Modeling, Volume 1A. North Holland Press.

Bourguignon, F., Bussolo, M. and Pereira da Silva, L. (2008). The Impact of Macroeconomic Policies on Poverty and Income Distribution. Macro-Micro Evaluation Techniques and Tools. Washington, DC: The World Bank.

Bourguignon, F., Ferreira, F. and Leite, P. (2008). Beyond Oaxaca-Blinder: Accounting for differences in households income distributions. Journal of Economic Inequality, 6(2), pp. 117-148.

Bourguignon, F., Ferreira, F. and Lustig, N. (2005). The microeconomics of income distribution dynamics in East Asia and Latin America. Washington, DC: The World Bank.

Bourguignon, F., Levin, V. and Rosenblatt, D. (2004). Declining international inequality and economic divergence: reviewing the evidence through different lenses. Économie internationale 100, pp. 13-25.

Bourguignon, F. and Morrison, C. (2002). Inequality among world citizens: 1820-1992. American Economic Review 92(4), pp. 727-744.

Burkhauser, R., Feng, S., Jenkins, S. and Larrimore, J., (2012). "Recent Trends in Top Income Shares in the United States: Reconciling Estimates from March CPS and IRS Tax 
Return Data," The Review of Economics and Statistics, 94(2): 371-388.

Cameron, L. (2002), Growth with or without equity? The distributional impact of Indonesian development. Asian-Pacific Economic Literature, 16: 1-17.

Caselli, F., Esquivel, G. and Lefort, F. (1996). Reopening the convergence debate: a new look at cross-country growth empirics. Journal of Economic Growth 1, 363-389.

Caselli, F. and Michaels, G. (2013). Do oil windfalls improve living standards? Evidence from Brazil. American Economic Journal vol. 5(1), pp. 208-38.

Chakravarty, S. (1987). Development Planning: The Indian Experience. Oxford University Press, New Delhi.

Chen, S. and Ravallion, M. (2001). How did the world's poorest fare in the 1990s? Review of Income and Wealth 47(3), pp. 283-300.

Chen, S. and Ravallion, M. (2007). Absolute poverty measures for the developing world, 1981-2004. Proceedings of the National Academy of Sciences of the United States of America, 104/43, pp. 16757-62.

Chen, S. and Ravallion, M. (2008). China is poorer than we thought, but no less successful in the fight against poverty. World Bank Policy Research Working Paper No. 4621.

Chen, S. and Ravallion, M. (2010). The developing world is poorer than we thought, but no less successful in the fight against poverty. The Quarterly Journal of Economics 125(4), pp. 1577-1625.

Chen, S. and Ravallion, M. (2012). More relatively-poor people in a less absolutely-poor world. The World Bank Policy Research Working Paper 6114.

Chotikapanich, D., Valenzuela, R. and Prasada Rao, D. (1997). Global and regional inequality in the distribution of income: Estimation with limited and incomplete data. Empirical Economics 22(4), pp. 533-546.

Christiansen, L., Demery, L. and Paternostro, S. (2002). Growth, distribution and poverty in Africa: Messages from the 1990s. The World Bank Policy Research Paper 2810 .

Chusseau, N. and Hellier, J. (2012). Globalization and inequality: Where do we stand? ECINEQ Working Paper 279.

Cockburn, J., Duclos, J. and Zabsonré, A. (2012). Is the value of humanity increasing? A critical-level enquiry. FERDI Working Paper 52.

Conte, A. and Vivarelli, M. (2007). Globalization and employment: Imported skill biased technological change in developing countries. IZA Discussion Paper 2797.

Cornia, G. (1996). Transition and income distribution: Theory, evidence and initial interpretation. UNU-WIDER Research in Progress 1.

Cornia, G. (2011). Economic integration, inequality and growth: Latin America vs. the European Economies in Transition. Review of Economics and Institutions 2(2).

Cornia, G. and Kiiski, S. (2001). Trends in income distribution in the post-world war II period: Evidence and interpretation. UNU-WIDER Discussion Paper, 2001/89. 
Cornia, G. and Reddy, S. (2001). The impact of adjustment related social funds on income distribution and poverty. UNU/WIDER Discussion Paper 2001/1.

Cruces, G. and Gasparini, L. (2012). Políticas sociales para la reducción de la desigualdad y la pobreza en América Latina y el Caribe. Diagnóstico, propuesta y proyecciones en base a la experiencia reciente. Premio Fundación Vidanta 2012, Contribuciones a la reducción de la pobreza y la desigualdad en América Latina y el Caribe, Fundación Vidanta, México.

Datt, G. and Ravallion, M. (1992). Growth and redistribution components of changes in poverty measures: A decomposition with applications to Brazil and India in the 1980s. Journal of Development Economics 38(2), pp. 275-295.

Deaton, A. (1997). The analysis of household surveys: A microeconometric approach to development policy. Washington D.C: The World Bank.

Deaton, A. (2003). How to monitor poverty for the millennium development goals. Journal of Human Development 4(3), pp. 353-378.

Deaton, A. (2005). Measuring poverty in a growing world (or measuring growth in a poor world). Review of Economics and Statistics 87(1), pp. 1-19.

Deaton, A. (2010). Price indexes, inequality, and the measurement of world poverty. American Economic Review 100(1), pp. 5-34.

Deaton, A. and Dupriez, O. (2008). Poverty PPPs around the world: an update and progress report. Development Data Group, World Bank.

Deaton, A. and Dupriez, O. (2011). Purchasing power parity exchange rates for the global poor. Applied Economics 3(2), pp. 137-166.

Deaton, A. and Heston, A. (2010). Understanding PPPs and PPP-based national accounts. Macroeconomics 2(4), pp. 1-35.

Deaton, A. and Zaidi, S. (2002). Guidelines for constructing consumption aggregates for welfare analysis. Living Standards Measurement Study Working Paper 135, The World Bank.

Deininger, K. and Squire, L. (1996). A new data set measuring income inequality. World Bank Economic Review 10(3), pp. 565-591.

De Ferranti, D., Perry, G., Ferreira, F. and Walton, M. (2004). Inequality in Latin America, breaking with history? Washington, DC: The World Bank.

Devarajan S. and Nabi, I. (2006). Economic Growth in South Asia: Promising, Unequalizing,...Sustainable? South Asia Region, World Bank.

Dhongde, S. and Minoui, C. (2010). Global poverty estimates: Present and future. ECINEQ Working Papers 181.

Dhongde, S. and Miao, X. (2013). Cross-country convergence in income inequality. ECINEQ Working Papers 290.

Dollar, D. and Kraay, A. (2002). Growth is good for the poor. Journal of Economic Growth 7(3), pp. 195-225. 
Essama-Nssah, B. (2012). Identification of sources of variation in poverty outcomes. The World Bank Policy Research Working Papers 5954.

Feenstra, R. (2008). Offshoring in the Global Economy: Lecture 1: Microeconomic Structure; Lecture 2: Macroeconomic Implications. The Ohlin Lectures, presented at the Stockholm School of Economics on September 17-18, 2008.

Ferreira, F. (1999). Economic transition and the distributions of income and wealth. The Economics of Transition 7(2), pp. 377-410.

Ferreira, F. (2010). Distributions in motion: Economic growth, inequality, and poverty dynamics. The World Bank Policy Research Working Paper 5424.

Ferreira, F. (2012). Inequality of opportunity around the world: what do we know so far? Inequality in Focus 1(1), pp. 8-11, The World Bank.

Ferreira, F., Leite, P. and Wai-Poi, M. (2010). Trade Liberalization, Employment Flows, and Wage Inequality in Brazil. In Nissanke and Thorbecke (eds). The poor under globalization in Asia, Latin America and Africa. Oxford: Oxford University Press.

Ferreira, F. and Ravallion, M. (2009). Poverty and inequality: The global context. In Salverda, Nolan and Smeeding (eds). The Oxford Handbook of Economic Inequality. Oxford: Oxford University Press.

Fields, G. (2002). Distribution and Development: A New Look at the Developing World. Cambridge: MIT Press.

Fiszbein, A. and Schady, N. (2009). Conditional cash transfers. Reducing present and future poverty. The World Bank Policy Research Report.

Fleisher, Belton M., Sabirianova, K. and Wang, X. (2005). Returns to skills and the speed of reforms: evidence from Central and Eastern Europe, China, and Russia. Journal of Comparative Economics, vol. 33(2), pp. 351-370, June.

Forbes, K. (2011). Inequality in crisis and recovery : revealing the divides: the case of Brazil. ILO Working Papers 469849, International Labour Organization.

Fortin, N., Lemieux, T. and Firpo, S. (2011). Decomposition Methods in Economics. In Ashenfelter and Card (eds). Handbook of Labor Economics, Volume 4, Part A.

Fosu, A. (2009). Inequality and the impact of growth on poverty: Comparative evidence for Sub-Saharan Africa. Journal of Development Studies 45(5), pp. 726-745.

Fosu, A. (2010). The global financial crisis and development: Whither Africa? UNUWIDER Working Paper 2010/124.

Fosu, A. (2011). Growth, inequality, and poverty reduction in developing countries. Recent global evidence. UNU-WIDER Working Paper 2011/1.

Galbraith, J. and Kum, H. (2005). Estimating the inequality of household incomes: toward a dense and consistent global data set. Review of Income and Wealth 51(1), pp. 115-143.

Garcia, M. and Moore, C. (2012). The cash dividend: The rise of cash transfer programs in Sub-Saharan Africa. Washington DC: The World Bank. 
Gasparini, L., Cicowiez, M. and Sosa Escudero, W. (2013). Pobreza y desigualdad en América Latina. Conceptos, herramientas y aplicaciones. Editorial Temas.

Gasparini, L., Cruces, G. and Tornarolli, L. (2011). Recent trends in income inequality in Latin America. Economia 10(2), pp. 147-201.

Gasparini, L., Galiani, S., Cruces, G. and Acosta, P. (2011). Educational upgrading and returns to skills in Latin America: evidence from a supply-demand framework, 19902010. IZA Discussion paper 6244.

Gasparini, L. and Gluzmann, P. (2012). Estimating income poverty and inequality from the Gallup World Poll: the case of Latin America and the Caribbean. Journal of Income Distribution 21(1).

Gasparini, L. and Lustig, N. (2011). The rise and fall of income inequality in Latin America". In Ocampo and Ros (eds). The Oxford Handbook of Latin American Economics, Chapter 27. Oxford: Oxford University Press.

Gentilini, U. and Sumner, A. (2012). Poverty where people live: what do national poverty lines tell us about global poverty? International Policy Centre for Inclusive Growth Working Paper 98.

Gertler, P. (2004). Do conditional cash transfers improve child health? Evidence from PROGRESA's control randomized experiment. American Economic Review 94(2), pp. 336-341.

Ghani, E. (2010). The poor half billion in South Asia. What is holding back lagging regions? Oxford University Press.

Gluzmann, P. (2012). Desigualdad del ingreso y del bienestar subjetivo. Análisis y comparaciones internacionales. Ph.D. dissertation, Universidad Nacional de La Plata.

Go, D., Nikitin, D., Wang, X. and Zou, H. (2007). Poverty and inequality in Sub-Saharan Africa: Literature survey and empirical assessment. Annals of Economics and Finance, Society for AEF, 8(2), pp. 251-304.

Goldberg, P. and Pavcnik, N. (2007). Distributional Effects of globalization in developing countries. Journal of Economic Literature 45(1), pp. 39-82.

Goldin, C. and Katz, L. (2008). The race between education and technology. Cambridge: Harvard University Press.

Goñi-Pacchioni, J., López, H. and Servén, L. (2011). Fiscal redistribution and income inequality in Latin America. World Development 39(9), pp. 1558-1569.

Gorodnichenko, Y. and Sabirianova, K. (2005). Returns to schooling in Russia and Ukraine: A semiparametric approach to cross-country comparative analysis. Journal of Comparative Economics 33(2), pp. 324-350.

Gosh, J. (2012). Unequal in Asia. Frontline, 29(15) Jul 28-Aug 10, pp. 127-128.

Harrison, A., McLaren, J. and McMillan, M. (2011). Recent perspectives on trade and inequality. Annual Review of Economics 3(1), pp. 261-289.

Hellier, J. and Lambrecht, S. (2012). Inequality, growth and welfare: The main links. ECINEQ Working Paper 258. 
Helpman, E. and Trajtenberg, M. (1998). A time to sow and a time to reap: Growth based on general purpose technologies. In Helpman (ed). General Purpose Technologies and Economic Growth. Cambridge: MIT Press.

Heston, A., Summers, R. and Aten, B. (2012). Penn World Table Version 7.1, Center for International Comparisons of Production, Income and Prices at the University of Pennsylvania, July.

Hussain, A. (2008). Power dynamics, institutional instability and economic growth: The case of Pakistan. The Asia Foundation.

IDB (1999). América Latina frente a la desigualdad. Informe de Progreso Económico y Social, Banco Interamericano de Desarrollo.

Iqbal, F. (2006). Sustaining gains in poverty reduction and human development in the Middle East and North Africa. Washington, DC: The World Bank.

International Labor Organization (ILO) (2010). World Social Security Report 2010/11: Providing Coverage in Times of Crisis and Beyond; Geneva.

Inchauste, G., Olivieri, S., Saavedra, J. and Winkler, H. (2012). What Is Behind the Decline in Poverty Since 2000? Evidence from Bangladesh, Peru and Thailand. The World Bank Policy Research Working Paper 6199.

Ivaschenko, O. (2002). Growth and Inequality: Evidence from transitional economies. CESIFO Working Paper 746.

Kakwani, N. (2000). On measuring growth and inequality components of poverty with application to Thailand. Journal of Quantitative Economics 16, pp. 67-8.

Kakwani, N., Khandker, S. and Son, H. (2003). Poverty equivalent growth rate: With applications to Korea and Thailand. Technical report, Economic Commission for Africa.

Kakwani, N., and Krongkaew, M. (2000). Economic growth, poverty and income inequality in the Asia-Pacific region. Journal of the Asia Pacific Economy 5(1-2), pp. 913.

Kakwani, N. and Pernia, E. (2000). What is pro-poor growth? Asian Development Review 18(1), pp. 1-16.

Kakwani, N. and Subbarao, K. (1990). Rural poverty and its alleviation in India. Economic and Political Weekly 25.

Kanbur, R. and Sumner, A. (2011). Poor countries or poor people? Development assistance and the new geography of global poverty. Cornell University Working Paper 2011-08.

Karshenas, M. (2003). Global poverty: National Accounts based versus survey based estimates. Development and Change 34(4), pp. 683-712.

Khan, A. R. (2008). Measuring inequality and poverty in Bangladesh: an assessment of the survey data. The Bangladesh Development Studies. 31(3/4), pp. 1-34

Klasen, S. (1997). Poverty, inequality and deprivation in South Africa: an analysis of the 1993 SALDRU survey. Social Indicators Research, 41(1-3), pp. 51-94. 
Klasen, S. (2005). Measuring poverty and deprivation in South Africa. Review of Income and Wealth, 46(1), pp. 33-58.

Korinek, A., Mistiaen, J. and Ravallion, M. (2006). Survey nonresponse and the distribution of income. Journal of Economic Inequality 4 (2).

Kraay, A. (2006). When is growth pro-poor? Evidence from a panel of countries. Journal of Development Economics 80(1), pp. 198-227.

Krongkaew, M. (1994). Income distribution in East Asian developing countries: An update. Asia Pacific Economic Literature 8(2), pp. 58-73.

Krongkaew, M. and Zin, R. (2007). Income distribution and sustainable economic development in East Asia: A Comparative Analysis. IDEAs Working Paper 02/2007.

Kuznets, S. (1955). Economic growth and income inequality. American Economic Review 45(1), pp. 1-28.

Leibbrandt, M., Woolard, I. and Woolard, C., (2009). A long-run perspective on contemporary poverty and inequality dynamics. In J. Aron, B. Kahn and G. Kingdon (editors) South Africa economic policy under democracy. Oxford University Press, Oxford, Chapter 10.

Leibbrandt, M., Woolard, I., McEwen, H., and Koep, C. (2010). Better employment to reduce inequality further in South Africa. In Tackling inequalities in Brazil, China, India and South Africa, OECD, Paris.

Leibbrandt, M., Woolard, I., Finn, A. and Argent, J. (2010). Trends in South African income distribution and poverty since the fall of apartheid. OECD Social, Employment and Migration Working Papers n. 101.

Leigh, A. (2007). How closely do top income shares track other measures of inequality? The Economic Journal, 117: F619-F633.

Lewis, A. (1954). Economic development with unlimited supplies of labor. Manchester School of Economics and Social Studies 22, pp. 139-192.

Li, H., Squire, L. and Zou, H. (1998). Explaining international and intertemporal variations in income inequality. Economic Journal 108(446).

Li, S. Chuliang, L. and Sicular, T. (2013). Overview: income inequality and poverty in China, 2002-2007. In Li Shi, Hiroshi Sato, and Terry Sicular (eds.). Rising Inequality in China: Challenge to the Harmonious Society, Cambridge University Press.

Lind, J. and Mehlum, H. (2010). With or without U? The appropriate test for a U shaped relationship. Oxford Bulletin of Economics and Statistics 72(1), pp. 109-118.

Loayza, N. and Raddatz, C. (2010). The composition of growth matters for poverty alleviation. Journal of Development Economics 93(1), pp. 137-151.

Londoño, J. and Székely, M. (2000). Persistent poverty and excess inequality: Latin America, 1970-1995. Journal of Applied Economics 3(1), pp. 93-134.

López Calva, L. and Lustig, N. (eds.) (2010). Declining inequality in Latin America: A decade of progress? Brookings Institution and UNDP. 
Lustig, N. (1990). Economic crisis, adjustment and living standards in Mexico, 1982-85. World Development, 18(10), pp. 1325-1342.

Lustig, N. (1995). Coping with Austerity: Poverty and Inequality in Latin America. Washington, DC: Brookings Institution.

Lustig, N. (2012). Fiscal policy and income redistribution in Latin America: Challenging the conventional wisdom. Tulane University Economics Working Paper 1124.

Mahmoudi, V. (2001). Growth-Equity decomposition of a change in poverty: An application to Iran. University of Essex.

Mavridis, D. and Mosberger, P. (forthcoming). Capital and labor: top income shares in Hungary, 1915-2010.

Mazundar, D. (2012) Decreasing poverty and increasing inequality in India; in OECD (editor), Tackling Inequalities in Brazil, China, India and South Africa: The Role of Labour Market and Social Policies, OECD Publishing, chapter 4, pp. 157-207.

McGrath, M. D. and Whiteford, A. (1994). The distribution of income in South Africa, Human Science Research Council, Pretoria.

McGrath, M. D. (1983). The distribution of personal income in South Africa in selected years over the period from 1945 to 1980 . Ph D thesis, University of Natal, Durban.

Milanovic, B. (1995). Poverty, inequality and social policy in transition economies. The World Bank Policy Research Working Paper 9.

Milanovic, B. (1998). Income, inequality, and poverty during the transition from planned to market economy. World Bank Regional and Sectoral Studies. The World Bank, Washington, D.C.

Milanovic, B. (1999). Explaining the increase in inequality during transition. Economics of Transition 7(2), pp. 299-341.

Milanovic, B. (2002). True world income distribution, 1988 and 1993: first calculation based on household surveys alone. Economic Journal 112(476), pp. 51-92.

Milanovic, B. (2003). Is Inequality in Africa really different? The World Bank Policy Research Working Paper 3169.

Milanovic, B. (2005). Worlds apart: measuring international and global inequality. Princeton: Princeton University Press.

Milanovic, B. (2011). A short history of global inequality: The past two centuries. Explorations in Economic History 48(4), pp. 494-506.

Milanovic, B. (2012a). Global income inequality by the numbers: In history and now. An overview. The World Bank Policy Research Working Paper 6259.

Milanovic, B. (2012b). Global inequality recalculated and updated: The effect of new PPP estimates on global inequality and 2005 estimates. Journal of Economic Inequality 10(1), pp. 1-18. 
Milanovic, B. and Ersado, L. (2010). Reform and inequality during the transition. An analysis using panel household survey data, 1990-2005. UNU/WIDER Working Paper 62.

Minoiu, C. and Reddy, S. G. (2008). Chinese poverty: assessing the impact of alternative assumptions. Review of Income and Wealth, 54(4), pp. 572-596.

Miranti, R., Vidyattama, Y., Hansnata, E., Cassells, R. and Duncan, A. (2013). Trends in Poverty and Inequality in Decentralising Indonesia. OECD Social, Employment and Migration Working Papers No. 148.

Mitra, P. and Yemtsov, R. (2006). Increasing inequality in transition economies: Is there more to come? The World Bank Policy Research Working Paper 4007.

Moradi, A. and Baten, J. (2005). Inequality in Sub-Saharan Africa: new data and new insights from anthropometric estimates. World Development 33(8), pp. 1233-1265.

Morley, S. (2001). The income distribution problem in Latin America and the Caribbean. Santiago: CEPAL.

Nattrass, N. and Seekings, J. (1997). Citizenship and Welfare in South Africa: Deracialisation and Inequality in a Labour-Surplus Economy. Canadian Journal of African Studies, 31(3), pp. 452-481.

Nissanke, M. and Thorbecke, E. (editors) (2010). The poor under globalization in Asia, Latin America and Africa. Oxford University Press, 2010.

Okojie, C. and Shimeles, A. (2006). Inequality in Sub-Saharan Africa. The Inter-Regional Inequality Facility. London: DFID.

Page, J. (2007). Boom, bust, and the poor: Poverty dynamics in the Middle East and North Africa, 1970-1999. The Quarterly Review of Economics and Finance 46(5), pp. 832-851.

Palma, J. (2011). Homogeneous middles vs. heterogeneous tails, and the end of the "inverted-U": the share of the rich is what it's all about. Cambridge Working Papers in Economics 1111.

Parker, S. and Skoufias, E. (2001). Conditional cash transfers and their impact on child work and school enrollment: evidence from the PROGRESA program in Mexico. Economia 2(1).

Piketty, T. and Qian, N. (2010). Income inequality and progressive income taxation in China and India, 1986-2015. In A. B. Atkinson and T. Piketty (eds.), Top Incomes: A Global Perspective, Oxford University Press.

Pinkovskiy, M. (2013). World welfare is rising: Estimation using nonparametric bounds on welfare measures. Journal of Public Economics 97(1), pp. 176-195.

Pinkovskiy, M. and Sala-i-Martin, X. (2009). Parametric estimations of the world distribution of income. NBER Working Paper 1543.

Pissarides, C. (1997). Learning by trading and the returns to human capital in developing countries. World Bank Economic Review 11(1), pp. 17-32. 
Rama, M. (2003). Globalization and workers in developing countries. The World Bank Policy Research Working Paper 2958.

Ravallion, M. (1997). Can high-inequality developing countries escape absolute poverty? Economics Letters 56(1), pp. 51-57.

Ravallion, M. (2001). Growth, inequality and poverty: Looking beyond averages. World Development 29(11), pp. 1803-1815.

Ravallion, M. (2003). Inequality convergence. Economic Letters 80(3), pp. 351-356.

Ravallion, M. (2004a). Pro-poor growth: a primer. The World Bank Policy Research Working Paper 3242.

Ravallion, M. (2004b). Competing concepts of inequality in the globalization debate. The World Bank Policy Research Working Paper 3243.

Ravallion, M. (2007). Inequality is bad for the poor. In Jenkins and Micklewright (eds). Inequality and poverty re-examined. Oxford: Oxford University Press.

Ravallion, M. (2010). Price levels and economic growth: making sense of the PPP changes between ICP rounds. The World Bank Policy Research Working Paper 5229.

Ravallion, M. (2012). Why don't we see poverty convergence? American Economic Review 102(1).

Ravallion, M. (2013). How long will it take to lift one billion people out of poverty? The World Bank Policy Research Working Paper 6325.

Ravallion, M. and Chen, S. (1997). What can new survey data tell us about recent changes in distribution and poverty? World Bank Economic Review 11(2), pp. 357-382.

Ravallion, M. and Chen, S. (2003). Measuring pro-poor growth. Economic Letters 78(1), pp. 93-99.

Ravallion, M., and Chen, S. (2007). China's (uneven) progress against poverty. Journal of Development Economics 82(1), pp. 1-42.

Ravallion, M. and Chen, S. (2011). Weakly relative poverty. Review of Economics and Statistics 93(4), pp. 1251-1261.

Ravallion, M., Chen, S. and Sangraula P. (2009). Dollar a day revisited. World Bank Economic Review 23(2), pp. 163-184.

Ravallion, M., Datt, G. and van de Walle, D. (1991). Quantifying absolute poverty in the developing world. Review of Income and Wealth 37(4), pp. 345-361.

Reddy, S. and Minoiu, C. (2007). Has world poverty really fallen? Review of Income and Wealth 53(3), pp. 484-502.

Reddy, S. and Pogge, T. (2010). How not to count the poor. In Anand, Segal and Stiglitz (eds.). Debates on the measurement of poverty. Oxford: Oxford University Press.

Robinson, J. (2009). The political economy of inequality. ERF Working Paper 493.

Sala-i-Martin, X. (2006). The world distribution of income: falling poverty and ... convergence, period. The Quarterly Journal of Economics 121(2), pp. 351-397. 
Sala-i-Martin, X. and Pinkovskiy, M. (2010). African poverty is falling ... Much faster than you think! NBER Working Paper 15775.

Salehi-Isfahani, D. (2010). Human development in the Middle East and North Africa. UNDP Human Development Research Paper 2010/26.

Sen, A. (1976). Real national income. Review of Economic Studies 43(1), pp. 19-39.

Sen, A. (1983). Poor, relatively speaking. Oxford Economic Papers 35(2), pp. 153-69.

Sharma, M., Inchauste, G. and Feng, J. (2011). Rising inequality with high growth and falling poverty. An eye on East Asia and Pacific; no. 9, World Bank.

Shorrocks, A. and Wan, G. (2008). Ungrouping income distributions: Synthesising samples for inequality and poverty analysis. In Basu and Kanbur (eds). The Oxford Handbook of Arguments for a Better World: Essays in Honor of Amartya Sen. Volume I: Ethics, Welfare and Measurement. Oxford: Oxford University Press.

Simai, M. (2006). Poverty and inequality in Eastern Europe and the CIS Transition Economies. DESA Working Paper No. 17.

Simkins, C. (1991). The Urban Foundation income distribution model: Phase One. Mimeo. Johannesburg: Urban Foundation.

Skoufias, E. and Suryahadi, A., (2000). Changes in Regional Inequality and Social Welfare in Indonesia between 1996 and 1999, Working Paper, Social Monitoring and Early Response Unit (SMERU) Research Institute, Jakarta.

Soares, S., Guerreiro Osório, R., Veras Soares, F., Medeiros, M. and Zepeda, E. (2009). Conditional cash transfers in Brazil, Chile and Mexico: impacts upon inequality. Estudios Económicos 0 (Special i), pp. 207-224.

Solt, F. (2009). Standardizing the world income inequality database. Social Science Quarterly 90(2), pp. 231-242.

Standing, G. and Vaughan-Whitehead, D. (1995). Minimum wages in Central and Eastern Europe: from protection to destitution International Labour Office. Central and Eastern European Team.

Sumner, A. (2012). From deprivation to distribution: is global poverty becoming a matter of national inequality? IDS Working Paper 2012-394.

Székely, M. and Hilgert, M. (1999). What's behind the inequality we measure : an investigation using Latin American data. Inter-American Development Bank, Research Department Working Paper 409.

Tabatabai, H. (1996). Statistics on poverty and income distribution: an ILO compendium of data. Geneva: International Labor Office.

Terreblanche, S. (2002). A history of inequality in South Africa, 1652-2002. University of Natal Press, Pietermaritzburg.

Tinbergen, J. (1975). Income Differences: Recent Research. Amsterdam: North-Holland. 
Todd, P. and Wolpin, K. (2006). Assessing the impact of a school subsidy program in Mexico: Using a social experiment to validate a dynamic behavioral model of child schooling and fertility. American Economic Association 96(5), pp. 1384-1417.

United Nations-UNECE (2004) Economic Survey of Europe, 2004 No. 1, chapter 7.

van der Berg, S., and Louw, M. (2004). Changing patterns of South African income distribution: towards time series estimates of distribution and poverty. South African Journal of Economics, 72(3), pp. 546-572.

Van de Walle, N. (2008). The institutional origins of inequality in Sub-Saharan Africa. Cornell University Mario Einaudi Center for International Studies Working Paper 6-08.

Voitchovsky, S. (2009). Inequality, Growth and Sectoral Change. Chapter 22 in Nolan, Salverda and Smeeding (eds.), Oxford Handbook of Economic Inequality.

Whiteford, A. and Van Seventer, D. (2000). South Africa's changing income distribution in the 1990s. Studies in Economics \& Econometrics 24(3), pp. 7-30.

Winters, A., McCulloch, N. and McKay, A. (2004). Trade liberalization and poverty: The Evidence so far. Journal of Economic Literature 42, pp. 72-115.

Wodon, Q., Castro, R. and Lee, K. (2001). Poverty in Latin America: Trends (1986-1998) and determinants. Latin American Journal of Economics - formerly Cuadernos de Economía 38(114).

Wood, A. (1997). Openness and wage inequality in developing countries: The Latin American challenge to East Asian conventional wisdom. World Bank Economic Review 11(1), pp. 33-57.

World Bank (2000). World Development Report: Attacking Poverty. New York: Oxford University Press.

World Bank (2005). ECAPOV II. Growth, Poverty and Inequality in Eastern Europe and Former Soviet Union. Washington, DC: The World Bank.

World Bank (2006). World development report: Equity and development. World Bank and Oxford University Press.

World Bank (2006). Can South Asia reduce poverty in a generation? http://go.worldbank.org/NF9FFJTM20

World Bank (2008). Global Purchasing Power Parities and Real Expenditures. 2005 International Comparison Program. Washington, DC: The World Bank.

World Bank (2009). The World Development Report 2009: Reshaping Economic Geography. Washington, D.C.: The World Bank.

World Bank (2012). East Asia and Pacific Data Monitor, October.

World Bank (2013). The East Asian Miracle: Economic Growth and Public Policy. Oxford University Press.

Zin, R.H.M. (2005). Income distribution in East Asian developing countries: recent trends. Asian-Pacific Economic Literature, 19(2), 36-54. 
Table A.1

List of developing countries by region and population, 2010

\begin{tabular}{|c|c|c|c|c|c|c|c|c|c|c|c|c|c|c|c|c|c|c|c|c|}
\hline \multicolumn{3}{|c|}{ East Asia and Pacific } & \multicolumn{3}{|c|}{ Eastern Europe and Central Asia } & \multicolumn{3}{|c|}{ Latin America and the Caribbean } & \multicolumn{3}{|c|}{ Middle East and North Africa } & \multicolumn{3}{|c|}{ South Asia } & \multicolumn{6}{|c|}{ Sub-Saharan Africa } \\
\hline Countries & Pop. & Data & Countries & & Data & Countries & & Data & Countries & Pop. & Data & Countries & Pop. & Data & Countries & Pop. & Data & & Pop. & Data \\
\hline American Samoa & 0.066 & & Albania & 3.181 & & Antigua and Barbuda & 0.087 & & Algeria & 34.428 & $\mathrm{x}$ & Afghanistan & 32.518 & & & 18.038 & $\mathrm{x}$ & & & \\
\hline Cambodia & 13.823 & $x$ & Armenia & 3.079 & $\mathrm{x}$ & Argentina & 39.714 & $\mathrm{x}$ & Djibouti & 0.856 & $\mathrm{x}$ & Bangladesh & 145.478 & $x$ & Benin & 8.356 & $\mathrm{x}$ & Rwanda & 10.004 & $\mathrm{x}$ \\
\hline China & 1324.655 & $\mathrm{x}$ & Azerbaijan & 8.763 & $x$ & Belize & 0.322 & $x$ & Egypt & 78.323 & $x$ & Bhutan & 0.701 & $x$ & Botswana & 1.955 & $x$ & São Tomé \& P. & 0.160 & $x$ \\
\hline Fiji & 0.844 & $x$ & Belarus & 9.602 & $x$ & Bolivia & 9.618 & $\mathrm{x}$ & Iran & 72.289 & $\mathrm{x}$ & India & 1190.864 & $x$ & Burkina Faso & 15.515 & $\mathrm{x}$ & Senegal & 11.787 & $x$ \\
\hline $\begin{array}{l}\text { Indonesia } \\
\text { Kiribati }\end{array}$ & $\begin{array}{c}234.951 \\
0.097\end{array}$ & $x$ & $\begin{array}{l}\text { Bosnia and Herzegovina } \\
\text { Bulgariaa }\end{array}$ & $\begin{array}{l}3.774 \\
7.623\end{array}$ & $\begin{array}{l}x \\
x\end{array}$ & $\begin{array}{l}\text { Brazil } \\
\text { Chile }\end{array}$ & $\begin{array}{l}191.543 \\
16.796\end{array}$ & $\begin{array}{l}x \\
x\end{array}$ & $\begin{array}{l}\text { Iraq } \\
\text { Jordan }\end{array}$ & $\begin{array}{l}30.178 \\
5.778\end{array}$ & $\begin{array}{l}x \\
x\end{array}$ & $\begin{array}{l}\text { Maldives } \\
\text { senal }\end{array}$ & $\begin{array}{r}0.308 \\
28005\end{array}$ & $\begin{array}{l}x \\
x\end{array}$ & Burundi & $\begin{array}{r}7.943 \\
18759\end{array}$ & $\begin{array}{l}x \\
x\end{array}$ & $\begin{array}{l}\text { Seychelles } \\
\text { Gierzaleope }\end{array}$ & 0.087 & $x$ \\
\hline $\begin{array}{l}\text { Kiribati } \\
\text { Korea, Dem. Rep. }\end{array}$ & $\begin{array}{r}0.907 \\
24.126\end{array}$ & & $\begin{array}{l}\text { Bulgaria } \\
\text { Croatia }\end{array}$ & $\begin{array}{l}7.623 \\
4.434\end{array}$ & $\begin{array}{l}x \\
x\end{array}$ & $\begin{array}{l}\text { Chile } \\
\text { Colombia }\end{array}$ & $\begin{array}{l}16.796 \\
45.006\end{array}$ & $\begin{array}{l}x \\
x\end{array}$ & $\begin{array}{l}\text { Jordan } \\
\text { Lebanon }\end{array}$ & $\begin{array}{l}5.787 \\
4.176\end{array}$ & & $\begin{array}{l}\text { Nepal } \\
\text { Pazistan }\end{array}$ & 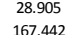 & $\begin{array}{l}x \\
x\end{array}$ & $\begin{array}{l}\text { Cameroon } \\
\text { Cape verde }\end{array}$ & $\begin{array}{l}18.759 \\
0.47\end{array}$ & $\begin{array}{l}x \\
x \\
x\end{array}$ & $\begin{array}{l}\text { Sierra Leone } \\
\end{array}$ & 5.612 & \\
\hline $\begin{array}{l}\text { Korea, Dem. Rep. } \\
\text { Lao }\end{array}$ & $\begin{array}{l}24.126 \\
6.022\end{array}$ & $x$ & $\begin{array}{l}\text { Croatala } \\
\text { Czech Republic }\end{array}$ & $\begin{array}{l}\begin{array}{l}4.434 \\
10.424\end{array} \\
\end{array}$ & $\begin{array}{l}x \\
x\end{array}$ & $\begin{array}{l}\text { Colombia } \\
\text { Costa Rica }\end{array}$ & $\begin{array}{l}45.006 \\
4.522\end{array}$ & $\begin{array}{l}x \\
x\end{array}$ & $\begin{array}{l}\text { lebanono } \\
\text { Libya }\end{array}$ & $\begin{array}{l}4.1 .16 \\
6.150\end{array}$ & & $\begin{array}{l}\text { Pakiktan } \\
\text { Sri Lanka }\end{array}$ & $\begin{array}{l}166.442 \\
20.217\end{array}$ & $\begin{array}{l}x \\
x\end{array}$ & $\begin{array}{l}\text { Cape Verde } \\
\text { Central African R. }\end{array}$ & $\begin{array}{l}0.487 \\
4.238\end{array}$ & $\begin{array}{l}x \\
x\end{array}$ & $\begin{array}{l}\text { Somala } \\
\text { South Africa }\end{array}$ & $\begin{aligned} 8.9222 \\
48.793\end{aligned}$ & $x$ \\
\hline Malaysia & $\begin{array}{l}6.022 \\
27.502\end{array}$ & $\hat{x}$ & Estonia & 1.341 & $\hat{x}$ & $\begin{array}{l}\text { Costa Rica } \\
\text { Cuba }\end{array}$ & $\begin{array}{r}\text { 4.522 } \\
11.267\end{array}$ & & $\begin{array}{l}\text { Lbya } \\
\text { Morocco }\end{array}$ & $\begin{array}{l}6.130 \\
31.321\end{array}$ & $x$ & & & & $\begin{array}{l}\text { Central Arrican } \mathrm{K} \text {. } \\
\text { Chad }\end{array}$ & 10.654 & $\hat{x}$ & South Sudan & $\begin{array}{l}48.973 \\
8.977\end{array}$ & i \\
\hline Marshall Islands & 0.053 & & Georgia & 4.384 & $x$ & Dominica & & & & & $x$ & & & & & 0.697 & $x$ & & 32.438 & $x$ \\
\hline Micronesia & 0.110 & $x$ & Hungary & $\begin{array}{l}10.038 \\
10.038\end{array}$ & $\hat{x}$ & Dominican Republic & 9.665 & $x$ & Tunisia & 10.329 & $\hat{x}$ & & & & Congo, Dem. R. & 62.475 & $\hat{x}$ & $\begin{array}{l}\text { Swaziland } \\
\text { Swa }\end{array}$ & 1032 & $\hat{x}$ \\
\hline Mongolia & 2.667 & $x$ & Kazakhstan & 15.674 & $x$ & Ecuador & 14.057 & $x$ & West Bank and Gaza & 3.937 & $x$ & & & & Congo, Rep. & 3.836 & $x$ & Tanzania & 42.268 & $x$ \\
\hline Myanmar & 47.250 & & Kosovo & 1.747 & & El Salvador & 6.130 & $x$ & Yemen & 22.627 & $x$ & & & & Cotte d'voire & 18.987 & $\hat{x}$ & Togo & 5.777 & $\hat{x}$ \\
\hline Palau & 0.020 & & Kyrgyz Republic & 5.319 & $x$ & Grenada & 0.104 & & & & & & & & Eritrea & 4.948 & & Uganda & 31.339 & $\mathrm{x}$ \\
\hline Papua New Guinea & 6.549 & & Latvia & 2.266 & $x$ & Guatemala & 13.691 & $x$ & & & & & & & Ethiopia & 79.446 & $x$ & Zambia & 12.380 & $x$ \\
\hline Philippines & 90.173 & $x$ & Lithuania & 3.358 & $x$ & Guyana & 0.752 & $x$ & & & & & & & Gabon & 1.450 & $\mathrm{x}$ & Zimbabwe & 12.452 & \\
\hline Samoa & 0.182 & & Macedonia & 2.053 & $x$ & Haiti & 9.736 & $\mathrm{x}$ & & & & & & & Gambia & 1.636 & $\mathrm{x}$ & & & \\
\hline Solomon Islands & $\begin{array}{l}0.510 \\
68268\end{array}$ & & $\begin{array}{l}\text { Moldova } \\
\text { Montenerar }\end{array}$ & 3.570 & $\begin{array}{l}x \\
x\end{array}$ & Honduras & 7.303 & $x$ & & & & & & & Ghana & 23.264 & $x$ & & & \\
\hline $\begin{array}{l}\text { Thailand } \\
\text { Timor-Leste }\end{array}$ & $\begin{array}{l}68.268 \\
1078\end{array}$ & $\begin{array}{l}x \\
x\end{array}$ & $\begin{array}{l}\text { Montenegro } \\
\text { Polazd }\end{array}$ & $\begin{array}{l}0.629 \\
38126\end{array}$ & $\begin{array}{l}x \\
x\end{array}$ & Jamaica & $\begin{array}{r}2.687 \\
1106927\end{array}$ & $\begin{array}{l}x \\
x\end{array}$ & & & & & & & Guinea & 9.559 & $\begin{array}{l}x \\
x \\
x\end{array}$ & & & \\
\hline $\begin{array}{l}\text { Timor-Leste } \\
\text { Tonga }\end{array}$ & $\begin{array}{l}1.078 \\
0.103\end{array}$ & $x$ & $\begin{array}{l}\text { Poland } \\
\text { Romania }\end{array}$ & $\begin{array}{l}38.126 \\
21.514\end{array}$ & $\begin{array}{l}x \\
x\end{array}$ & $\begin{array}{l}\text { Mexico } \\
\text { Nicaragua }\end{array}$ & $\begin{array}{l}110.627 \\
5.636\end{array}$ & $\begin{array}{l}x \\
x\end{array}$ & & & & & & & $\begin{array}{l}\text { Guinea-Bissau } \\
\text { Kenya }\end{array}$ & $\begin{array}{l}1.444 \\
38.455\end{array}$ & $\begin{array}{l}x \\
x \\
x\end{array}$ & & & \\
\hline $\begin{array}{l}\text { Tonga } \\
\text { Tuvalu }\end{array}$ & 0.010 & & $\begin{array}{l}\text { Romania } \\
\text { Russian Federation }\end{array}$ & 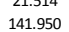 & $x$ & $\begin{array}{l}\text { Nicargagua } \\
\text { Panama }\end{array}$ & $\begin{array}{l}5.666 \\
3.406\end{array}$ & $x$ & & & & & & & $\begin{array}{l}\text { Kenya } \\
\text { Lesotho }\end{array}$ & $\begin{array}{l}38.455 \\
2.127\end{array}$ & $\begin{array}{l}x \\
x\end{array}$ & & & \\
\hline $\begin{array}{l}\text { vanuatu } \\
\text { Vanua }\end{array}$ & 0.228 & & Serbia & 7.350 & $\hat{x}$ & $\begin{array}{l}\text { Paraguay } \\
\text { Parlina }\end{array}$ & $\begin{array}{l}.3 .400 \\
6.230\end{array}$ & $\hat{x}$ & & & & & & & Liberia & 3.658 & $x$ & & & \\
\hline \multirow[t]{7}{*}{ Vietnam } & 85.122 & $x$ & Slovak Republic & 5.407 & $x$ & Peru & 28.463 & $\mathrm{x}$ & & & & & & & Madagascar & 19.546 & $\mathrm{x}$ & & & \\
\hline & & & Slovenia & 2.021 & $x$ & St. Kitts and Nevis & 0.051 & & & & & & & & Malawi & 14.005 & $x$ & & & \\
\hline & & & Tajkikistan & 6.691 & $x$ & St. Lucia & 0.170 & $x$ & & & & & & & Mali & 14.460 & $\mathrm{x}$ & & & \\
\hline & & & Turkey & 70.924 & $x$ & St. Vincent and G. & 0.109 & & & & & & & & Mauritania & 3.295 & $\mathrm{x}$ & & & \\
\hline & & & Turkmenistan & 4.918 & $x$ & Suriname & 0.515 & $x$ & & & & & & & Mauritius & 1.269 & & & & \\
\hline & & & Ukraine & 46.258 & $\mathrm{x}$ & Trinidad and Tobago & 1.331 & $x$ & & & & & & & Mozambique & 22.333 & $\mathrm{x}$ & & & \\
\hline & & & Uzbekistan & 27.303 & $\mathrm{x}$ & $\begin{array}{l}\text { Uruguay } \\
\text { venezuela }\end{array}$ & $\begin{array}{r}3.334 \\
27.935\end{array}$ & $\begin{array}{l}x \\
x\end{array}$ & & & & & & & $\begin{array}{l}\text { Namibia } \\
\text { Niger }\end{array}$ & $\begin{array}{r}2.200 \\
14.450\end{array}$ & $\begin{array}{l}x \\
x\end{array}$ & & & \\
\hline
\end{tabular}

Source: population (in million) is taken from the United Nations Demographic Yearbook.

Note: an " $X$ " in the Data column marks that the country has distributive information in PovcalNet. 


\section{Figure 5.5}

\section{Map of poverty in the developing world, circa 2010}

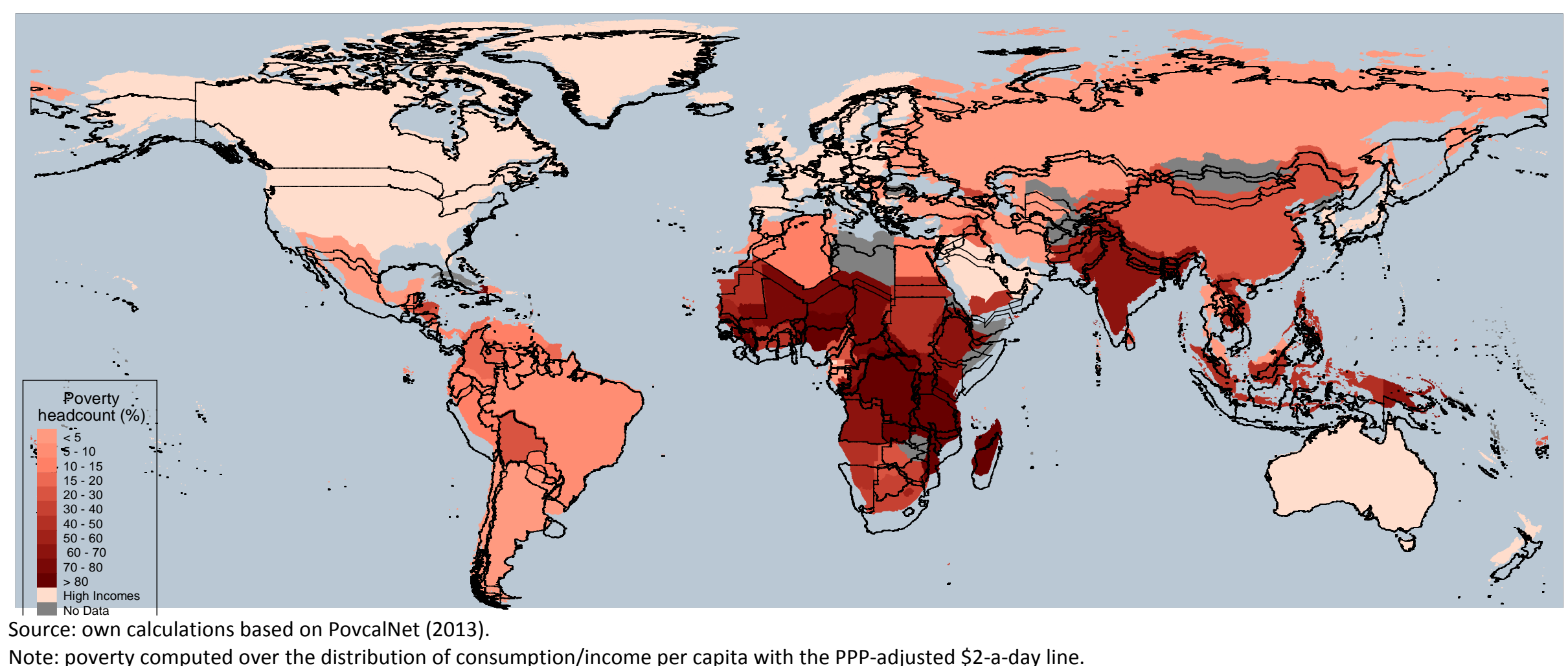

